\title{
CRUSTAL MAGNETIC FIELD ADVECTION ON MARS BY IONOSPHERIC PLASMA FLOW
}

Isabela de Oliveira Martins

\begin{abstract}
Master's Dissertation of the Graduate Course in Space Geophysics/Science of the SolarTerrestrial Environment, guided by Drs. Ezequiel Echer, Adriane Marques de Souza Franco and Wolfram Johannes Markus Fränz, approved in August 25, 2020.
\end{abstract}

URL of the original document:

<http://urlib.net/8JMKD3MGP3W34R/433F7E8>

INPE

São José dos Campos

2020 


\section{PUBLISHED BY:}

Instituto Nacional de Pesquisas Espaciais - INPE

Gabinete do Diretor (GBDIR)

Serviço de Informação e Documentação (SESID)

CEP 12.227-010

São José dos Campos - SP - Brasil

Tel.:(012) 3208-6923/7348

E-mail: pubtc@inpe.br

\section{BOARD OF PUBLISHING AND PRESERVATION OF INPE INTELLECTUAL PRODUCTION - CEPPII (PORTARIA No 176/2018/SEI-INPE): \\ Chairperson:}

Dra. Marley Cavalcante de Lima Moscati - Centro de Previsão de Tempo e Estudos Climáticos (CGCPT)

\section{Members:}

Dra. Carina Barros Mello - Coordenação de Laboratórios Associados (COCTE)

Dr. Alisson Dal Lago - Coordenação-Geral de Ciências Espaciais e Atmosféricas (CGCEA)

Dr. Evandro Albiach Branco - Centro de Ciência do Sistema Terrestre (COCST)

Dr. Evandro Marconi Rocco - Coordenação-Geral de Engenharia e Tecnologia Espacial (CGETE)

Dr. Hermann Johann Heinrich Kux - Coordenação-Geral de Observação da Terra (CGOBT)

Dra. Ieda Del Arco Sanches - Conselho de Pós-Graduação - (CPG)

Silvia Castro Marcelino - Serviço de Informação e Documentação (SESID)

\section{DIGITAL LIBRARY:}

Dr. Gerald Jean Francis Banon

Clayton Martins Pereira - Serviço de Informação e Documentação (SESID)

\section{DOCUMENT REVIEW:}

Simone Angélica Del Ducca Barbedo - Serviço de Informação e Documentação (SESID)

André Luis Dias Fernandes - Serviço de Informação e Documentação (SESID)

\section{ELECTRONIC EDITING:}

Ivone Martins - Serviço de Informação e Documentação (SESID)

Cauê Silva Fróes - Serviço de Informação e Documentação (SESID) 


\title{
CRUSTAL MAGNETIC FIELD ADVECTION ON MARS BY IONOSPHERIC PLASMA FLOW
}

Isabela de Oliveira Martins

\begin{abstract}
Master's Dissertation of the Graduate Course in Space Geophysics/Science of the SolarTerrestrial Environment, guided by Drs. Ezequiel Echer, Adriane Marques de Souza Franco and Wolfram Johannes Markus Fränz, approved in August 25, 2020.
\end{abstract}

URL of the original document:

<http://urlib.net/8JMKD3MGP3W34R/433F7E8>

INPE

São José dos Campos

2020 
Martins, Isabela de Oliveira.

M366c Crustal magnetic field advection on Mars by ionospheric plasma flow / Isabela de Oliveira Martins. - São José dos Campos : INPE, 2020.

xxiv + 91 p. ; (sid.inpe.br/mtc-m21c/2020/08.12.07.13-TDI)

Dissertation (Master in Space Geophysics/Science of the Solar-Terrestrial Environment) - Instituto Nacional de Pesquisas Espaciais, São José dos Campos, 2020.

Guiding : Drs. Ezequiel Echer, Adriane Marques de Souza Franco and Wolfram Johannes Markus Fränz.

1. Mars atmosphere. 2. Planetary ionospheres. 3. Planetary magnetic fields. 4. Remanent magnetization. 5. Advection. I.Title.

CDU 523.43

\section{cc) (i) (5)}

Esta obra foi licenciada sob uma Licença Creative Commons Atribuição-NãoComercial 3.0 Não Adaptada.

This work is licensed under a Creative Commons Attribution-NonCommercial 3.0 Unported License. 
Aluno (a): Isabela de Oliveira Martins

Título: "CRUSTAL MAGNETIC FIELD ADVECTION ON MARS BY IONOSPHERIC PLASMA FLOW"

"ADVECCÃO DO CAMPO MAGNÉTICO CRUSTAL EM MARTE PELO FLUXO IONOSFERICO DE PLASMA"

Aprovado (a) pela Banca Examinadora em cumprimento ao requisito exigido para obtenção do Título de Mestre

em

Geofísica Espacial/Ciências do Amblente Solar-Terrestre

Dr. Cristiano Max Wrasse

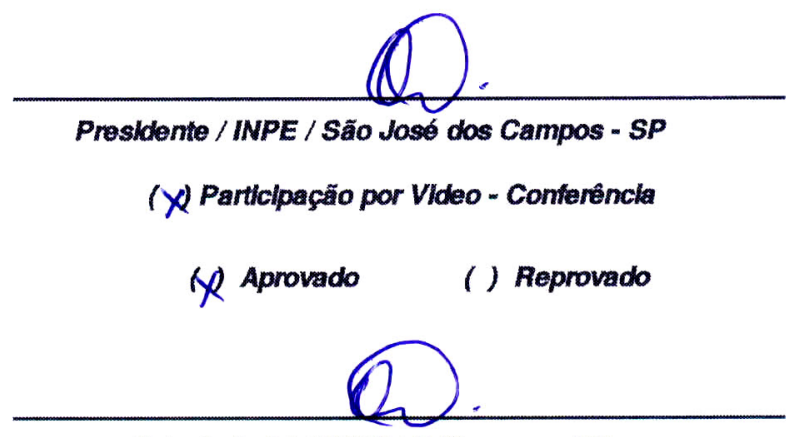

Orientador(a) / INPE / SJCampas - SP

IX Partklpaçäo por Vldeo - Conferêncla

(x) Aprovado (1) Reprovado

Dra. Adriane Marques de Souza Franco

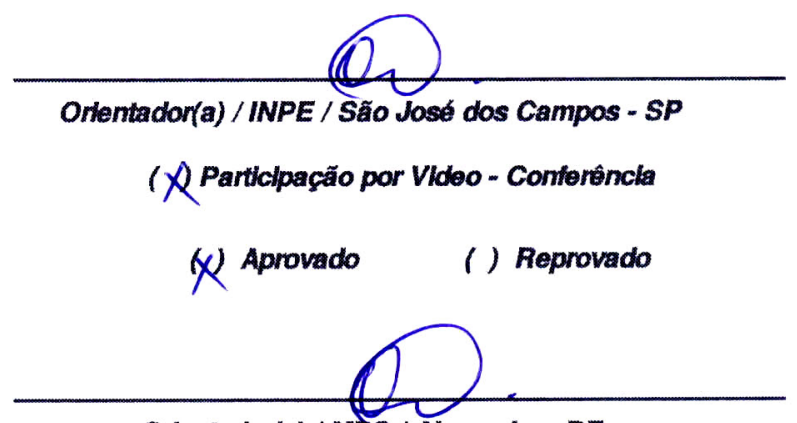

Orlentador(a) / MPS / Alemanha - DE

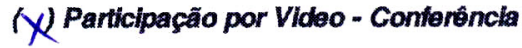

X) Aprovado (1) Reprovado

Dr. Alisson Dal Lago

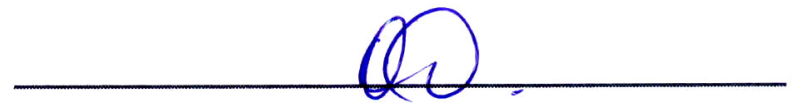

Membro da Banca / INPE / São José dos Campos - SP

(X) Particlpação por Vldeo - Conferêncla

(X Aprovado () Reprovado

Este trabalho fol aprovado por:

( ) malorla simples

(X unanimidade 
Aprovado (a) pela Banca Examinadora em cumprimento ao requisito exigido para obtenção do Título de Mestre

em

Geofísica Espacial/Ciências do Ambiente Solar-Terrestre

Dr. Fábio Becker Guedes

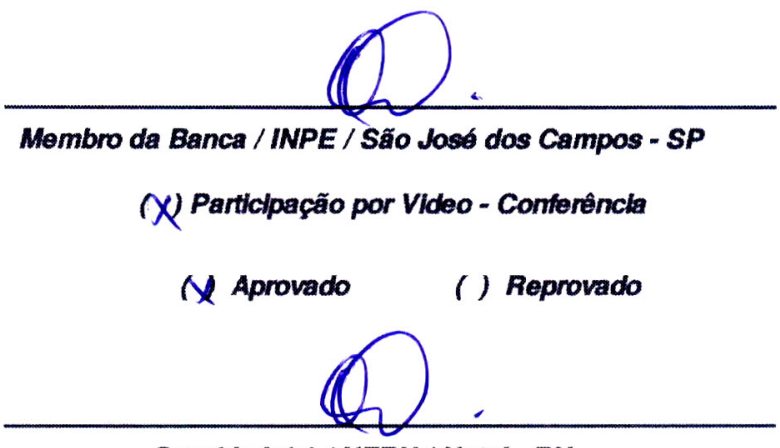

Convidado(a) / UFRN / Natal - RN

(X) Partlcipação por Video - Conferéncla
(X) Aprovado
() Reprovado

Este trabalho fol aprovado por:

() malorta simples

() unanimidade 
"You gotta conquer the monster in your head and then you'll fly, phoenix, fly"

LEAGUe OF LEGENDS 

I dedicate this Master Dissertation to my mother Auriluce and to my husband Richard. 



\section{ACKNOWLEDGEMENTS}

I would like to thank the two financial agencies that make this Master Dissertation possible: the São Paulo Research Foundation (FAPESP — grants n. 2018/17098-7 and n. 2019/01716-6) and the Brazilian National Council for Scientific and Technological Development (CNPq — grant n. 131260/2018-9).

I would like to thank my great supervisors Dr. Ezequiel Echer, Dr. Adriane Franco and Dr. Markus Fränz, for all the guidance, the help and the patience through this journey.

I would like to thank the National Institute for Space Research (INPE) and the MaxPlanck-Institute for Solar System Research (MPS) for the amazing opportunity of working in scientific environments among several intelligent, supportive and kind people.

I would like to thank the Mars Glboal Surveyor team and the Mars Atmosphere and Volatile Evolution team for gathering the data and making them publicly available.

I thank my husband Dr. Richard Larsson for countless reasons that do not fit in this page.

I thank my colleagues from INPE and from MPS for the support and for the spontaneous moments they provide me.

I thank the researchers from INPE and from MPS for all of the knowledge they share, not only on the scientific field.

Finally, I thank my mother for every step forward I take in life. 



\begin{abstract}
The planet Mars has unique magnetic features among the solar system bodies. Although the planet does not currently have an active dynamo that generates a global magnetic field, like Earth has, there are regions in its crust which are strongly magnetized. Some of these magnetic fields have magnitudes comparable to magnetic fields on Earth. Evidences suggest that the crustal magnetic fields on Mars are remanent signatures from a Martian dynamo that was active in the past. These strongly magnetized regions, above which "mini-magnetospheres" are formed, are what distinguishes Mars from the other planets of the Solar System. Like at Venus, the interactions between the solar wind and Mars are mostly dominated by the properties of its ionosphere. However, Mars' mini-magnetospheres influence the ionospheric interactions, changing ionospheric parameters and disturbing or generating local and global ionospheric currents. In this work, we propose that the crustal magnetic fields of Mars not only interfere in the planet's ionosphere, but that also the contrary can happen, i.e., the ionosphere can disturb the crustal magnetic fields. We specifically study whether the ionospheric flow is able to displace the crustal magnetic fields by advection, dragging them in the anti-solar direction, along the day-to-night flow of the ionospheric plasma. In order to identify advection of the magnetic fields on Mars, we perform statistical analyses using data from MAVEN and MGS spacecraft over long periods of time. MAVEN radial magnetic field data of the whole planet are selected for the dawn-side and the dusk-side of Mars and compared to a crustal magnetic field model, for altitude ranges between $200-1000 \mathrm{~km}$. The results show evidences that the magnetic fields are displaced and the cause for the displacement is likely to be advection due to the ionospheric flow. We also use MGS radial magnetic field data to investigate the advection on small regions of the planet and with a higher spatial resolution. We compare day-side data to night-side data at the orbit altitude of $\sim 400 \mathrm{~km}$. The displacement of the magnetic fields seems to be correlated to the distance from the magnetic field to the main patch of magnetization in the Southern hemisphere of the planet. In order to have a general idea of the forces involved in the advection of the magnetic fields, we compare the dynamic pressure of the ionospheric plasma flow to the magnetic pressure of the crustal magnetic fields. For this study, we use MAVEN magnetic field and ionospheric data between 200-1000 km and between 04:00-20:00 local times. The results indicate that the advection of the magnetic fields is likely to be more expressive at the terminator regions of the planet, above regions of weak magnetic field background, e.g., in the Northern hemisphere of Mars.
\end{abstract}

Keywords: Mars atmosphere. Planetary ionospheres. Planetary magnetic fields. Remanent magnetization. Advection. 



\title{
ADVECÇÃO DO CAMPO MAGNÉTICO CRUSTAL EM MARTE DEVIDO AO FLUXO DE PLASMA IONOSFÉRICO
}

\begin{abstract}
RESUMO
O planeta Marte tem características magnéticas únicas dentre os corpos do sistema solar. Embora o planeta atualmente não tenha um dínamo ativo que gere um campo magnético global, como o da Terra, existem regiões fortemente magnetizadas em sua crosta. Alguns desses campos magnéticos têm magnitudes comparáveis aos campos magnéticos da Terra. Evidências sugerem que os campos magnéticos crustais de Marte são assinaturas remanescentes de um dínamo marciano que esteve ativo no passado. Essas regiões fortemente magnetizadas, acima das quais "minimagnetosferas" são formadas, são o que distingue Marte dos outros planetas do Sistema Solar. Como em Vênus, as interações entre o vento solar e Marte são predominantemente dominadas pelas propriedades de sua ionosfera. Contudo, minimagnetosferas de Marte influenciam as interações ionosféricas, alterando os parâmetros ionosféricos e perturbando ou gerando correntes ionosféricas locais e globais. Neste trabalho, propomos que os campos magnéticos crustais de Marte não apenas interferem na ionosfera do planeta, mas que também o contrário pode acontecer, ou seja, a ionosfera pode perturbar os campos magnéticos crustais. Estudamos especificamente se o fluxo ionosférico é capaz de deslocar os campos magnéticos da crosta por advecção, arrastando-os na direção anti-solar, ao longo do fluxo diário do plasma ionosférico. Para identificar a advecção dos campos magnéticos de Marte, realizamos análises estatísticas usando os dados das espaçonaves MAVEN e MGS por longos períodos de tempo. Os dados da componente radial do campo magnético da MAVEN de todo o planeta são selecionados para o lado do amanhecer e do crepúsculo de Marte e comparados com um modelo de campo magnético crustal, para faixas de altitude entre $200-1000 \mathrm{~km}$. Os resultados mostram evidências de que os campos magnéticos estão deslocados e a causa do deslocamento provavelmente é a advecção devido ao fluxo ionosférico. Também usamos dados da componente radial do campo magnético da MGS para investigar a advecção em pequenas regiões do planeta e com uma resolução espacial mais alta. Comparamos os dados diurnos com os noturnos na altitude da órbita de $\sim 400 \mathrm{~km}$. O deslocamento dos campos magnéticos parece estar correlacionado à distância do campo magnético ao principal bloco de magnetização no hemisfério Sul do planeta. Para ter uma idéia geral das forças envolvidas na advecção dos campos magnéticos, comparamos a pressão dinâmica do fluxo de plasma ionosférico com a pressão magnética dos campos magnéticos crustais. Para este estudo, usamos dados da MAVEN do campo magnético e da ionosfera entre 200-1000 km e entre 04:00-20:00 do horário local. Os resultados indicam que a advecção dos campos magnéticos é provavelmente mais expressiva nas regiões do terminadouro do planeta, acima das regiões de fraco campo magnético de fundo, e.g., no hemisfério Norte de Marte.
\end{abstract}

Palavras-chave: Atmosfera de Marte. Ionosferas planetárias. Campos magnéticos planetários. Magnetização remanescente. Advecção. 



\section{LIST OF FIGURES}

Page

1.1 Mars and its moons, Phobos and Deimos. . . . . . . . . . . . . 2

1.2 Topographic map of Mars from the Mars Orbiter Laser Altimeter onboard Mars Global Surveyor spacecraft. . . . . . . . . . . . . . . . . . . 3

1.3 Map of the crustal magnetic field of Mars. . . . . . . . . . . . . . . . . 4

1.4 First empirical model of the crustal magnetic field of Mars. . . . . . . . . 7

1.5 Altitude profiles of the averaged density of ionospheric ions at Mars, at $\mathrm{SZA}=60^{\circ} \ldots \ldots \ldots \ldots \ldots \ldots$

1.6 Illustration of the Mars' magnetosphere. . . . . . . . . . . . . . . . . . . 12

1.7 Cartoon of the Martian obstacle to the solar wind. . . . . . . . . . . . 13

1.8 Diagram of magnetic field topologies on Mars. . . . . . . . . . . . . . . . 14

1.9 Example of detachment of crustal magnetic field lines. . . . . . . . . . 15

2.1 Sketch of the magnetic field advection of a wire. . . . . . . . . . . . 25

2.2 Illustration of the geometry of the problem. . . . . . . . . . . 26

3.1 Artist's concept of Mars Global Surveyor in orbit above Mars. . . . . . . 28

3.2 Artist's concept of Mars Atmosphere and Volatile Evolution at Mars. . . 29

3.3 Histograms of $|\Delta \mathrm{B}|$ for Arkani-Hamed, Cain, and Morschhauser models of the crustal magnetic field of Mars. . . . . . . . . . . . . . . . . . 34

3.4 Maps of the day-side $|\Delta \mathrm{B}|$ for the magnitude and for the two components of the magnetic field of Mars, using the Morschhauser model. . . . . . . . 36

3.5 Maps of the night-side $|\Delta \mathrm{B}|$ for the magnitude and for the two components of the magnetic field of Mars, using the Morschhauser model. . . . 37

3.6 Histograms of $|\Delta \mathrm{B}|$ for the magnitude and for the two components of the magnetic field of Mars, using the Morschhauser model. . . . . . . . . . . 38

$3.7 \Delta \mathrm{B}$ and $\mathrm{O}_{2}^{+}$signed horizontal speed as a function of altitude and local time. . . . . . . . . . . . . . . . . . . . . . 41

3.8 Maps of modeled $B_{r}$, overplotted with arrows of $\mathrm{O}_{2}^{+}$horizontal velocity. . 42

3.9 Map of the location of the seven selected anomalies. . . . . . . . . . . 46

3.10 Temperature as a function of local time and altitude. . . . . . . . . . . . 50

3.11 Density as a function of local time and altitude. . . . . . . . . . . . . 52

3.12 Horizontal speed and magnetic field intensity as a function of local time and altitude. . . . . . . . . . . . . . . . . . . 53

3.13 Number of samples per bin as a function of local time and altitude for electron parameters. 
3.14 Number of samples per bin as a function of local time and altitude for

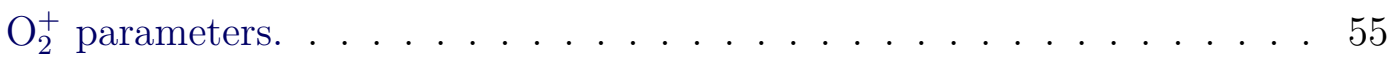

4.1 Maps of $B_{r}$ at the altitude range of $200-400 \mathrm{~km} \ldots \ldots \ldots$. . . . . . 58

4.2 Maps of $B_{r}$ at the altitude range of $400-600 \mathrm{~km}$. . . . . . . . . . . . 59

4.3 Maps of $B_{r}$ at the altitude range of $600-800 \mathrm{~km}$. . . . . . . . . . . . 60

4.4 Maps of $B_{r}$ at the altitude range of $800-1000 \mathrm{~km}$. . . . . . . . . . 61

4.5 Plots of the best fit of $\Delta \mathrm{B}^{\prime}{ }_{\text {MAVEN }}$ to a Gaussian function. . . . . . . . . . 63

4.6 Plot of the linear regression of the absolute longitudinal offsets for minimum $\Delta \mathrm{B}_{\text {MAVEN }}^{\prime} \ldots \ldots \ldots \ldots \ldots$

4.7 Maps of $B_{r}$ for A1, A2, A3, and A4 anomalies. . . . . . . . . . . 66

4.8 Maps of $B_{r}$ for A5, A6, and A7 anomalies. . . . . . . . . . . . . 67

4.9 Plots of the best fit of $\Delta \mathrm{B}^{\prime}{ }_{\text {MGS }}$ to a Gaussian function. . . . . . . . . . 68

4.10 Dynamic, magnetic, and thermal pressures as a function of local time and altitude. . . . . . . . . . . . . . . . . . . . 71

4.11 Ratio between the thermal and the dynamic pressure as a function of local time and altitude. . . . . . . . . . . . . . . . . . . 72

4.12 Ratio between the dynamic and the magnetic pressure as a function of local time and altitude. The color scale ranges between 0.01-5.0 . . . . . . 73

4.13 Map of the location of the seven selected anomalies. . . . . . . . . . . . 75 


\section{LIST OF TABLES}

Page

4.1 Longitudinal offsets for minimum $\Delta \mathrm{B}_{\text {MAVEN }}{ }^{2} \ldots \ldots \ldots$. . . . . . . . 62

4.2 Longitudinal offsets for minimum $\Delta \mathrm{B}_{\mathrm{MGS}} \ldots \ldots \ldots$. . . . . . . . . . . 69

4.3 Longitudinal offsets for minimum $\Delta \mathrm{B}_{\text {MGS }}$ (anomalies only). Sorted by ascending distance from the center of the region with the strongest magnetic background. . . . . . . . . . . . . . . . . . . . . 75 



\section{LIST OF ABBREVIATIONS}

A1 $\quad-$ Magnetic anomaly centered approximately at $155^{\circ} \mathrm{E}$ and $25^{\circ} \mathrm{S}$ on Mars

A2 $\quad-$ Magnetic anomaly centered approximately at $75^{\circ} \mathrm{E}$ and $35^{\circ} \mathrm{N}$ on Mars

A3 - Magnetic anomaly centered approximately at $340^{\circ} \mathrm{E}$ and $30^{\circ} \mathrm{N}$ on Mars

A4 - Magnetic anomaly centered approximately at $315^{\circ} \mathrm{E}$ and $15^{\circ} \mathrm{S}$ on Mars

A5 $\quad-$ Magnetic anomaly centered approximately at $310^{\circ} \mathrm{E}$ and $5^{\circ} \mathrm{S}$ on Mars

A6 - Magnetic anomaly centered approximately at $35^{\circ} \mathrm{E}$ and $0^{\circ} \mathrm{N}$ on Mars

A7 $\quad-$ Magnetic anomaly centered approximately at $105^{\circ} \mathrm{E}$ and $15^{\circ} \mathrm{S}$ on Mars

$\mathrm{AB} / \mathrm{SPO} \quad-$ Aerobraking and Science Phase Orbits

CCATi $\quad-$ Cluster Ion Spectrometer and Mars Express/Venus Express Analyzer of Space Plasma and Energetic Atoms Analysis Tool Interactive

$\mathrm{cm} \quad-$ centimeter

GSFC $\quad-$ Goddard Space Flight Center

h $\quad-$ hour

IDL $\quad-$ Interactive Data Language

IMF $\quad-$ Interplanetary Magnetic Field

JPL-Caltech - Jet Propulsion Laboratory - California Institute of Technology

$\mathrm{K}-$ kelvin

$\mathrm{km} \quad-$ kilometer

LPW - - Langmuir Probe and Waves

LT $\quad-$ Local time

m - meter

MAG - Magnetometer

MAG/ER - Magnetometer and Electron Reflectometer

MAVEN - Mars Atmosphere and Volatile EvolutioN

MGS - Mars Global Surveyor

MPB $\quad-\quad$ Magnetic Pile-up Boundary

MPO $\quad-\quad$ Mapping Phase Orbit

MPR $\quad-$ Magnetic Pile-up Region

MSO $\quad-$ Mars-Centered Solar Orbital coordinate system

NASA $\quad-$ National Aeronautics and Space Administration

$\mathrm{nPa} \quad-$ nanopascal

nT $\quad-$ nanotesla

PEB $\quad-$ Photo-Electron Boundary

S $\quad-$ second

STATIC - SupraThermal and Thermal Ion Composition

SZA - Solar zenith angle 



\section{LIST OF SYMBOLS}

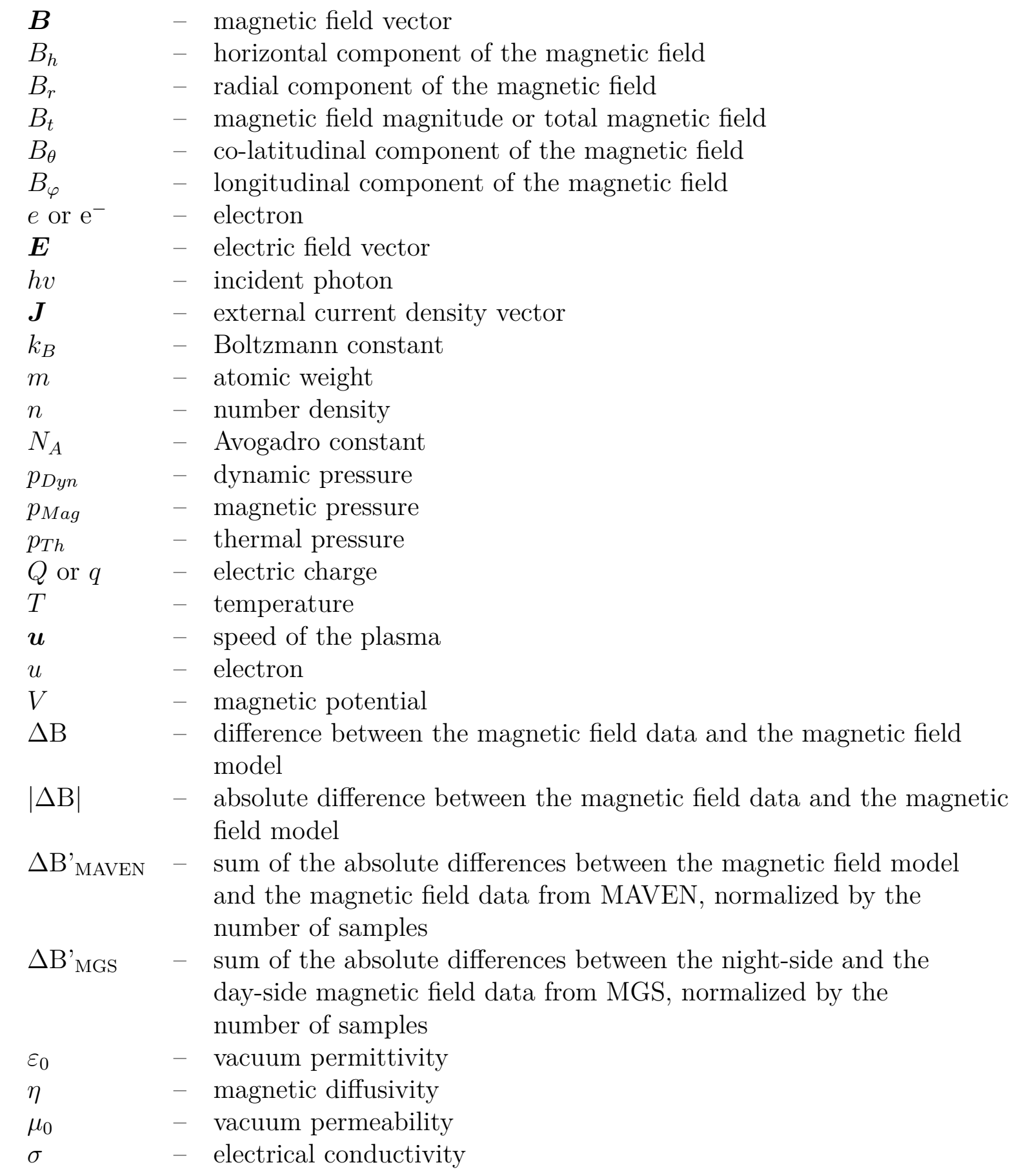





\section{CONTENTS}

Page

1 INTRODUCTION .................... 1

1.1 General features of Mars . . . . . . . . . . . . . . . . . . . 1

1.2 Crustal magnetic fields of Mars . . . . . . . . . . . . . . . . . . . 4

1.3 Representation of the crustal magnetic fields of Mars . . . . . . . . . 6

1.4 Plasma . . . . . . . . . . . . . . . . . . . . . . 8

1.5 Mars' ionosphere . . . . . . . . . . . . . . . . . . . . . 8

1.6 Induced magnetic field on Mars . . . . . . . . . . . . . . . . . . . . 10

1.7 The influence of the crustal magnetic fields on Mars' ionosphere . . . . . 11

1.8 Displacement of Mars' crustal magnetic fields . . . . . . . . . . . . . . . 14

1.9 Objectives of this study . . . . . . . . . . . . . . . . . . . 16

2 THEORY .......................... 17

2.1 Coordinate systems . . . . . . . . . . . . . . . . . . 17

2.2 Fundamentals of electromagnetism . . . . . . . . . . . . . . . 18

2.3 Fundamentals of plasma physics . . . . . . . . . . . . . . . . . . 21

2.4 Representation of magnetic fields by spherical harmonic functions . . . . 23

2.5 The advection of the crustal magnetic fields on Mars . . . . . . . . . . . 25

3 METHODOLOGY .................... 27

3.1 Data description . . . . . . . . . . . . . . . . . 27

3.1 .1 MGS data . . . . . . . . . . . . . . . . . . . . 27

3.1 .2 MAVEN data . . . . . . . . . . . . . . . . . . . 29

3.2 Crustal magnetic field models . . . . . . . . . . . . . . . . . . . 30

3.3 Software . . . . . . . . . . . . . . . . . . . . 32

3.4 Data and model reduction . . . . . . . . . . . . . . . . . . . 32

3.4.1 Comparisons among crustal magnetic field models . . . . . . . . . . . . 32

3.4.2 Comparisons among different components of the observed magnetic field 35

3.5 Preliminary analysis of data . . . . . . . . . . . . . . . . . 40

3.6 Applied methods . . . . . . . . . . . . . . . . . . . . . . . . 43

3.6.1 Shifting technique . . . . . . . . . . . . . . . . . . 43

3.6 .2 Pressure analysis . . . . . . . . . . . . . . . . . . . . . . . . . . . 48

4 RESULTS AND DISCUSSION . . . . . . . . . . . . 57 
5 CONCLUSIONS $\ldots \ldots \ldots \ldots \ldots \ldots$

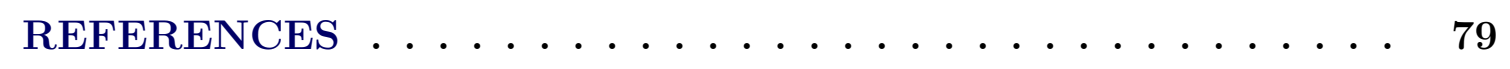




\section{INTRODUCTION}

With the progress of space technologies, the human exploration of bodies other than Earth in the solar system has become a matter of when, not if. Mars is the 4th planet from the Sun, Earth's neighbor, and a long-term candidate for hosting life. For numerous reasons, the red planet is considered an option for colonization by humans in the near future (PETRANEK, 2015; DO et al., 2016). In this study, we investigate the interaction of its ionosphere with its crustal magnetic fields, in order to obtain a better knowledge of the whole Martian system and make contributions to the scientific community.

This Master Dissertation is divided in five Chapters, with the Introduction as the first one. Here, we introduce the general characteristics of Mars and the aspects of its magnetic fields and its ionosphere that are related to this study. The subjects that require further theoretical and mathematical approaches are explained in Chapter 2. In Chapter 3, the data and the instrumentation are described and the techniques used to solve the problem are explained. The obtained results and their discussions are presented in Chapter 4. Finally, Chapter 5 summarizes the conclusions of this work.

\subsection{General features of Mars}

Along with the rest of the solar system, Mars was formed $\sim 4.5$ billion years ago, by accretionary processes (BARLOW, 2008). The planet's distance to the Sun ranges between 1.38 to 1.67 Astronomical Units $\left(\sim 2.1 \times 10^{8}\right.$ to $\left.\sim 2.5 \times 10^{8} \mathrm{~km}\right)$ and its orbital period takes nearly 687 Earth days. Mars has a rotation period of $\sim 24.7 \mathrm{~h}$ and an inclination axis of $25.2^{\circ}$ in relation to its orbital plane, which means the planet has four distinct seasons throughout the year. Regarding the size, Mars has $\sim 11 \%$ of the mass and $\sim 53 \%$ of the radius of our planet.

The internal structure of Mars is inferred to be similar to that of Earth: a rocky crust, a mantle, and a partially liquid metal core (BARLOW, 2008). The state of the inner layers is uncertain and is being actively studied by the InSight mission (PANNING et al., 2017). Current models of the planet's interior imply a core region of $\sim 1794 \mathrm{~km}$ in radius and a composition that consists of iron, nickel, and sulfur (PATER; LISSAUER, 2010). The core is surrounded by a silicate mantle and a thick iron crust, which is thicker than Earth's, in proportion. The average thickness of the crust is $\sim 50 \mathrm{~km}$, with a maximum of $125 \mathrm{~km}$. 
Mars has two small and irregular moons, both discovered by Hall (1878). Phobos is the largest and innermost, with approximate dimensions of $27 \times 22 \times 19 \mathrm{~km}$ and actual orbital distance of 1.4 Martian diameters $\left(\sim 9.5 \times 10^{3} \mathrm{~km}\right)$. Deimos is the smallest and outermost, with about $10 \times 12 \times 16 \mathrm{~km}$ in size and actual orbital distance of 3.5 Martian diameters $\left(\sim 2.4 \times 10^{4} \mathrm{~km}\right)$. Their respective orbital periods around Mars are $\sim 7.7$ and $\sim 30.4 \mathrm{~h}$. Their irregular shapes can be seen in Figure 1.1 , as well as their relative sizes in comparison to the planet.

Figure 1.1 - Mars and its moons, Phobos and Deimos.

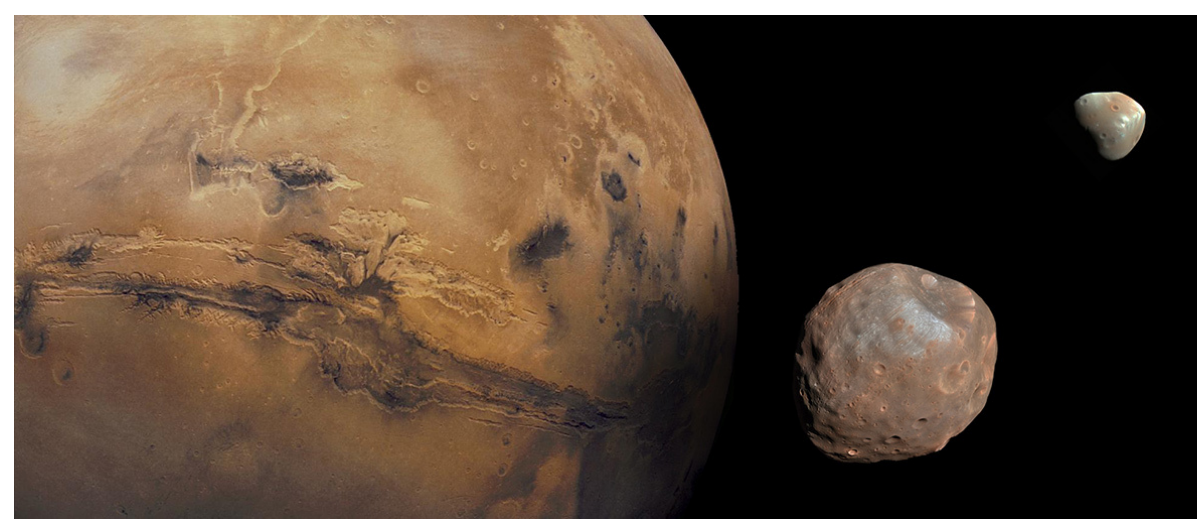

This is an assembly of pictures of Mars, Phobos, and Deimos, in scale. The mosaic of Mars is made from a compilation of images captured by the Viking Orbiter 1 . The pictures of Phobos and Deimos are enhanced-color images from the Mars Reconnaissance Orbiter mission.

SOURCE: Courtesy NASA/JPL-Caltech (2008).

Analyses of supposed Martian meteorites that reached Earth suggest that, while the overall evolution of Mars and Earth are quite similar, there are important differences between the two planets. For example, Mars lacks active plate tectonics and has a higher volatile concentration in its dryer mantle, in comparison to Earth's (PATER; LISSAUER, 2010).

Mars had suffered a period of heavy bombardment and, as a consequence, its surface is densely cratered. Its topography, shown in Figure 1.2, is characterized by a large elevation range and many distinct morphological features, including three giant volcanoes in the Tharsis province, a massive canyon system called Valles Marineris, and Hellas huge impact basin (SMITH et al., 1999). At the poles, there are ice caps, composed by $\mathrm{H}_{2} \mathrm{O}$ and $\mathrm{CO}_{2}$. The surface shows strong evidence that water may have 
flowed on the planet in the past (SMITH et al., 2001).

The planet has a hemispheric crustal dichotomy, which leads to several differences between the Southern and the Northern hemispheres (SMITH et al., 1999; SMITH et al., 2001). As can be seen in Figure 1.2, most of the Southern hemisphere is heavily cratered and elevated, while the Northern hemisphere has smooth topography and lower altitudes. This suggests that the Northern hemisphere is younger than the Southern one (ACUÑA et al., 1999). The dichotomy boundary is not circular in form and leading theories on its formation are a giant impact in the Northern hemisphere, which melted the regional crust (WILHELMS; SQUYRES, 1984; MARINOVA et al., 2008), or a large-scale mantle convection, with patterns that caused up-welling in the Southern hemisphere and subsidence in the Northern one (ZHONG; ZUBER, 2001; ROBERTS; ZHONG, 2006).

Figure 1.2 - Topographic map of Mars from the Mars Orbiter Laser Altimeter onboard Mars Global Surveyor spacecraft.

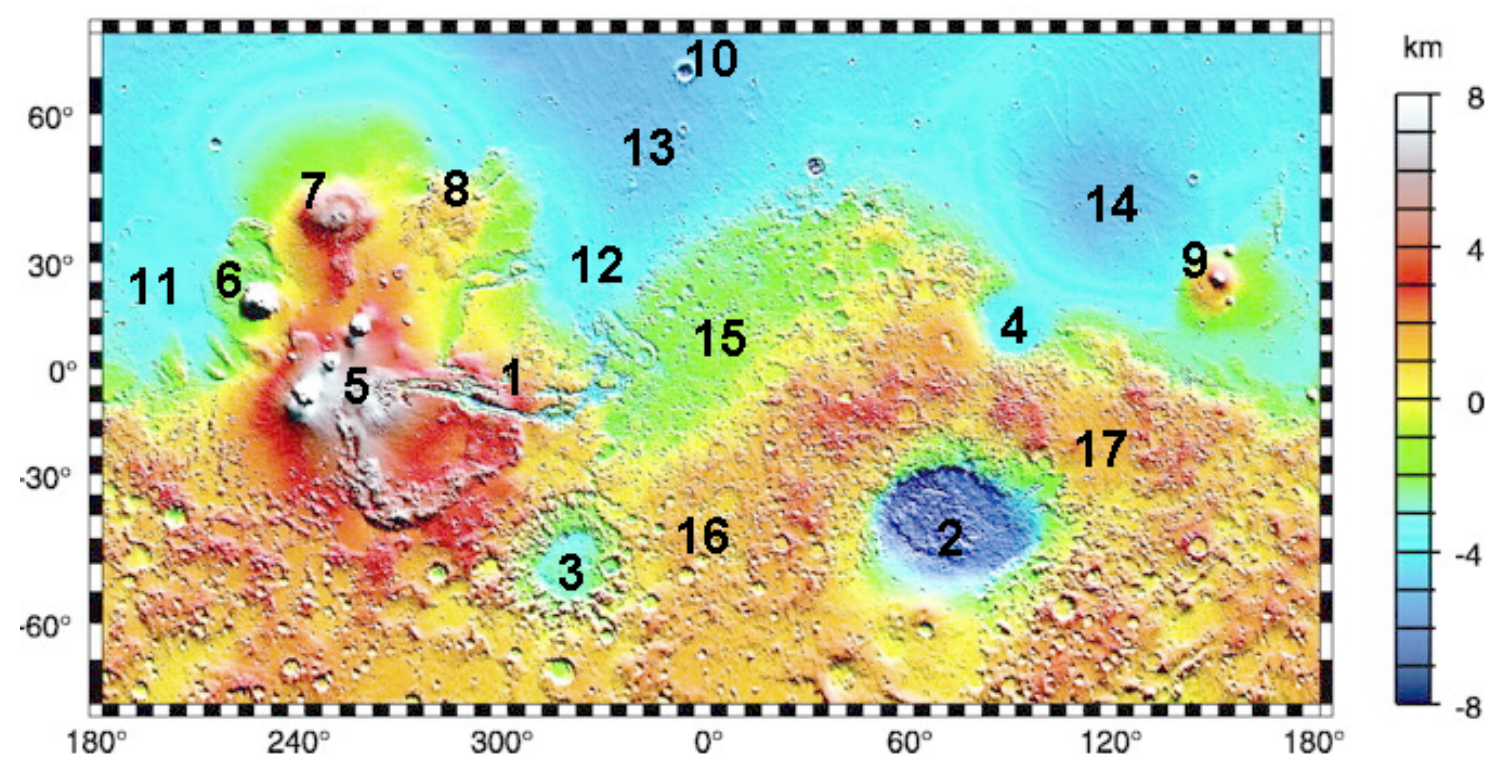

The color scale saturates at elevations above $8 \mathrm{~km}$. The indices show the major crustal features: Valles Marineris canyon system (1); Hellas (2), Argyre (3), and Isidis (4) impact basins; Tharsis Mons (5), Olympus Mons (6), Alba Mons (7), Tempe Terra (8), and Elysium Mons (9) volcanic provinces; Vastitas Borealis lowlands (10), containing Amazonis (11), Chryse (12), Acidalia (13), and Utopia (14) Planitiae; Arabia Terra (15); Noachis Terra (16), and Hesperia Planum (17).

SOURCE: Adapted from Smith et al. (1999). 


\subsection{Crustal magnetic fields of Mars}

The first measurements of localized crustal magnetic sources on Mars were made by the National Aeronautics and Space Administration (NASA)'s Mars Global Surveyor (MGS) spacecraft, in September 1997 (ACUÑA et al., 1998). These small-scale remanent magnetic anomalies were associated with the heavily cratered and ancient terrain of the Southern hemisphere. Figure 1.3 shows the radial component of the magnetic field $\left(B_{r}\right)$, measured by the MGS spacecraft.

Figure 1.3 - Map of the crustal magnetic field of Mars.

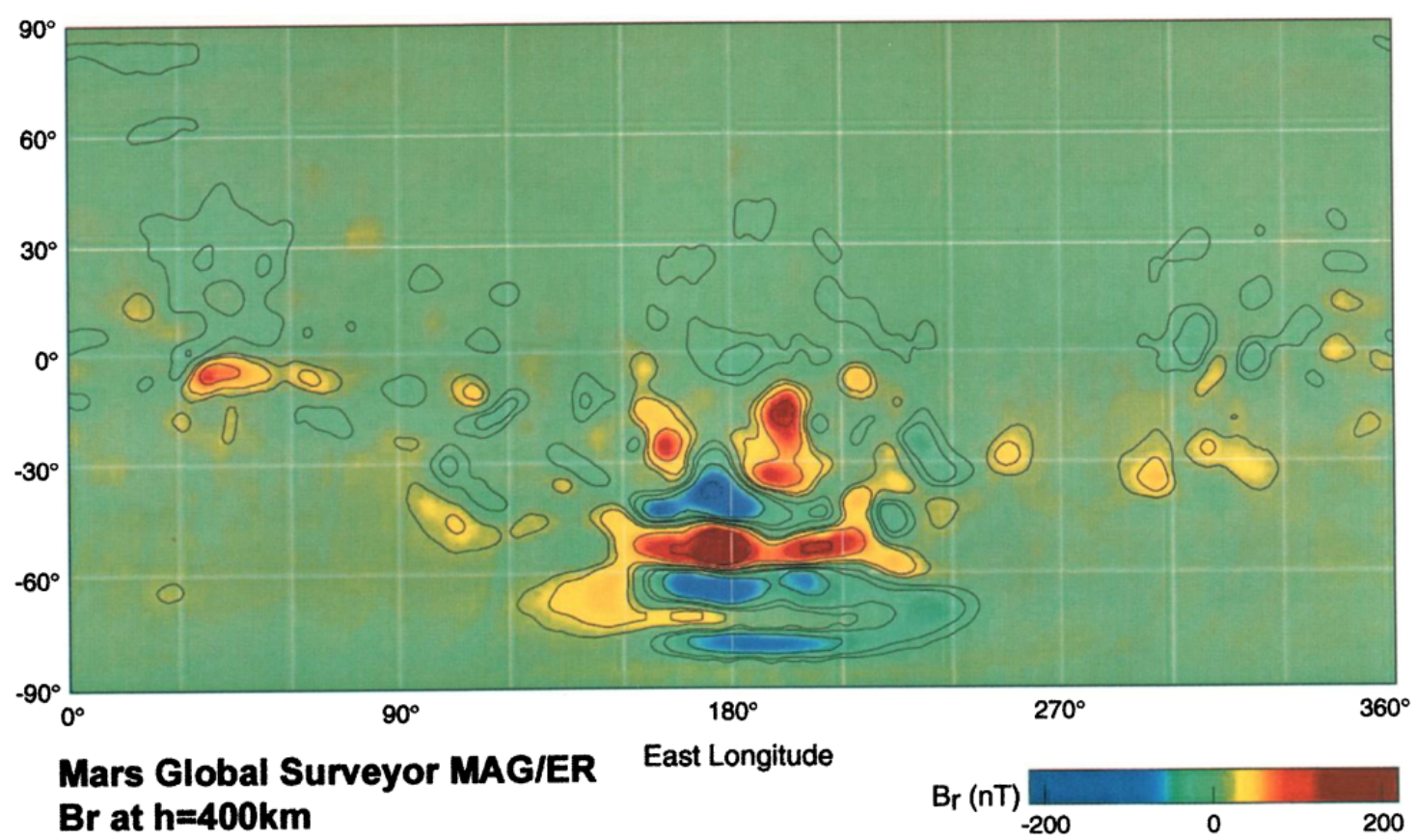

Contour map of the radial component of the magnetic field, observed at an altitude of $400 \pm 20 \mathrm{~km}$. Notice that the longitude axis is displaced when compared to Figure 1.2.

SOURCE: Acuña et al. (2001).

The strong magnetization in the Southern hemisphere indicates that magnetic activities occurred in the planet's interior in the past. Consider Earth as an example. It is known that dynamic physical/chemical processes occurring in Earth's core region are responsible for the continuous generation of a global magnetic field (ELSASSER, 1939). This dynamo mechanism is self-sustainable and it is currently also present in 
other bodies of the solar system, like Mercury (NESS et al., 1976).

It is believed that Mars also had an active magnetic field dynamo during the first few hundred million years of its history. However, unlike on Earth, the activities on Mars had ceased between 4.1 and 3.6 billion years ago, causing the global magnetic field to dissipate (ACUÑA et al., 2001; STEVENSON, 2001; MILBURY et al., 2012; LILLIS et al., 2013; VERVELIDOU et al., 2017). The reason for the cessation of dynamo activities on Mars is thought to be related to giant impacts that substantially reduced the coremantle boundary heat flow, causing the planet's core to have insufficient thermal forcing to sustain a global magnetic field (NIMMO; STEVENSON, 2000; ROBERTS et al., 2009).

The evidences for a previous active magnetic field on Mars are imprinted on the magnetic signature observed on the planet's crust. This happens due to the magnetic properties of ferrimagnetic minerals that are present in the crust. Ferrimagnetic minerals have the capability of acquiring magnetization when subjected to an external magnetic field as they cool down (BUTLER, 1992). When this magnetic field is removed, they still keep their magnetic moment. In other words, these minerals retain information about the global magnetic field that was present by the time of their formation.

Ferrimagnetic minerals are responsible for the magnetization on Mars' surface, as well as on Earth's. This type of magnetization, known as remanent magnetization, is the key for paleomagnetic studies, which investigate planetary features in the past based on magnetic signatures of minerals (BUTLER, 1992). By analyzing Mars' remanent magnetism, Connerney et al. (1999) and Connerney et al. (2004) could infer that Mars' magnetic dynamo had a larger magnetic moment than Earth's current geodynamo, which means that the global magnetic field must have had a great intensity by the time the Southern hemisphere was formed.

From Figure 1.3, we see east-west-trending linear features of alternating magnetic polarity and intense magnetization in the Southern hemisphere. Paleomagnetic studies suggest that these features are related to the occurrence of tectonic processes on Mars, like those associated with mid-ocean ridges on Earth (HEIRTZLER; PICHON, 1965; CONNERNEY et al., 1999).

Although remanent magnetization can persist indefinitely, ferrimagnetic minerals lose their magnetic properties when subjected to very high temperatures, above the Curie temperature, which is usually 800-900 K (BUTLER, 1992). Some examples 
of when the Curie temperature can be reached are by meteorite impacts or by volcanic lava flows. A leading idea on how the Northern hemisphere of Mars was demagnetized is by a large meteorite impact, which melted the regional crust, rising temperatures above the Curie point. Also, the weak magnetization observed in that region indicates that dynamo activities were already ceased by the time of its thermal evolution and crustal differentiation (ACUÑA et al., 1999; ACUÑA et al., 2001).

\subsection{Representation of the crustal magnetic fields of Mars}

The analysis of magnetic field data by itself is not enough when it comes to solving problems related to the crustal magnetic fields of Mars. Raw data contain information about external fields, are not corrected for altitude, and are contaminated by signals generated over a large area of magnetized rock (MORSCHHAUSER et al., 2014). Moreover, the characteristics of the Martian core field can be better understood if the directions of crustal magnetizations are known.

In principle, crustal magnetizations can be associated with an empirical crustal magnetic field model, which can be used to derive a high resolution map of the vector components of the field, corrected for altitude variations (ARKANI-HAMED; DYMENT, 1996; ARKANI-HAMED, 2001). Crustal magnetic field models of Mars are extensively used in comparative studies related to the magnetic field and magnetosphere of Mars, as well as in studies of the general behavior of the Martian system. Therefore, several empirical crustal magnetic field models of Mars have been developed by the scientific community over the years, using different approaches.

The first published model, shown in Figure 1.4, was based on equivalent source dipoles and it was built by Purucker et al. (2000). Later, Langlais et al. (2004), followed by Langlais et al. (2010), used the same approach to improve that model with the analysis of a larger data set and more appropriate parameters. Two other models that directly solve for a magnetization distribution that fits the data are the ones made by Whaler and Purucker (2005) and Chiao et al. (2006). 
Figure 1.4 - First empirical model of the crustal magnetic field of Mars.
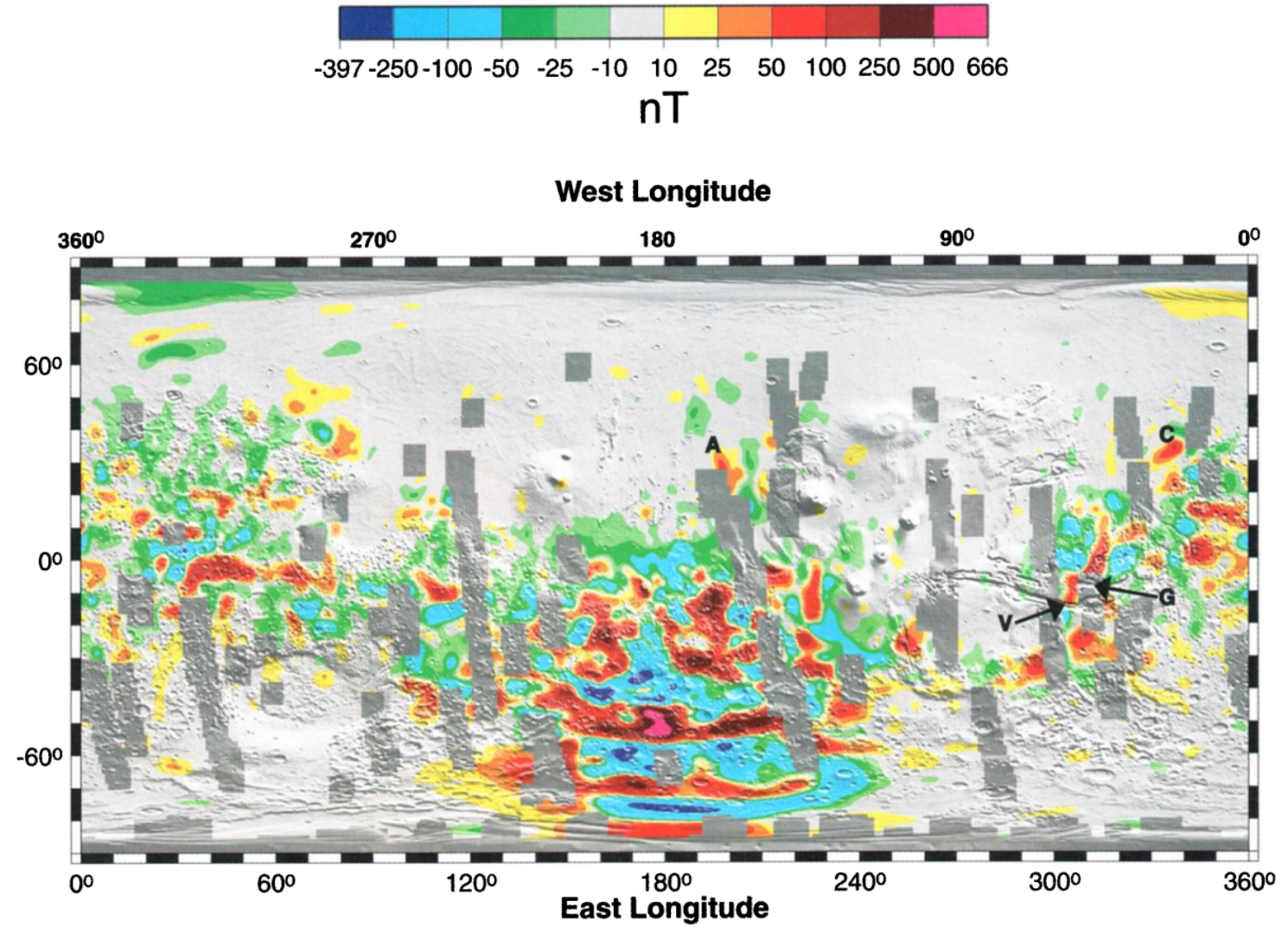

Radial component of the magnetic field, at $200 \mathrm{~km}$ altitude, over-plotted on a topographic map of Mars. The dark gray areas are regions of inadequate data coverage, which means this very early model does not fully represent the actual crustal magnetic field and it is no longer used nowadays.

SOURCE: Purucker et al. (2000).

Another way to solve the problem is by using spherical harmonic functions. These functions can describe the magnetic potential associated with the field in a unique way, which makes the spherical harmonic models more consistent than the models created by the equivalent source dipoles method. Among them, we can mention the ones built by Cain et al. (2003), Arkani-Hamed (2004), and Morschhauser et al. (2014), which are properly discussed in Section 3.2 and compared in Subsection 3.4.1.

All models mentioned so far are built with data acquired by the MGS spacecraft. Langlais et al. (2019) have recently published a new model of the field, in which they use not only data provided by MGS, but also by NASA's Mars Atmosphere 
and Volatile EvolutioN (MAVEN) mission. The model consists of a combination of both equivalent source dipoles and spherical harmonic functions and has higher spatial resolution, accuracy, and robustness than the previous models.

\subsection{Plasma}

There are four common states of matter in our universe: solid, liquid, gaseous, and plasma. The most basic difference between those states, for a given substance, is the amount of kinetic energy - or temperature - of its constituent particles. The higher the temperature, the less the atoms or the molecules are bound to each other. If a gas has sufficient kinetic energy, this means that its atoms are able to overcome the binding energy of the outermost orbital electrons, resulting in a substance composed of ions and electrons, instead of neutral particles. This ionized gas is known as plasma and it can be created either by raising the temperature of a substance or by subjecting it to an ionization process (BITTENCOURT, 1995).

The layer where plasma is the dominant state in planetary atmospheres is called the ionosphere. This layer is created by photoionization processes, in which solar extreme ultraviolet and x-ray radiation are absorbed by atmospheric neutral components (HARGREAVES, 1992). Electrons are ejected from the atoms or molecules, generating ions in the atmosphere.

Another type of plasma studied in planetary sciences is the solar wind. This plasma is a continuously emitted flux of protons and electrons and it is the result of the supermagnetosonic expansion of the Sun's atmosphere (HUNDHAUSEN, 1995). The solar wind is highly conductive and it carries a magnetic field of solar origin, known as the interplanetary magnetic field (IMF).

\subsection{Mars' ionosphere}

Up to $\sim 130 \mathrm{~km}$ altitude, the behavior of the Martian atmosphere is mostly dominated by neutral species. The major atmospheric component is $\mathrm{CO}_{2}(\sim 95.3 \%)$, followed by small contributions of $\mathrm{N}_{2}(\sim 2.7 \%)$ and $\operatorname{Ar}(\sim 1.6 \%)$, and traces of $\mathrm{O}_{2}$, $\mathrm{CO}, \mathrm{H}_{2} \mathrm{O}$, and NO (NIER; MCELROY, 1977; FOX; DALGARNO, 1979).

Above $\sim 130 \mathrm{~km}$ altitude, ionized components begin to play a significant role in the behavior of the atmosphere, and this region is considered to be the bottom of the Martian ionosphere. $\mathrm{O}_{2}^{+}$is the dominant ion up to $300 \mathrm{~km}$ altitude. Above that, $\mathrm{O}^{+}$ becomes similarly common (FOX, 2009; BENNA et al., 2015; WITHERS et al., 2015). 
Figure 1.5 shows the altitude profiles of the density of the major ionospheric ions at Mars, between $150-500 \mathrm{~km}$ altitude, for a solar zenith angle ${ }^{1}$ (SZA) of $60^{\circ}$. The altitude profiles of $\mathrm{O}_{2}^{+}$and $\mathrm{O}^{+}$are represented by the rightmost red curves.

Figure 1.5 - Altitude profiles of the averaged density of ionospheric ions at Mars, at SZA $=60^{\circ}$.

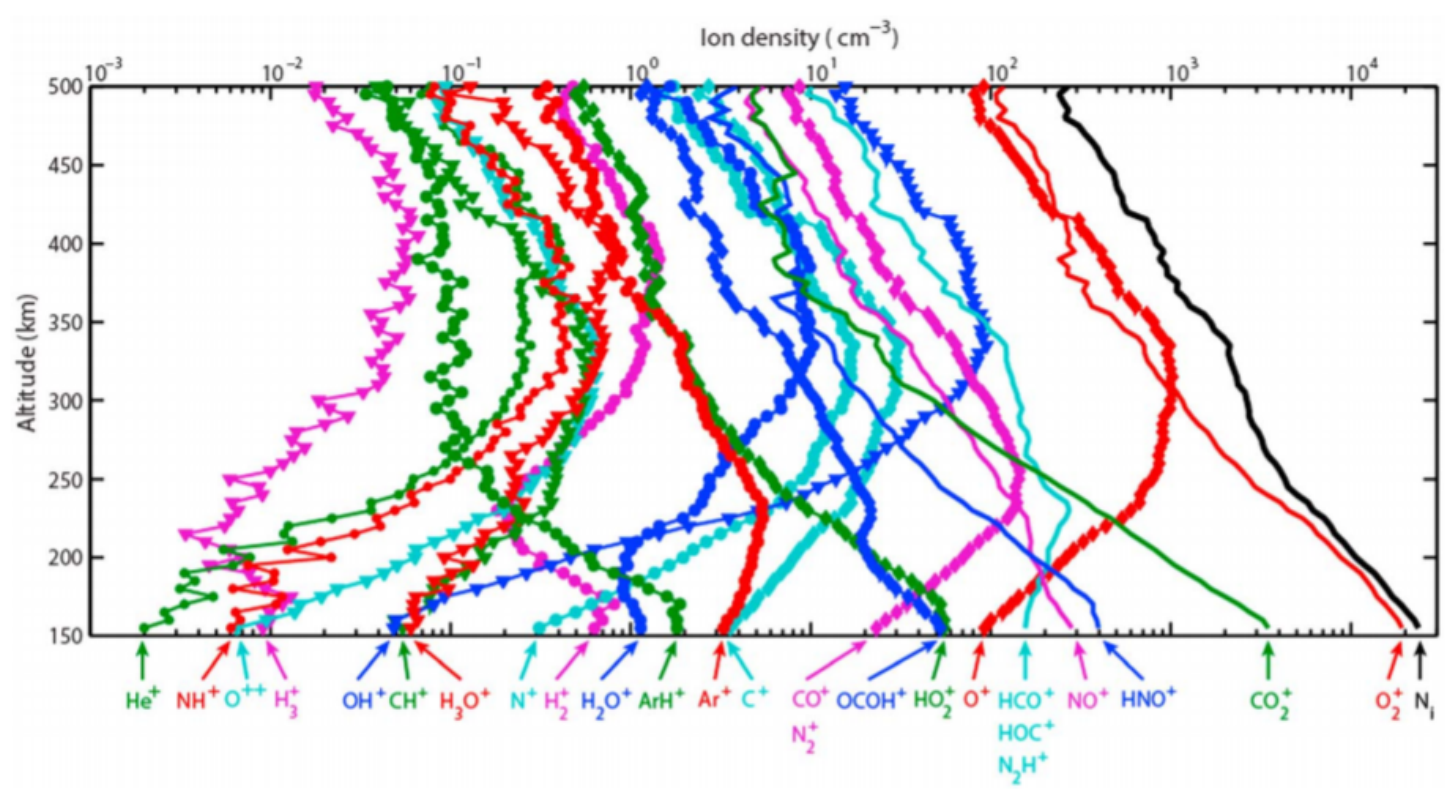

The profiles are built from the data obtained by the Neutral Gas and Ion Mass Spectrometer onboard MAVEN. The black curve represents the total ion density.

SOURCE: Benna et al. (2015).

According to Krasnopolsky (2002), $\mathrm{O}_{2}^{+}$and $\mathrm{O}^{+}$are generated by a chain of chemical reactions at the Martian ionosphere. $\mathrm{CO}_{2}$ molecules undergo photo-chemical processes due to incident photons $(h v)$, resulting in $\mathrm{O}$ and $\mathrm{CO}$. The expression is given by

$$
\mathrm{CO}_{2}+\mathrm{hv} \longrightarrow \mathrm{CO}+\mathrm{O}
$$

\footnotetext{
${ }^{1}$ The solar zenith angle (SZA) is the angle between the zenith and the position of solar incidence at a given point on the planet. For example, if an observer is at $\mathrm{SZA}=0^{\circ}$, this means that the Sun is right above him/her; if another observer is at $\mathrm{SZA}=180^{\circ}$, this implies that he/she is exactly on the opposite side of the planet from the first observer.
} 
$\mathrm{O}$ and $\mathrm{CO}$ produce primary ions $\left(\mathrm{CO}_{2}^{+}, \mathrm{O}^{+}, \mathrm{CO}^{+}\right.$, and $\left.\mathrm{C}^{+}\right)$and electrons $(e)$. These ions react with molecules and form the secondary ion $\mathrm{O}_{2}^{+}$. In summary, the reactions that form the dominant ions in the ionosphere of Mars are

$$
\begin{gathered}
\mathrm{O}+\mathrm{hv} \longrightarrow \mathrm{O}^{+}+e \\
\mathrm{O}^{+}+\mathrm{CO}_{2} \longrightarrow \mathrm{O}_{2}^{+}+\mathrm{CO} \\
\mathrm{CO}+\mathrm{hv} \longrightarrow \mathrm{O}^{+}+\mathrm{C} \\
\mathrm{CO}_{2}^{+}+\mathrm{O} \longrightarrow \mathrm{O}_{2}^{+}+\mathrm{CO}
\end{gathered}
$$

Particles can acquire sufficient energy to overcome the gravitational attraction of the planet, which results in atmospheric loss. Especially at Mars, the atmospheric losses are of great importance for determining the evolution of the planet's atmosphere (LUNDIN et al., 1989; JAKOSKY et al., 2015). The escape occurs by several different mechanisms, e.g., Jeans' escape (CHAFFIN et al., 2014), photo-chemical loss (LILLIS et al., 2015), atmospheric sputtering (LUHMANN et al., 1992; JOHNSON, 1994), ion bulk escape (BRAIN et al., 2010), and ion outflow (FRÄNZ et al., 2015; HARADA et al., 2017).

Due to the lack of an active magnetic field to contain and protect the gases, the atmosphere of Mars has been constantly depleted by solar effects. The ionosphere cannot retain the solar heat, and a large thermal gradient is generated between the day-side and the night-side of the planet. Besides that, the plasma density is larger on the day-side, as this is the region of incidence of solar radiation. Thermal and density gradients in the ionosphere cause the plasma to diffuse from hot and dense regions (day-side) to cold and rarefied regions (night-side), creating the ionospheric flows (FOX et al., 1993; BITTENCOURT, 1995; BENNA et al., 2015; CUI et al., 2015).

\subsection{Induced magnetic field on Mars}

Every planet in the solar system is surrounded by a magnetosphere, a region formed due to its interaction with the solar wind (KIVELSON; RUSSELL, 1995). When the solar wind encounters a planetary obstacle, a bow shock is generated in front of the magnetosphere, which deflects the supermagnetosonic flux around the magnetospheric cavity.

In planets with an active magnetic dynamo and developed atmosphere, like Earth and Jupiter, the solar wind interacts directly with the planet's magnetic field, creat- 
ing a magnetosphere of intrinsic nature. On the other hand, in planets that have an atmosphere but no global magnetic field, like Mars and Venus, the magnetosphere is considered to be induced (KIVELSON; RUSSELL, 1995; RUSSELL, 2001; LUHMANN et al., 2004). Conducting systems existing in the planet's interior or in its ionosphere allow electric currents to flow through the body and interact with the incident solar wind. This process creates forces which are responsible for decelerating and deflecting the solar wind around a region similar to a magnetospheric cavity (KIVELSON; BAGENAL, 2007).

Mars' ionosphere is usually in a state in which the solar wind dynamic pressure, typically $\sim 1 \mathrm{nPa}$, exceeds the maximum ionospheric thermal pressure. This causes the IMF to pile up into the ionosphere and drape around the planet (SHINAGAWA; CRAVENS, 1992; NAGY et al., 2004). This process induces a mostly horizontal magnetic field with intensities of $\sim 50 \mathrm{nT}$ on the sub-solar point, at $\sim 400 \mathrm{~km}$ of altitude. The intensity of the radial component of the induced field is only a few $\mathrm{nT}$ for all altitudes. (BRAIN et al., 2003; WITHERS, 2009).

\subsection{The influence of the crustal magnetic fields on Mars' ionosphere}

Mars is a unique case in the solar system. Although it has an induced magnetosphere, its crustal magnetic fields are sufficiently strong to interfere with the way that the solar wind interacts with the planet. Over most of the Martian surface ( $70 \%)$, the influence of crustal magnetic field lines extends above $120 \mathrm{~km}$ altitude. In regions of very intense magnetization in the Southern hemisphere, this influence extends above $1000 \mathrm{~km}$ altitude (BRAIN et al., 2003; BRAIN, 2006). These regions are commonly called "mini-magnetospheres", as their planetary origins resemble those of intrinsic magnetospheres (KIVELSON; BAGENAL, 2007).

The mini-magnetospheres block portions of the Martian atmosphere from interacting directly with the solar wind (MITCHELL et al., 2001). This prevents ionization processes caused by solar radiation, which provokes significant changes in ionospheric parameters (BRAIN, 2006), such as composition (WITHERS et al., 2015), electron density (WITHERS et al., 2005; GURNETT et al., 2008), ion density (MA et al., 2004), scale heights (GURNETT et al., 2008), and escape fluxes (FANG et al., 2017). The crustal magnetic fields also have a role in generating ionospheric dynamo currents, affecting global ionospheric behavior (WITHERS et al., 2005; LILLIS et al., 2019).

Figure 1.6 shows the magnetosphere of Mars and its main plasma regions and boundaries, as well as an example of how a mini-magnetosphere can interfere in those 
regions.

Figure 1.6 - Illustration of the Mars' magnetosphere.

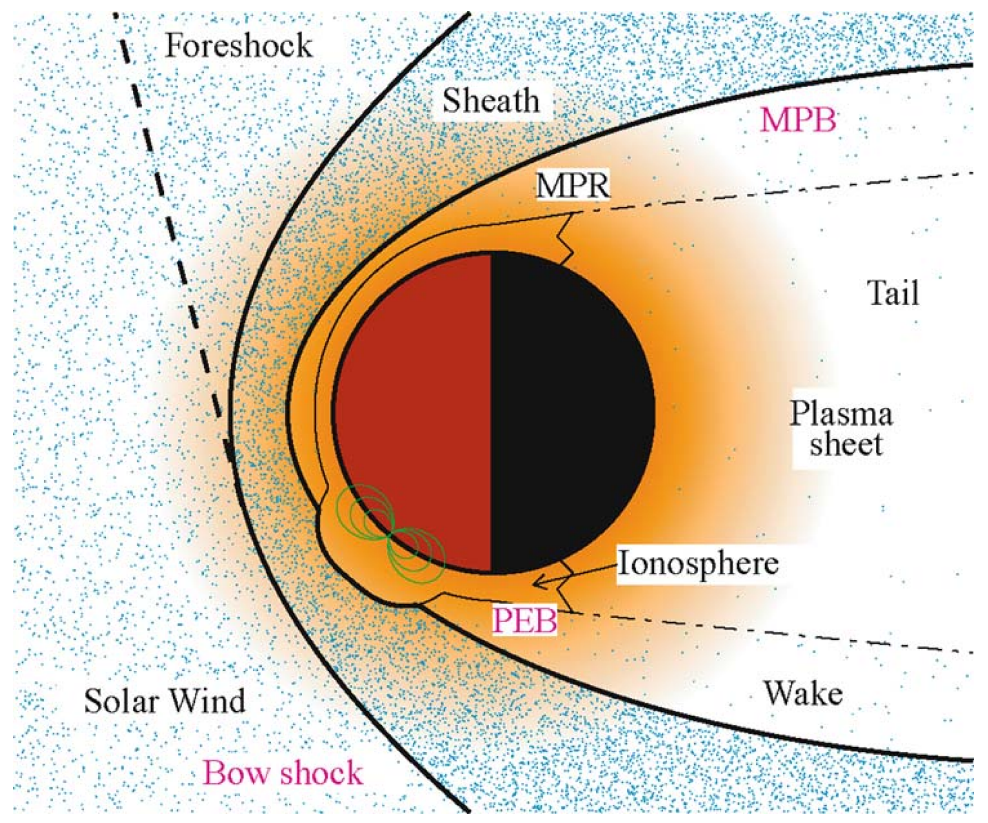

Cartoon of the interaction between the solar wind and the Martian environment. The orange region indicates the relative electron density of the ionospheric region. The blue dots indicate the relative density of the solar wind ions in different plasma regions. The green lines indicate an example of magnetic field lines due to a local crustal magnetization. The labels represent the different plasma regions and boundaries of Mars' induced magnetosphere. The abbreviations MPB, MPR, and PEB stand for Magnetic Pile-up Boundary, Magnetic Pule-up Region, and Photo-Electron Boundary, respectively.

SOURCE: Brain (2006).

Brain (2006) calculated the theoretical shape of the Martian obstacle to the solar wind when the mini-magnetospheres are taken into consideration. Figure 1.7 shows this shape, which is highly irregular and asymmetric, due to the different intensities and locations of the crustal magnetic fields that are spread across the planet. In general, the Southern hemisphere consists of a much more salient obstacle to the solar wind than the Northern hemisphere. 
Figure 1.7 - Cartoon of the Martian obstacle to the solar wind.

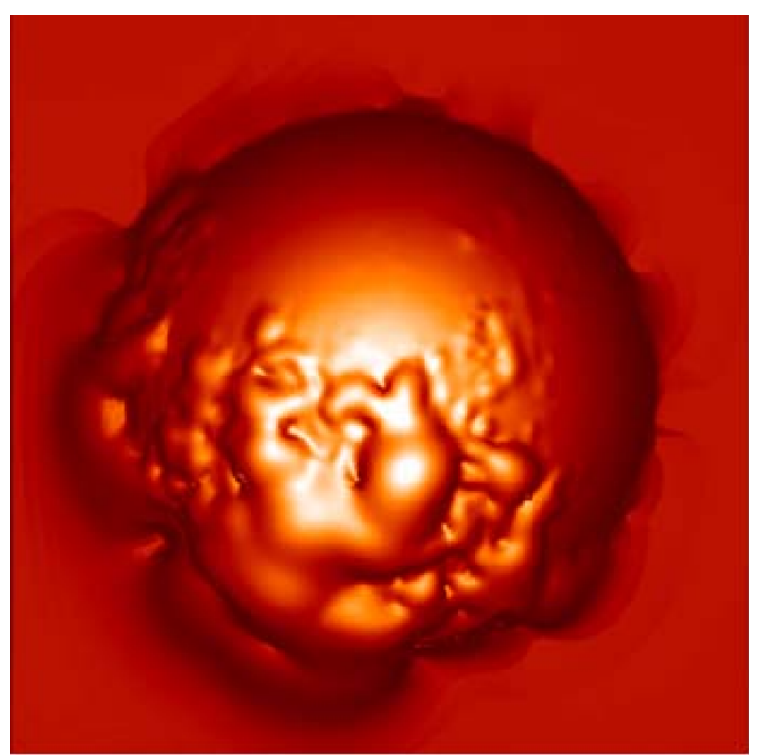

The shape is derived from a calculation of pressure balance between upstream solar wind dynamic pressure and a combination of ionospheric thermal pressure and magnetic pressure from crustal magnetic fields.

SOURCE: Brain (2006).

In a simple scenario of an induced magnetosphere, the IMF carried along by the solar wind drapes around the planetary body and does not penetrate the ionosphere (KIVELSON; BAGENAL, 2007). This means that there should be only one configuration for magnetic field lines in an induced magnetospheric environment. However, the existence of crustal magnetic fields on Mars implies three different magnetic field topologies (BRAIN, 2006; BRAIN et al., 2007; WEBER et al., 2017). In this case, there are not only draped IMF lines but also closed and "open" magnetic field lines. Figure 1.8 illustrates the three different topologies.

The closed topology refers to the crustal magnetic field lines, where both ends of the line are bound to the crust. The open topology refers to the magnetic field lines that have one end on the crust and the other end connected to the IMF. Here, the usage of the word "open" does not mean that the magnetic field diverges, but that the crustal magnetic field lines get connected to the IMF lines. 
Figure 1.8 - Diagram of magnetic field topologies on Mars.

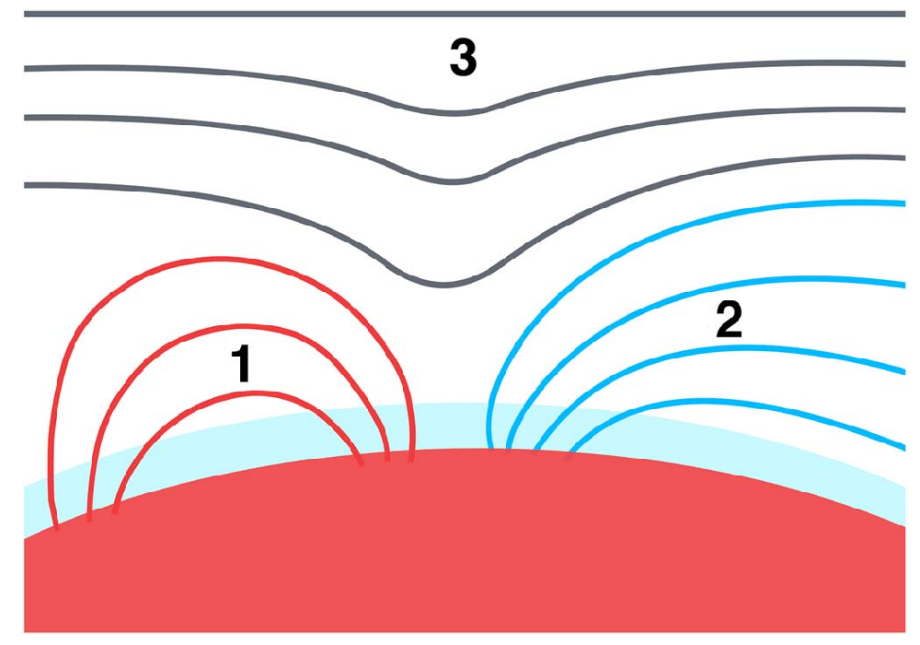

Magnetic field lines configurations are (1) closed, (2) open and (3) draped.

SOURCE: Adapted from Weber et al. (2019).

The open magnetic field lines can form cusp-like regions, enhancing direct particle and energy exchange between the solar wind and the lower portions of the Martian ionosphere (LUHMANN et al., 2002; BRAIN, 2006).

\subsection{Displacement of Mars' crustal magnetic fields}

An important process related to both magnetic fields and ionospheric plasmas is the formation of "magnetic flux ropes". At different environments throughout the solar system, including at Venus and at Mars, there have been reports of cylindrical bodies of magnetized plasma, characterized by twisted magnetic field lines and surrounded by ionospheric plasma (RUSSELL; ELPHIC, 1979; CLOUTIER et al., 1999; VIGNES et al., 2004; BRIGGS et al., 2011). This feature has been proposed to occur due to the interaction between the solar wind and the planet's ionosphere.

Brain et al. (2010) were the first to relate magnetic flux tubes on Mars with regions of strong crustal magnetic fields. They reported large differences between MGS magnetic field data and a crustal magnetic field model. According to Cain et al. (2003), small differences of 15-60 nT, at $400 \mathrm{~km}$ altitude, between measurements and the model can be explained by the compressed IMF around the day-side ionosphere. However, the feature observed by Brain et al. (2010) had a larger amplitude, which led to the conclusion that it was a magnetic flux rope. The feature was observed just 
before the MGS spacecraft entered a region of strong crustal magnetic field, which implies in the displacement of the crustal magnetic field in the anti-solar direction. This means that the crustal magnetic field lines were being dragged towards the night-side, and this was caused by the effects of the solar wind on the ionosphere.

Brain et al. (2010) also explained that the stretched crustal magnetic fields eventually detach and the ionospheric plasma contained inside them escapes from the planet. Figure 1.9 illustrates this phenomenon. Inferring that this is a frequent process on Mars, they estimate that $\sim 5-10 \%$ of the total ionospheric loss is due to the detachment of magnetic flux ropes. Hara et al. (2015) and Hara et al. (2017) report MAVEN observations of magnetic flux ropes associated with crustal magnetic fields on Mars. In these studies, they suggest that the detachments occur frequently and that a single flux rope detachment can contribute up to $\sim 10 \%$ of the total ionospheric loss.

Figure 1.9 - Example of detachment of crustal magnetic field lines.
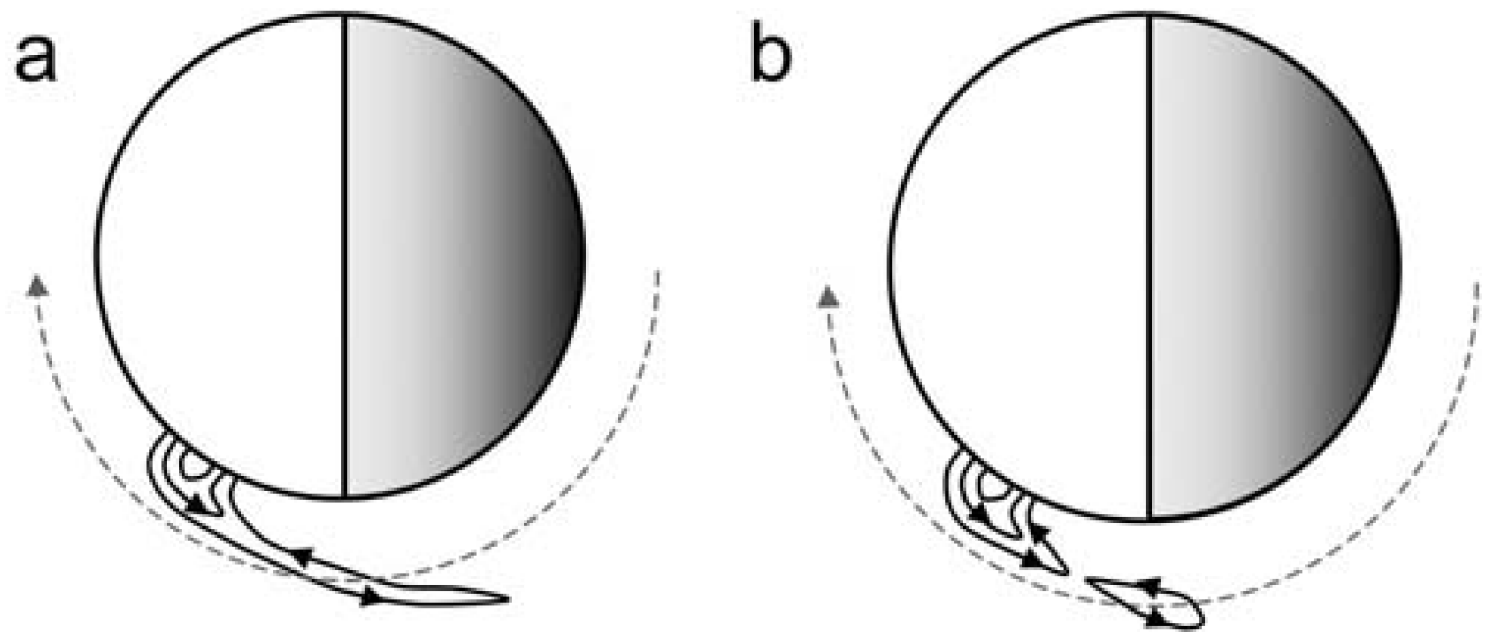

Schematic illustration of the ionospheric plasma removal process by the detachment of the crustal magnetic field lines, due to the interaction with the solar wind. The Sun is to the left. (a) Crustal magnetic field lines are still connected to the planet and are stretched by the solar wind in the night-side direction. (b) Upper portions of the field lines are detached, removing ionospheric plasma from Mars.

SOURCE: Brain et al. (2010).

So far, the detachment of magnetic flux ropes has been the only reported process of displacement of crustal magnetic fields on Mars. 


\subsection{Objectives of this study}

We know that crustal magnetic fields perturb global and local ionospheric behavior. In this study, we investigate whether and how ionospheric parameters influence the crustal magnetic fields on Mars. In particular, we want to know if the ionospheric flux drags the crustal magnetic fields, changing its local shape and magnitude, in a process which is similar to the stretching of magnetic flux ropes.

The motivation behind this study is the discovery that MGS magnetic field measurements from individual orbits can diverge significantly from the leading magnetic field models (private communication with Dr. Markus Fränz). If the solar wind can provoke detachment of magnetic flux ropes, it is also possible that the ionospheric flow can distort the crustal magnetic fields. This effect would then be seen at altitudes lower than the solar wind may influence. 


\section{THEORY}

In this Chapter, a theoretical foundation for the development of this Master Dissertation is presented. First, a description of Mars' coordinate systems is given. Next, we present the basic physical principles of electromagnetism and plasma on which this work is based. We also explain how the crustal magnetic field models are derived from spherical harmonic functions. At last, the geometry of the advection of the crustal magnetic fields on Mars is presented.

\subsection{Coordinate systems}

Just like in the case of Earth, universal coordinate systems have been defined for the planet Mars. Here, we present two of the most accepted systems for the studies of Mars. Also, we define the usual magnetic field components used for the studies of planetary magnetism.

The first coordinate system is in accordance to the International Astronomical Union and it is known as the planetocentric coordinate system (ARCHINAL et al., 2018). In this system, the longitude is measured positive eastward and the latitude is defined as the angle between the equatorial plane and a line from the center of the planet to a given point (DUXBURY et al., 2011).

On Mars, this system is called areocentric, which refers to the Greek counterpart of the Roman god of war, Ares. In the areocentric coordinate system, the $0^{\circ}$ meridian crosses the center of the Airy-0 crater, named after the astronomer Sir George Biddell Airy, who has defined the Greenwich transit circle on Earth (VAUCOULEURS et al., 1973). The areocentric coordinate system is used when the locations of the Martian features are relevant to the study, like in the case of the crustal magnetic field structures.

The second coordinate system is the Mars-centered Solar Orbital (MSO) cartesian system. In the MSO system, the X-axis points from Mars to the Sun, the Y-axis points antiparallel to Mars' orbital velocity and the Z-axis completes the righthanded system (VIGNES et al., 2000). This is especially useful for studies concerning the interaction between Mars and the Sun and for referencing the planet's location on a solar system scale.

The studies of planetary magnetism also require a coordinate system to describe the direction and magnitude of the magnetic fields. This coordinate system can be cartesian or, more usually, spherical. In spherical coordinates, the magnetic field 
is defined by a radial component $\left(B_{r}\right)$, which is positive upwards, a co-latitudinal component $\left(B_{\theta}\right)$, positive southwards, and a longitudinal component $\left(B_{\varphi}\right)$, positive eastwards (BUTLER, 1992; CAMPBELL, 2003).

The co-latitudinal and the longitudinal components can be combined into a general horizontal component $\left(B_{h}\right)$ as

$$
B_{h}=\sqrt{B_{\theta}^{2}+B_{\varphi}^{2}}
$$

The magnetic field magnitude (or the total magnetic field $-B_{t}$ ) can be described in terms of the horizontal and the radial components as

$$
B_{t}=\sqrt{B_{h}^{2}+B_{r}^{2}}
$$

The use of spherical coordinates improves the interpretation of the planetary magnetic fields because this system makes the visualization of the direction of the magnetic field easier than in cartesian systems.

\subsection{Fundamentals of electromagnetism}

In this Section, we present the basic equations that constitute the foundation for studies which are related to electromagnetism. The electromagnetic theory is broadly approached by many authors, and here we choose to refer to Griffiths (1999) and references therein.

Electrically charged particles, i.e., ions and electrons, generate electric fields, which can be associated to an arbitrary point in space. For a charge $Q[\mathrm{C}]$, its electric field $\boldsymbol{E}[\mathrm{V} / \mathrm{m}]$ is given by

$$
\boldsymbol{E}=\frac{Q}{4 \pi \varepsilon_{0} d^{2}} \hat{\boldsymbol{d}}
$$

where $\varepsilon_{0} \simeq 8.86 \times 10^{-12} \mathrm{~F} / \mathrm{m}$ is the vacuum permittivity, $d$ is the distance between the charge and the point and $\hat{\boldsymbol{d}}$ is a unit vector oriented away from $Q$ in the direction of the point.

When another charged particle $q$ is subjected to the electric field of $Q$, their interac- 
tion gives rise to a force of attraction or repulsion, depending on the nature of the charges. This is known as the Coulomb's Force $[\mathrm{N}]$ and it is expressed by

$$
\boldsymbol{F}_{E}=q \boldsymbol{E}
$$

The Coulomb's Force leads to the motion of the charge $q$, which generates an electric current $I[\mathrm{~A}]$, given by

$$
I=\frac{q}{\Delta t}
$$

where $\Delta t[\mathrm{~s}]$ is the time interval per which the charge flows through a cross section.

A steady current, i.e., a continuous flow with no charge variation, produces a constant magnetic field. The Biot-Savart Law states that the magnetic field $\boldsymbol{B}[\mathrm{T}]$ of a steady line current at an arbitrary point is given by

$$
\boldsymbol{B}=\frac{\mu_{0}}{4 \pi} I \int_{S} \frac{d \boldsymbol{S} \times \hat{\boldsymbol{d}}}{d^{2}}
$$

where $\mu_{0} \simeq 4 \pi \times 10^{-7} \mathrm{H} / \mathrm{m}$ is the vacuum permeability, $d \boldsymbol{S}$ is a vector of an infinitesimal element of length along the path $S, \hat{\boldsymbol{d}}$ is the direction of the vector from the source to the point and $d$ is the magnitude of this vector.

If a magnetic field is applied to a charged moving particle, the movement of this particle is changed due to a force, known as the Lorentz Force. An external electric field also influences the behavior of the particle. In general, considering both electric and magnetic fields, the Lorentz Force $[\mathrm{N}]$ is expressed by

$$
\boldsymbol{F}_{L}=q(\boldsymbol{E}+\boldsymbol{u} \times \boldsymbol{B})
$$

where $\boldsymbol{u}[\mathrm{m} / \mathrm{s}]$ is the velocity of the particle. This equation implies that the particle will be partially forced to move perpendicularly to both the directions of the external magnetic field and its own velocity. Notice that if there is no magnetic field, the Lorentz Force becomes the Coulomb's Force (Equation 2.4).

The behavior of electric and magnetic fields is described by four universal laws, 
known as the Maxwell's Equations. The first Equation is the Gauss' Law, expressed by

$$
\nabla \cdot \boldsymbol{E}=\frac{\rho}{\varepsilon_{0}}
$$

where $\rho\left[\mathrm{C} / \mathrm{m}^{3}\right]$ is the electric charge density. The Gauss' Law dictates that the electric flux related to a volume is proportional to the amount of charge inside that volume.

The second Maxwell's Equation is the Gauss's Law for magnetic fields, which is analogous to the Gauss' Law for electric fields (Equation 2.8) and is given by

$$
\nabla \cdot \boldsymbol{B}=0
$$

The Gauss' Law for magnetic fields states that the total magnetic flux that goes through a volume is null, i.e., magnetic fields do not diverge. Therefore, the magnetic field lines which are originated in a body always form a closed loop and the concepts of open magnetic field lines and magnetic monopole do not exist.

The next equation is the Faraday's Law, which is expressed by

$$
\nabla \times \boldsymbol{E}=-\frac{\partial \boldsymbol{B}}{\partial t}
$$

The Faraday's Law states that a time-varying magnetic field gives rise to a rotating electric field, and vice-versa.

The fourth Maxwell's Equation is the Ampère-Maxwell's Law, given by

$$
\nabla \times \boldsymbol{B}=\mu_{0}\left(\boldsymbol{J}+\varepsilon_{0} \frac{\partial \boldsymbol{E}}{\partial t}\right)
$$

where $\boldsymbol{J}\left[\mathrm{A} / \mathrm{m}^{2}\right]$ is an external current density. The Ampère-Maxwell's Law shows that an electric current, either originated by external sources or by a time-varying electric field, generates a magnetic field that rotates around it. 


\subsection{Fundamentals of plasma physics}

In this Section, we present the equations from the theory of plasma physics that are necessary for the basic understanding of the advection of magnetic fields in a plasma environment. The general references for this Section are the books written by Bittencourt (1995), Davidson (2001) and Chen (2016).

A plasma is composed of electrically charged particles, which produce an electric field, as stated by Equation 2.3. As seen in Section 1.5, thermal and density gradients in the ionosphere generate day-to-night plasma flows. An electric field flowing through a cross-section induces an electric current density. In the presence of an external magnetic field, the current density is given by the generalized Ohm's Law as

$$
\boldsymbol{J}=\sigma(\boldsymbol{E}+\boldsymbol{u} \times \boldsymbol{B})
$$

where $\boldsymbol{u}$ is the velocity of the plasma and $\sigma_{0}[\mathrm{~S} / \mathrm{m}]$ is its electrical conductivity, which is a measure of how strongly the ionosphere conducts electric currents.

Advection $^{2}$ is a physical process in which a quantity is transported by a velocity field. The quantity that is advected can be a fluid, a scalar field, or even a vector field, which is the case of the magnetic field. An example of advection in Space Geophysics is the distortion of the Sun's magnetic field lines by differential rotation, which generates an azimuthal magnetic field (e.g., Choudhuri (2007)).

In a plasma environment, the advection of the magnetic field can be evaluated in terms of the continuity (or induction) equation, which is derived from Equations $2.10,2.11$, and 2.12 as

$$
\frac{\partial \boldsymbol{B}}{\partial t}=\nabla \times(\boldsymbol{u} \times \boldsymbol{B})+\eta \nabla^{2} \boldsymbol{B}
$$

where $\eta\left[\mathrm{m}^{2} / \mathrm{s}\right]$ is the magnetic diffusivity, which is a term that depends on the electrical conductivity of the plasma (LUHMANN; CRAVENS, 1991). The magnetic diffusivity is given by

\footnotetext{
${ }^{2}$ Advection should not to be confused with convection. Although the two processes are similar, convection is applied to the movement of a fluid due to heat transfer among the particles or molecules within the fluid.
} 


$$
\eta=\frac{1}{\mu_{0} \sigma}
$$

In physical terms, Equation 2.13 means that the rate at which the magnetic field changes in time depends on its advection by the plasma velocity (first term on the right-side) and its diffusion through the plasma (second term on the right-side).

If $\sigma$ is sufficiently large, i.e., in highly conducting plasmas, $\eta$ can be disregarded and Equation 2.13 becomes

$$
\frac{\partial \boldsymbol{B}}{\partial t}=\nabla \times(\boldsymbol{u} \times \boldsymbol{B})
$$

In this case, the magnetic field lines are "frozen" to the plasma and carried along with it. This is what happens to the IMF, which is frozen to the solar wind, due to the very high conductivity of the plasma.

On the other hand, if the plasma is not a good conductor, the diffusion term dominates and Equation 2.13 becomes

$$
\frac{\partial \boldsymbol{B}}{\partial t}=\eta \nabla^{2} \boldsymbol{B}
$$

Here, the result is the decay of the magnetic field over time.

We consider Mars' ionosphere to be composed by a reasonably conducting plasma, so both advection and diffusion should occur. However, the conductivity of Mars' ionosphere cannot be directly measured and its derivation is not straightforward. This means that the continuity equation (Equation 2.13) cannot be easily solved for the advection term.

Other parameters that can be calculated in a plasma are its dynamic, thermal, and magnetic pressures (FRÄNZ et al., 2006). The dynamic pressure is the kinetic energy per unit volume of the plasma particles, which means that this is a measure of the force carried by the plasma velocity. The dynamic pressure $[\mathrm{Pa}]$ of an incompressible fluid is given by

$$
p_{D y n}=\frac{n m u^{2}}{2 N_{A}}
$$


where $n\left[\mathrm{~m}^{-3}\right]$ is the number density of the particles, $m[\mathrm{kDa}]$ is their atomic weight, $u[\mathrm{~m} / \mathrm{s}]$ is the flow speed and $N_{A}=6.02214076 \times 10^{23} \mathrm{~mol}^{-1}$ is the Avogadro constant.

The thermal pressure is a measure of the force per unit area carried by the kinetic energy of the random particle motions. For a fluid in thermal equilibrium, the thermal pressure $[\mathrm{Pa}]$ is given by the equation of state of an ideal gas, which is expressed as

$$
p_{T h}=n k_{B} T
$$

where $k_{B}=1.380649 \times 10^{-23} \mathrm{~J} / \mathrm{K}$ is the Boltzmann constant and $T[\mathrm{~K}]$ is the plasma temperature.

The magnetic pressure in a plasma is a measure of the repulsion force per unit area carried by the magnetic field lines in the direction perpendicular to the lines. The magnetic pressure $[\mathrm{Pa}]$ is given by

$$
p_{M a g}=\frac{B_{t}^{2}}{2 \mu_{0}}
$$

\subsection{Representation of magnetic fields by spherical harmonic functions}

As previously discussed, working with a crustal magnetic field model of Mars is of great importance in order to evaluate the observations. The magnetic field can be represented by fitting real data to a spherical harmonic expansion. Here, we introduce the basic concepts for building this type of model, based on Granzow (1983), Blakely (1996) and Arkani-Hamed (2004) and references therein.

Two of the Maxwell equations are fundamental to this theory: the Gauss' Law for magnetic fields (Equation 2.9) and the Ampère-Maxwell's Law (Equation 2.11). If we consider a current-free scenario, the magnetic field becomes irrotational and the Ampère-Maxwell's Law can be re-written as

$$
\nabla \times \boldsymbol{B}=0
$$

The Helmholtz Theorem states that any conservative and irrotational vector field that decays with distance can be expressed as the gradient of a scalar field. This 
means that the magnetic field can be related to a magnetic potential $V$ as

$$
\boldsymbol{B}=-\nabla V
$$

The substitution of Equation 2.21 into Equation 2.9 gives place to the Laplace's Equation, expressed as

$$
\nabla^{2} V=0
$$

The simplified solution for Laplace's Equation is a magnetic potential model, expressed by harmonic spherical functions as

$$
V(r, \theta, \varphi)=a \sum_{n=1}^{N} \sum_{m=0}^{n}\left(\frac{a}{r}\right)^{n+1}\left(g_{n}^{m} \cos m \varphi+h_{n}^{m} \sin m \varphi\right) P_{n}^{m}(\cos \theta)
$$

where $(r, \theta, \varphi)$ is the observation point in spherical coordinates, $a$ is the radius of the reference sphere that contains the magnetic sources $(a<r), g_{n}^{m}$ and $h_{n}^{m}$ are the Gauss' coefficients, $P_{n}^{m}(\cos \theta)$ are the associated Legendre's functions of degree $n$ and order $m$, and $N$ is the maximum degree chosen for the problem. $N$ represents the number of different geometries of spherical harmonics that contribute for the real shape of the magnetic field. This means that a higher maximum degree is supposed to give a higher accuracy to the model.

The components of the magnetic field are derived from the magnetic potential by

$$
\begin{gathered}
B_{r}=-\frac{\partial V}{\partial r} \\
B_{\theta}=-\frac{1}{r} \frac{\partial V}{\partial \theta} \\
B_{\varphi}=-\frac{1}{r \sin \theta} \frac{\partial V}{\partial \varphi}
\end{gathered}
$$

The Gauss' coefficients $g_{n}^{m}$ and $h_{n}^{m}$ are calculated by fitting the observations of the magnetic field components to Equations 2.24, 2.25, and 2.26. 


\subsection{The advection of the crustal magnetic fields on Mars}

In this section, we describe the movement of the crustal magnetic field lines on Mars, as they are advected by the ionospheric flux.

Figure 2.1 shows the sketch of a case where both advection and diffusion occurs. A thin wire carries a current directly into the page, which generates a rotating magnetic field, as stated by Equation 2.11. A uniform velocity field $\mathbf{u}$ drags the magnetic field, advecting it in the direction which is parallel to the velocity, i.e., in the $\mathbf{x}$-direction.

Figure 2.1 - Sketch of the magnetic field advection of a wire.

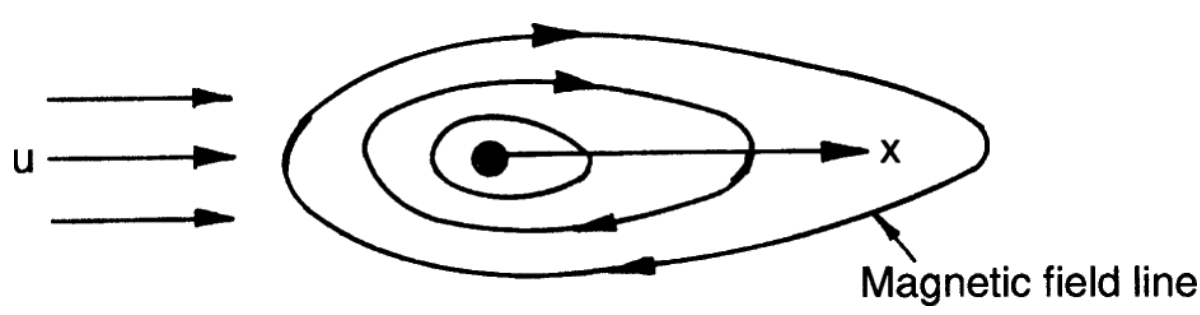

SOURCE: Davidson (2001).

We assume that the transport of crustal magnetic field lines by the ionospheric plasma flow on Mars occurs similarly to what is shown in Figure 2.1, where both advection and diffusion take place. Figure 2.2 illustrates the advection of the field in two different views, using the MSO coordinate system. 
Figure 2.2 - Illustration of the geometry of the problem.
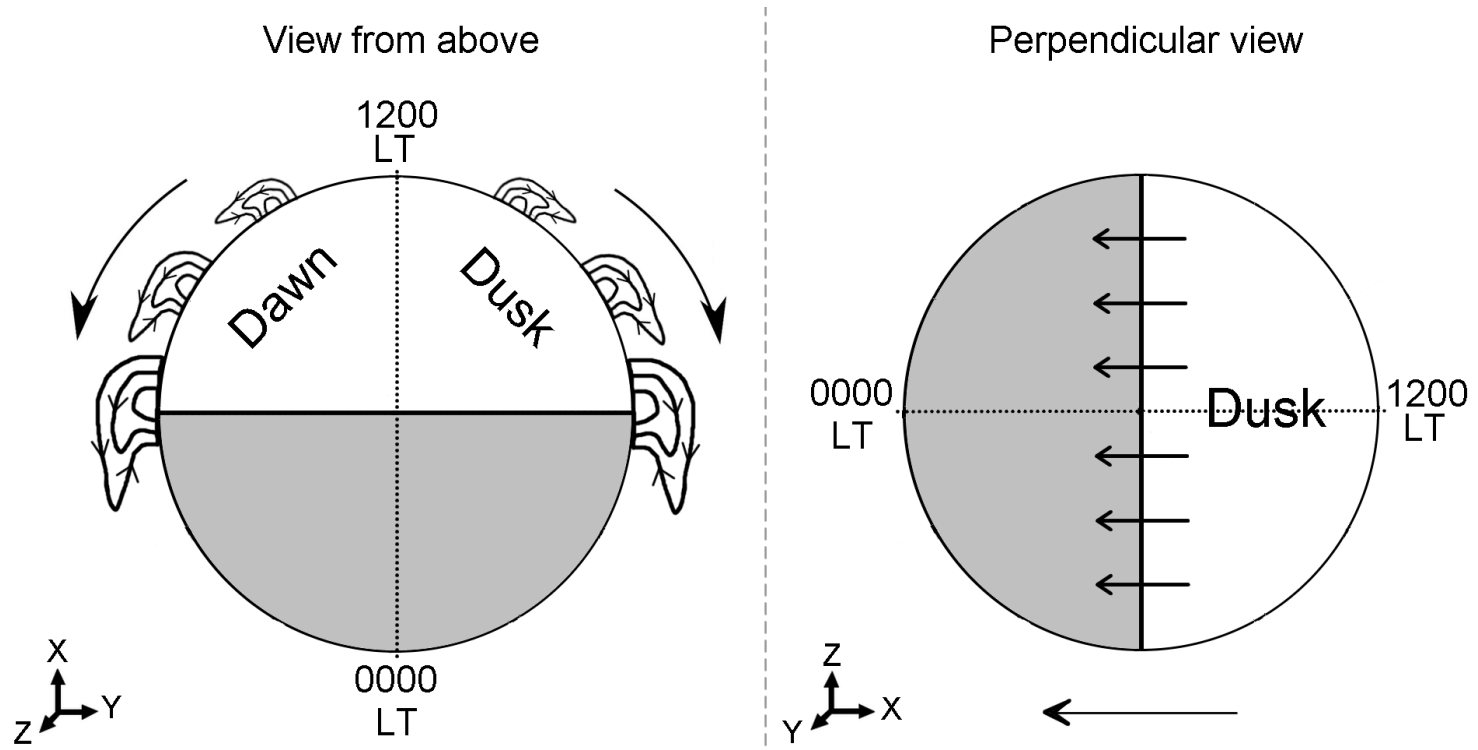

Schematic drawing of Mars, showing the advection of magnetic field lines from above (left) and from the the perpendicular view (right), in MSO coordinates. The arrows indicate the general day-to-night direction of the ionospheric flux.

SOURCE: Author's production.

According to our initial hypothesis, the magnetic field lines are advected in the anti-solar direction, which is generally the direction of the day-to-night flow of the ionospheric plasma. This means that the lines are supposed to move westward at dawn-side and eastward at dusk-side. The maximum distortion of the field lines is expected to happen in the terminator regions of the planet.

It should be mentioned that Figure 2.2 is only an empirical model of how the magnetic fields are expected to behave. In this work, we search for the first evidence of the advection of the magnetic fields on Mars and, therefore, no mathematical model for the movement of crustal magnetic fields on Mars has been proposed or built yet. 


\section{METHODOLOGY}

In this Chapter, the data and the crustal magnetic field models chosen for this Master Dissertation work are described, as well as the statistical methods applied for the investigation of the problem.

\subsection{Data description}

In this work, we analyze data gathered by the two NASA's spacecraft MGS and MAVEN. In this Section, these data are described.

MGS and MAVEN data are released by the Planetary Plasma Interactions Node of NASA's Planetary Data System and are publicly available at their webpage: https://pds-ppi.igpp.ucla.edu/.

\subsubsection{MGS data}

MGS spacecraft was launched on 7 November 1996. Figure 3.1 shows an illustration of the spacecraft. After MGS was inserted into Mars' orbit on 12 September 1997, the spacecraft went through a series of maneuvers in order to circularize and adjust its orbit. These early mission phases lasted from 17 September 1997 up to March 1999, and were called Aerobraking and Science Phase Orbits (AB/SPO). They were characterized by highly elliptical orbits of the spacecraft, varying periapsis altitude, and sparse global coverage.

From 9 March 1999 until the end of the mission on 21 November 2006, the spacecraft was in its Mapping Phase Orbit (MPO), in which MGS had a circular-mapping orbit with nearly-constant altitude of $\sim 400 \mathrm{~km}$. The spacecraft reached an inclination of $93^{\circ}$, which means it covered the region between $-87^{\circ}$ and $+87^{\circ}$ of latitude. More detailed information about the MGS mission is given by Acuña et al. (2001) and Albee et al. (2001).

In this work, we analyze MPO data between 12 June 1999 and 2 November 2006. Due to its Sun-synchronous orbit, the spacecraft only covered the 02:00/14:00 local time (LT) plane. Therefore, these data have a very restricted altitude range and local time coverage. On the other hand, the mission had a dense spatial coverage and high spatial resolution, due to its longevity. In a $1^{\circ} \times 1^{\circ}$ area, MGS sampled around 60 magnetic field measurements during MPO.

Magnetic field data were gathered by the Magnetometer and Electron Reflectome- 
Figure 3.1 - Artist's concept of Mars Global Surveyor in orbit above Mars.

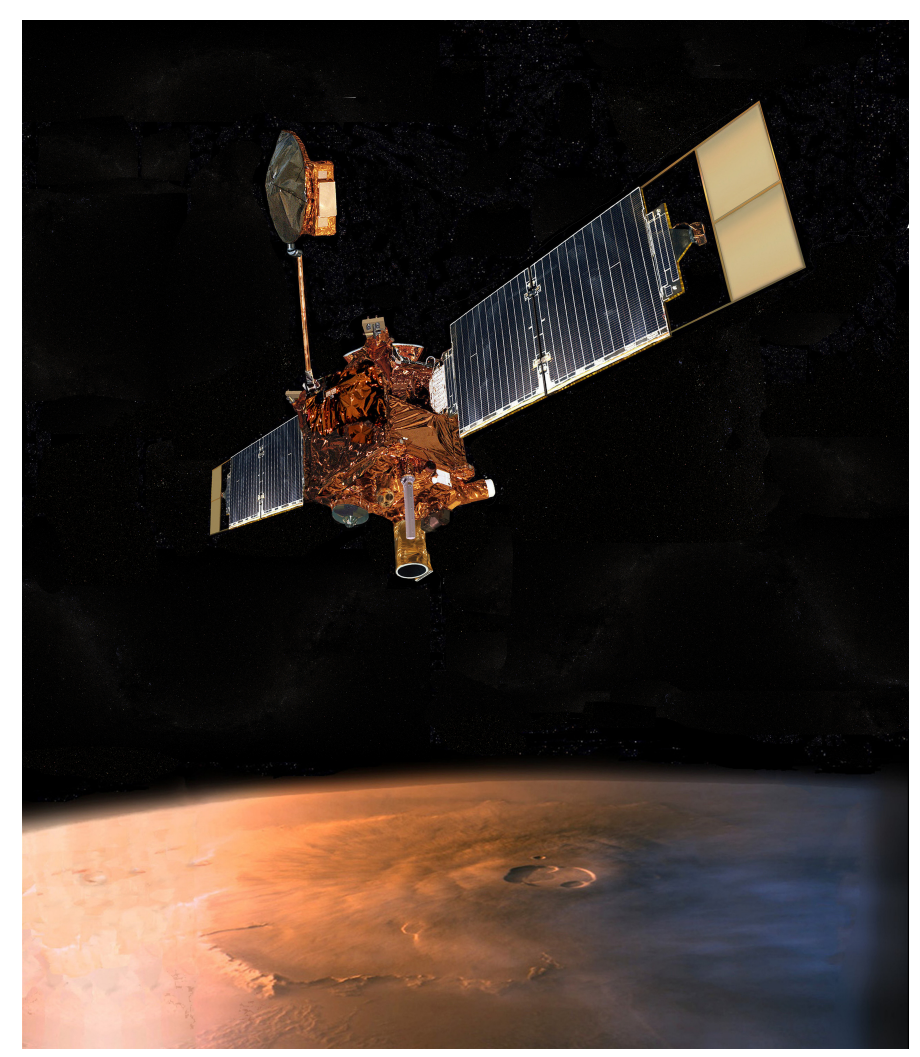

SOURCE: Courtesy NASA/JPL-Caltech (2002).

ter (MAG/ER) experiment, originally described by Acuña et al. (1992) for the Mars Observer mission. MAG/ER instrumentation included two triaxial fluxgate magnetometers, which provided measurements of the magnitude and direction of the magnetic field. Up to 32 samples/s could be acquired over eight dynamic ranges with maximum fields between $\pm 4 \mathrm{nT}$ and $\pm 65536 \mathrm{nT}$. The digital resolution of 12 bits varied from $0.002 \mathrm{nT}$ to $\sim 33 \mathrm{nT}$, according to each range.

In order to minimize spacecraft-generated magnetic fields, each magnetometer was placed in the external edge of articulated non-magnetic solar panels, about $5 \mathrm{~m}$ from the spacecraft center. The data were calibrated and corrected as explained by Acuña et al. (2001). 


\subsubsection{MAVEN data}

The MAVEN mission, which is broadly explained by Jakosky et al. (2015), has been acquiring data on Mars since its insertion in the planet's orbit on 21 September 2014. MAVEN spacecraft is illustrated in Figure 3.2. The altitude of the spacecraft covers between $125-175 \mathrm{~km}$ in the periapsis, and $\sim 6220 \mathrm{~km}$ in the apoapsis. The spacecraft has an inclination of $75^{\circ}$, which means it covers latitudes between $-75^{\circ}$ and $+75^{\circ}$, which leaves the polar regions out of the measurement range.

Figure 3.2 - Artist's concept of Mars Atmosphere and Volatile Evolution at Mars.

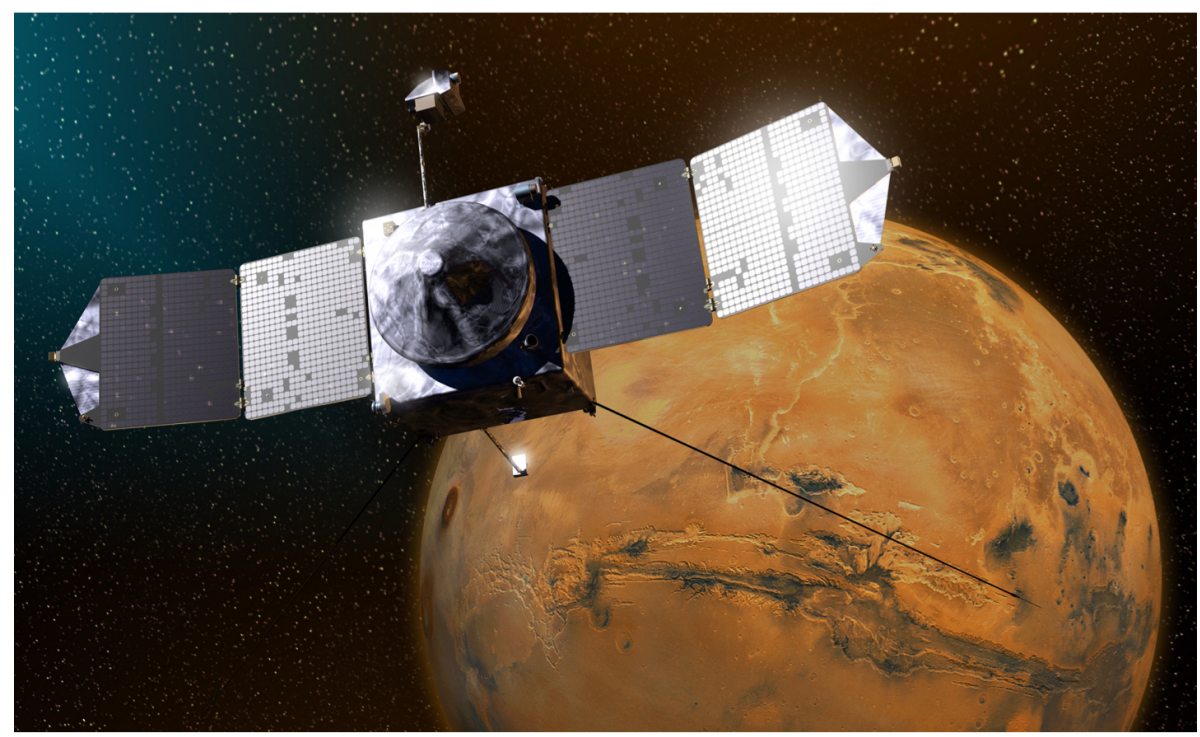

SOURCE: Courtesy NASA/GSFC (2014).

In a $1^{\circ} \times 1^{\circ}$ area, MAVEN has sampled between 1-10 measurements, considering altitudes between $200-1000 \mathrm{~km}$. In terms of local time, the most covered region lies between 04:00-16:00 LT. Although MAVEN still has a sparser spatial coverage than MGS at the time of writing, the data are better distributed in local time and in altitude.

The data used in this study range between 10 October 2014 and 14 November 2018. This period covers the Transition Phase and the Science Phase of the mission. Data gathered after this time range were not analyzed because they were either not released or had not yet been processed by the time of this work. The remanent magnetization on Mars mostly does not change over time, which means it is possible 
to study the crustal magnetic fields from data gathered by both MGS and MAVEN, despite the different periods of time.

Magnetic field data are provided by the Magnetometer (MAG) experiment, described by Connerney et al. (2015). Similarly to MAG/ER onboard MGS, MAVEN is equipped with two triaxial fluxgate magnetometers. They acquire 32 samples/s over three dynamic ranges with maximum fields between \pm 512 and $\pm 65536 \mathrm{nT}$ and digital resolution of 15 bits.

On MAVEN spacecraft, the two MAG sensors are located on small fixed booms, with an extension of $0.68 \mathrm{~m}$, extending out from each end of the solar arrays. By doing that, the sensors get the maximum possible distance from the rest of the spacecraft $(\sim 5.6 \mathrm{~m})$, in order to minimize spacecraft-generated magnetic fields. A strict magnetic "clean" program ensured that these fields are small enough for the experiment.

In addition to magnetic field data, we also use data of ionospheric components. The SupraThermal And Thermal Ion Composition (STATIC) instrument, described in details by McFadden et al. (2015), provides measurements of the energy spectra of ion fluxes and the ion composition. Ion density, temperature, and velocity are retrieved from the measurements. The data were previously processed and corrected for the spacecraft velocity and potential, as described by Dubinin et al. (2017).

STATIC is composed of an electrostatic analyzer and a velocity analyzer, operating over three dynamic energy ranges between $\sim 0.1-30 \mathrm{keV}$, with a time resolution of 4 s. STATIC is mounted on a $2 \mathrm{~m}$ boom which directs the instrument's field of view into the direction of the spacecraft motion at periapsis.

Electron density and temperature data are obtained by the Langmuir Probe and Waves (LPW) instrument (ANDERSSON et al., 2015). LPW consists of two sensors located at the outer end of two $7.1 \mathrm{~m}$ long booms on the spacecraft. The instrument measurements range between $\sim 10^{2}-10^{6} \mathrm{~cm}^{-3}$ for densities and $5 \times 10^{2}-5 \times 10^{5} \mathrm{~K}$ for temperatures, with a time resolution of $4 \mathrm{~s}$.

\subsection{Crustal magnetic field models}

As previously mentioned, three models for the crustal magnetic field of Mars are used in this work. They are derived from expansions of spherical harmonic functions that fit MGS observations. 
Cain model (CAIN et al., 2003) was published in 2003 and it is still the most widespread and popular crustal magnetic field model of Mars in the present days. The model is derived from vector magnetic field data obtained between 1997 and 2000 and goes up to degree and order 90. Two data sets are used to build the model: the first one includes $\mathrm{AB} / \mathrm{SPO}$ data and MPO night-time data, while the second one contains only MPO data. The model is created with a least-squares minimization technique developed for Earth field analysis, with a reference Martian radius of 3390 $\mathrm{km}$. Cain model shows general agreement with the ovbservations for MPO altitude ( $\sim 400 \mathrm{~km})$, but large discrepancies for altitudes below $200 \mathrm{~km}$.

Arkani-Hamed model (ARKANI-HAMED, 2004) was published in 2004 and it has as its main proposal to resolve small-scale weak magnetic anomalies. The model is built from only the night-side radial component of the magnetic field, in order to minimize the contributions from external magnetic fields. Night-time data acquired during the first $\sim 3$ years of the MPO period are divided into two almost equal sets and two spherical harmonic models up to degree and order 90 are determined for each of them. The two models are well-correlated up to degree and order 62 and the final result is derived from the averaging of these two models, up to this degree and order, considering a reference radius of $3390 \mathrm{~km}$. Arkani-Hamed model presents higher accuracy but lower resolution when comapred to the precedent models.

Morschhauser model (MORSCHHAUSER et al., 2014) was published in 2014, several years later than Cain and Arkani-Hamed results. The model is based on the entire MGS vector magnetic field data set, from 1997 to 2006, and it goes up to degree and order 110. They use data from MPO night-side data set, from AB/SPO night-side data set below $348 \mathrm{~km}$, and from AB/SPO day-side data set below $200 \mathrm{~km}$. The data are uniformly distributed in a sphere with a reference radius of $3393.5 \mathrm{~km}$. Data outliers and static external fields are properly treated, data are weighted, and the model is regularized by a least-squares algorithm to approach an absolute measure. Moreover, expansions with maximum degree and order of 10 and 5 are chosen for night-side and day-side external magnetic field models, respectively.

In terms of amount and variety of data, Morschhauser model is the number one among the three, followed by Cain and Arkani-Hamed models, respectively. Morschhauser model is also the most modern and robust, and reproduces the Martian crustal magnetic fields with a rich level of detail. For these reasons, we expect that this model fits the magnetic field data acquired by MAVEN better than the other two. 
Later in this work, we show a direct comparison among these three crustal magnetic field models (Subsection 3.4.1), in order to select the most appropriate for our subsequent analyses.

\subsection{Software}

The data selection and the data matrices used in this work are made with the Cluster Ion Spectrometer and Mars Express/Venus Express Analyzer of Space Plasma and Energetic Atoms Analysis Tool Interactive (CCATi), version 4.9.2. The software is an interactive interface, specialized in the analysis of data obtained by MAVEN, MGS, and other space missions. CCATi is written in the Interactive Data Language (IDL) and is developed by the Max Planck Institute for Solar System Research. More information on CCATi is available at the website: http://www2.mps.mpg.de/ projects/mars-express/aspera/ccati/.

The plots presented in this Chapter and in Chapter 4 are produced by the author in the programming languages IDL, version 7.1, and Python, version 3.7. For the plots produced in IDL, Coyote (FANNING, 2011) library is used. For the plots produced in Python, Matplotlib (HUNTER, 2007), NumPy (OLIPHANT, 2015), and SciPy (VIRTANEN et al., 2020) libraries are used.

\subsection{Data and model reduction}

First of all, we have to select which crustal magnetic field model is the most appropriate for our analysis and which component of the magnetic field we should use. In this Section, we show how the model and the component are chosen and explain the criteria used for the choices.

For simplicity, MAVEN data are gridded above Mars' surface with bin sizes of $1^{\circ} \times 1^{\circ}$ in latitude and longitude. The data have a time resolution of $4 \mathrm{~s}$.

\subsubsection{Comparisons among crustal magnetic field models}

The CCATi software is used to calculate the spherical harmonic equations for the crustal magnetic field models of Mars (Equations 2.23, 2.24, 2.25, and 2.26), based on the Gaussian coefficients of the models. Then, we produce maps of the median of the differences between the magnetic field measured by the spacecraft and the magnetic field model $(\Delta \mathrm{B})$.

The data in these maps are selected for two altitude ranges of $200-400 \mathrm{~km}$ and 400 - 
$1000 \mathrm{~km}$. We only use data from the years of 2015 and 2016, because this time range is enough to cover the whole latitudinal range of the MAVEN orbit. The maps are produced for SZA between $120^{\circ}-180^{\circ}$, which lies within the night-side of the planet. This analysis is restricted to the night-side only, due to the presence of an induced magnetic field in the day-side, which could affect the interpretation of the results.

For each model (Arkani-Hamed, Cain, and Morschhauser), we produce magnetic field maps showing the absolute values of $\Delta \mathrm{B}(|\Delta \mathrm{B}|)$ for the total magnetic field $\left(B_{t}\right.$, Equation 2.2), the horizontal component $\left(B_{h}\right.$, Equation 2.1), and the radial component $\left(B_{r}\right)$. We choose to show absolute values of $\Delta \mathrm{B}$ in this comparison study because we are only interested in the magnitude of these values, and not in the direction of the differences.

Since the maps showing the same component for different crustal models are visually too similar to each other, histograms of $|\Delta B|$, respective to each map, are also produced to quantify the differences between each model and the observations. Figure 3.3 shows the histograms of $|\Delta \mathrm{B}|$ for $B_{t}, B_{h}$, and $B_{r}$ at the altitude ranges of 200-400 km and 400-1000 km. Each histogram bin represents $4 \mathrm{nT}$. 
Figure 3.3 - Histograms of $|\Delta \mathrm{B}|$ for Arkani-Hamed, Cain, and Morschhauser models of the crustal magnetic field of Mars.

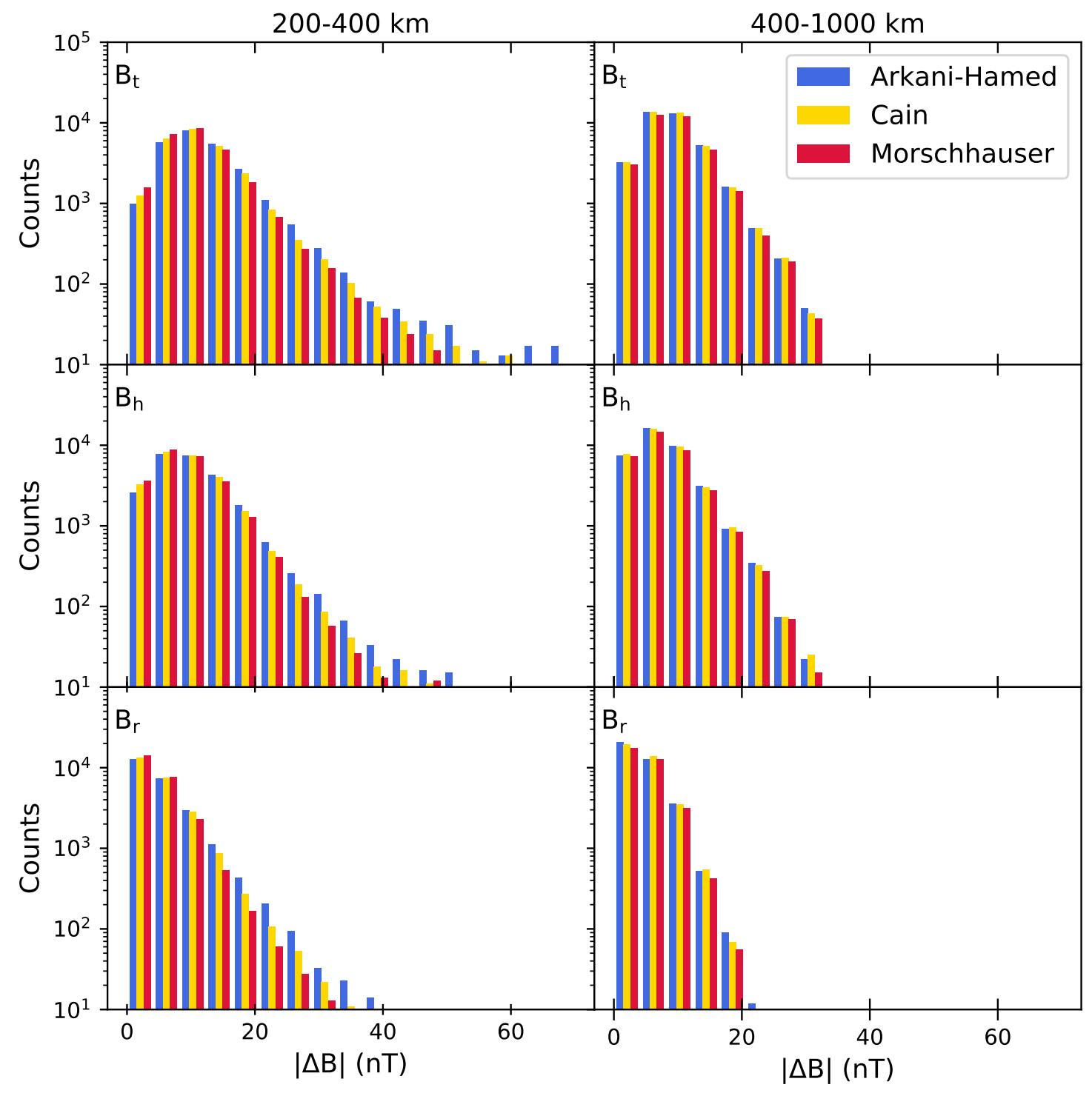

Histograms of $|\Delta \mathrm{B}|$ for $B_{t}$ (top), $B_{h}$ (middle), and $B_{r}$ (bottom), at altitudes between 200-400 km (left) and 400-1000 km (left), and SZA between $120^{\circ}-180^{\circ}$.

SOURCE: Author's production.

From Figure 3.3, we see that the Morschhauser model has the lowest number of large $|\Delta \mathrm{B}|$ and the highest number of small $|\Delta \mathrm{B}|$ at an altitude range of $200-400 \mathrm{~km}$. This means that the Morschhauser model presents the smallest overall $|\Delta B|$ among the three models. 
Also from Figure 3.3, we cannot observe relevant discrepancies among the models at an altitude range of 400-1000 km. This was expected because the models were produced with data obtained by MGS spacecraft, i.e., low altitude data, and they all aim for a good reproduction of the magnetic field at the altitude of MGS orbit, at the expense of resolution at higher altitudes. Still, the Morschhauser model presents slightly less data points for any $|\Delta \mathrm{B}|$ than the models from Arhani-Hamed and Cain.

If advection occurs in the ionosphere of Mars, we suppose that its magnitude is very small. Therefore, we do not want to use a crustal magnetic field model with a large overall $|\Delta \mathrm{B}|$. This could bias our investigation by hiding the effects of advection. Our criterion is to select the model with the smallest overall $|\Delta \mathrm{B}|$. For this reason, we decide to choose the Morschhauser crustal magnetic field model for the following analyses.

When comparing maps and histograms among $B_{t}, B_{h}$, and $B_{r}$, regardless of the model, $B_{r}$ shows the lowest $|\Delta \mathrm{B}|$ values. In the next Subsection, the magnitude and the two components of the magnetic field are compared in more detail.

\subsubsection{Comparisons among different components of the observed mag- netic field}

After selecting the crustal magnetic field model, we select the most appropriate component of the field for the study of advection. In order to perform this task, we make a comparative analysis, similar to what has been presented in the previous Subsection.

MAVEN data from 10 October 2014 to 14 November 2018 are selected for the altitude range of 200-400 km and divided into day-time and night-time subsets. Figures 3.4 and 3.5 show the maps of $|\Delta \mathrm{B}|$ for the total magnitude and for the horizontal and radial components for day-time and night-time, respectively. Figure 3.6 shows the respective histograms, with each bin representing $4 \mathrm{nT}$. 
Figure 3.4 - Maps of the day-side $|\Delta \mathrm{B}|$ for the magnitude and for the two components of the magnetic field of Mars, using the Morschhauser model.

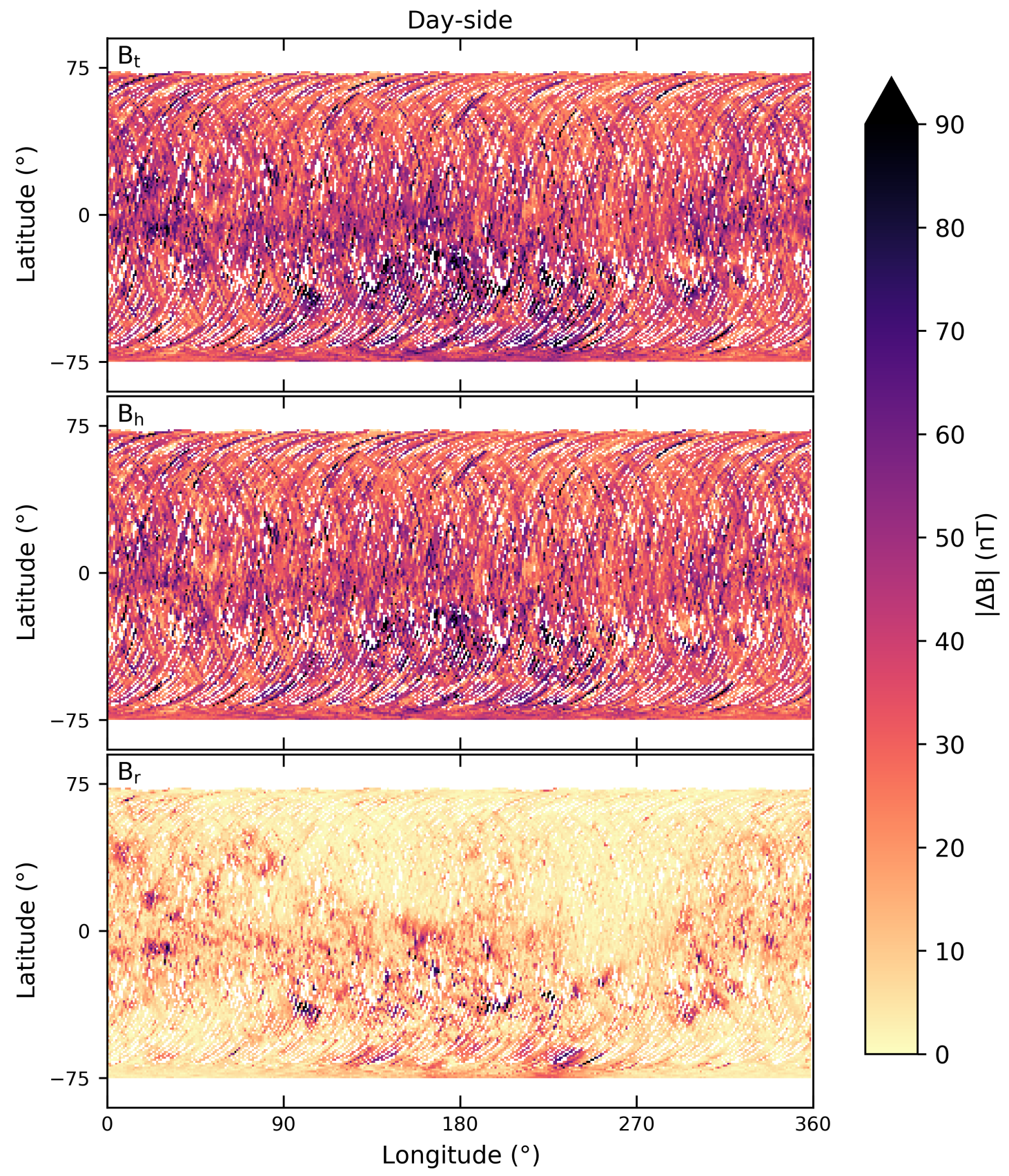

Maps of $|\Delta \mathrm{B}|$ for $B_{t}$ (top), $B_{h}$ (middle), and $B_{r}$ (bottom), at altitudes between 200-400 $\mathrm{km}$ and SZA between $0^{\circ}-90^{\circ}$.

SOURCE: Author's production. 
Figure 3.5 - Maps of the night-side $|\Delta \mathrm{B}|$ for the magnitude and for the two components of the magnetic field of Mars, using the Morschhauser model.

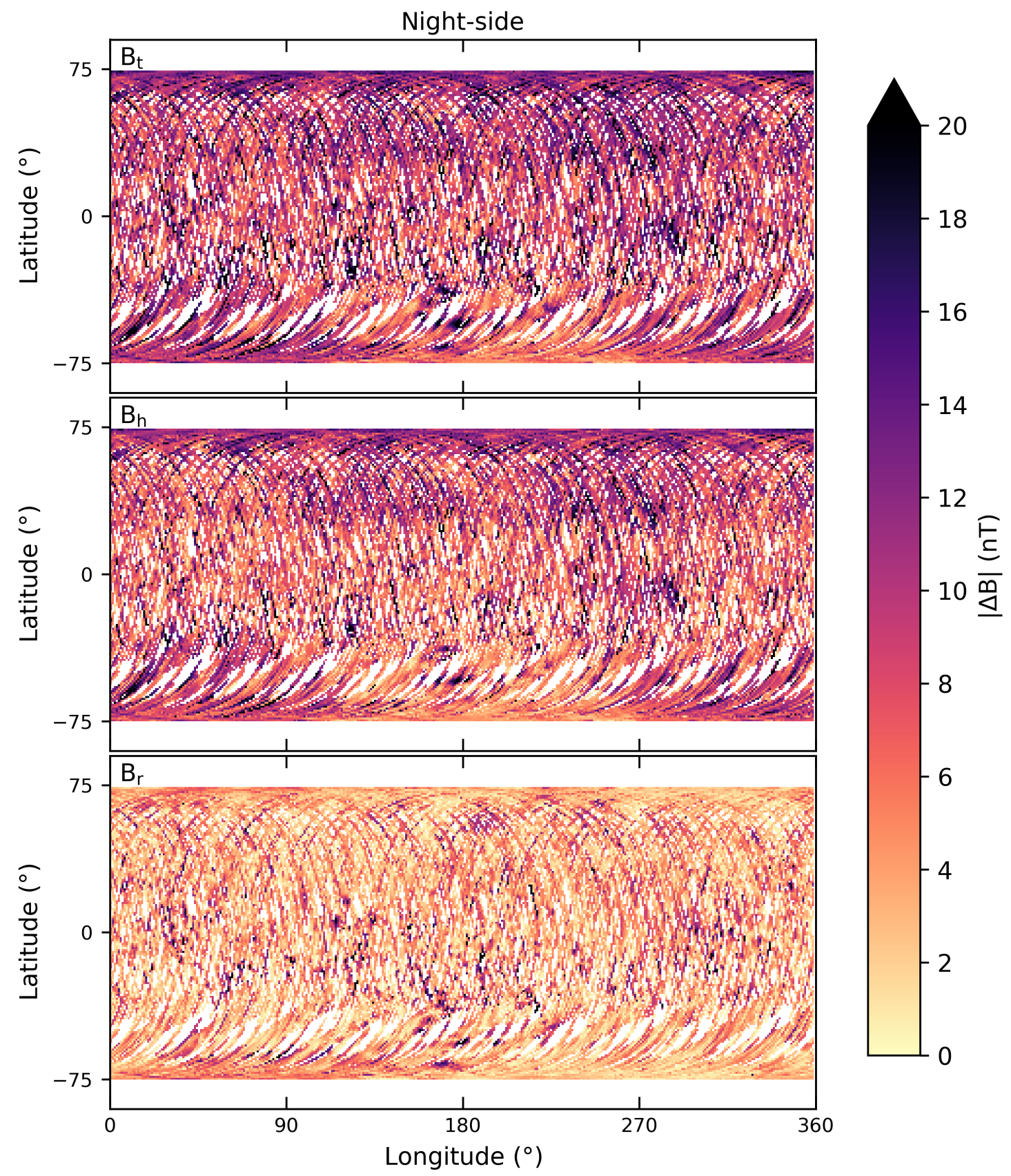

Maps of $|\Delta \mathrm{B}|$ for $B_{t}$ (top), $B_{h}$ (middle), and $B_{r}$ (bottom), at altitudes between 200-400 $\mathrm{km}$ and SZA between $90^{\circ}-180^{\circ}$. Notice the smaller range of the colorbar, in comparison to Figure 3.4.

SOURCE: Author's production. 
Figure 3.6 - Histograms of $|\Delta \mathrm{B}|$ for the magnitude and for the two components of the magnetic field of Mars, using the Morschhauser model.

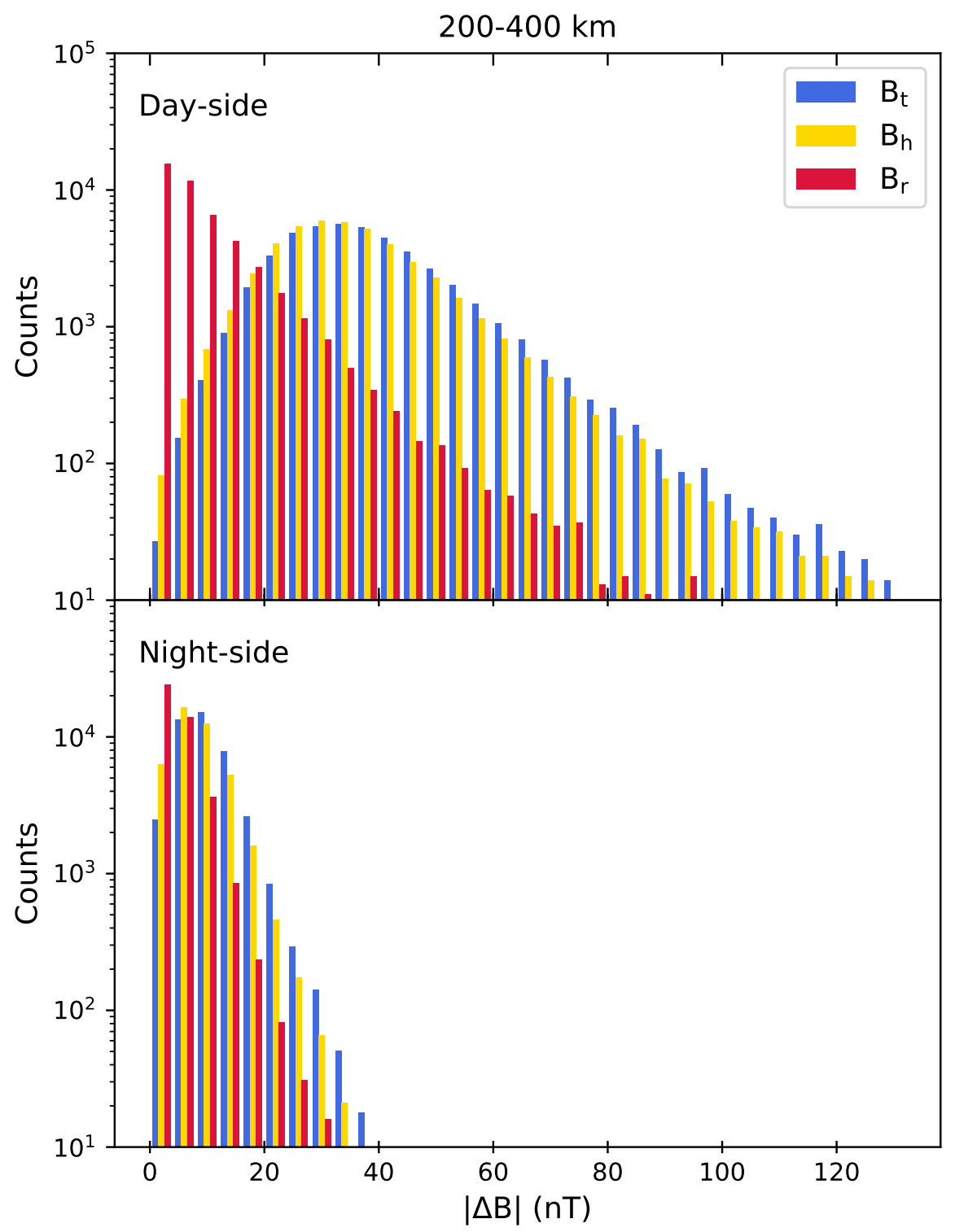

Histograms of $|\Delta \mathrm{B}|$ for day-side (top) and night-side (bottom) data, showing $B_{t}, B_{h}$, and $B_{r}$, at altitudes between $200-400 \mathrm{~km}$.

SOURCE: Author's production. 
Due to the induced magnetic field on the day-side of the planet, the maps of Figure 3.4 present higher values of $|\Delta \mathrm{B}|$ than the maps of Figure 3.5, in general. This becomes evident in Figure 3.6, where $|\Delta \mathrm{B}|$ values are mostly around $35 \mathrm{nT}$ in the day-side and around $10 \mathrm{nT}$ in the night-side.

In Figure 3.4, we observe that the highest values of $|\Delta \mathrm{B}|$ in the maps of $B_{t}, B_{h}$, and $B_{r}$ are related to regions of strong crustal magnetic fields (see Figures 1.3 and 1.4 for maps of the crustal magnetic field of Mars). These regions are more affected by the induced magnetic field, which leads to higher values of $|\Delta B|$. On the other hand, the larger values of $|\Delta \mathrm{B}|$ observed in the maps of Figure 3.5 do not seem to be related to the regions of strong crustal magnetic fields.

Furthermore, we can observe larger values of $|\Delta \mathrm{B}|$ in the maps of $B_{t}$ and $B_{h}$ than in the maps of $B_{r}$, for both Figures 3.4 and 3.5. This means that the magnitude and the horizontal component of the magnetic field are more affected by external influences than the radial component. In the day-side, this difference is very evident in Figure 3.6, as the distribution for $B_{r}$ falls faster than for $B_{t}$ and $B_{h}$. In the nightside, although the two components and the magnitude behave very similarly to each other, we can see that $B_{r}$ has more data points with low $|\Delta \mathrm{B}|$ and fewer data points with high $|\Delta \mathrm{B}|$ than $B_{t}$ and $B_{h}$, meaning that $B_{r}$ presents the smallest overall $|\Delta \mathrm{B}|$ among the three.

Since we do not want our results to be biased by external influences, we choose to investigate the advection of the magnetic fields with the magnetic field component that presents the smallest overall $|\Delta \mathrm{B}|$. Accordingly, most of the next analyses are performed using $B_{r}$.

Another factor that promotes the choice for $B_{r}$ regards the Lorentz Force (Equation 2.7). Due to the vector product between the ionospheric plasma velocity and the magnetic field, we expect to observe evidence of the displacement of the magnetic fields in the components that are perpendicular to the ionospheric flow. Considering that the day-to-night ionospheric flow is mostly horizontal, we assume that $B_{r}$ is always perpendicular to the flow, while $B_{h}$ is only perpendicular for some latitudes and/or longitudes. Therefore, the advection of the magnetic field by the ionospheric plasma flow is more likely to be observed in the radial component of the magnetic field. 


\subsection{Preliminary analysis of data}

In this Section, we make a preliminary analysis of $\Delta \mathrm{B}$ and ionospheric flow velocity as a function of altitude and local time. We choose to use local time instead of SZA, in order to spot any asymmetries between dawn and dusk. We also analyze the ionospheric flow as a function of longitude and latitude. The plots are made using MAVEN data from 10 October 2014 to 14 November 2018, with a time resolution of $4 \mathrm{~s}$ and at the altitude range of $200-1000 \mathrm{~km}$.

Low energy $\mathrm{O}_{2}^{+}$velocity data from STATIC are used to calculate the horizontal speed of the ionospheric plasma flow. The horizontal speed $\left(v_{h}\right)$ is calculated as the sum of the azimuthal $\left(v_{\theta}\right)$ and the polar $\left(v_{\varphi}\right)$ components of the velocity data in spherical coordinates. The sign (positive or negative) is given by the sign of $v_{\theta}$. Positive values of $v_{h}$ represent eastward velocities, while negative values refer to westward velocities. The equation for the calculation of $v_{h}$ is given as

$$
v_{h}=\sqrt{v_{\theta}^{2}+v_{\varphi}^{2}}
$$

We decide to use $\mathrm{O}_{2}^{+}$ions for this work as it is one of the dominant species on Mars' ionosphere (see Section 1.5). Also, we do not consider the radial component of the velocity, but only the horizontal component, since we are interested only in the influence of the horizontal ionospheric flow over the magnetic fields.

Magnetic field data are used to calculate $\Delta \mathrm{B}$ values. Now, we are interested in the direction of the fluctuations and use $\Delta B$ instead of $|\Delta B|$. Figure 3.7 shows the plots of $\Delta \mathrm{B}$ and $\mathrm{O}_{2}^{+}$horizontal speed. In general, $\Delta \mathrm{B}$ values are very small in the resolution of $20 \mathrm{~km} \times 0.5 \mathrm{~h}$, ranging between $-3 \mathrm{nT}$ to $+3 \mathrm{nT}$. There is a higher variation on the fluctuations of the magnetic field at low altitudes, although the intensities of the fluctuations are similar to the intensities at high altitudes.

We observe two very distinct regions in the $\Delta \mathrm{B}$ plot from Figure 3.7: the region between 06:00-10:00 LT, with the highest negative values of $\Delta \mathrm{B}$, and the region between 15:00-20:00 LT, with the highest positive values of $\Delta \mathrm{B}$. These two regions can be roughly approximated to dawn and dusk sides. Also, we see these variations in the magnetic field earlier at higher altitudes than at lower altitudes. In summary, this plot shows that the observed magnetic field is weaker than expected at the dawn-side and stronger than expected at the dusk-side. 
Figure $3.7-\Delta \mathrm{B}$ and $\mathrm{O}_{2}^{+}$signed horizontal speed as a function of altitude and local time.
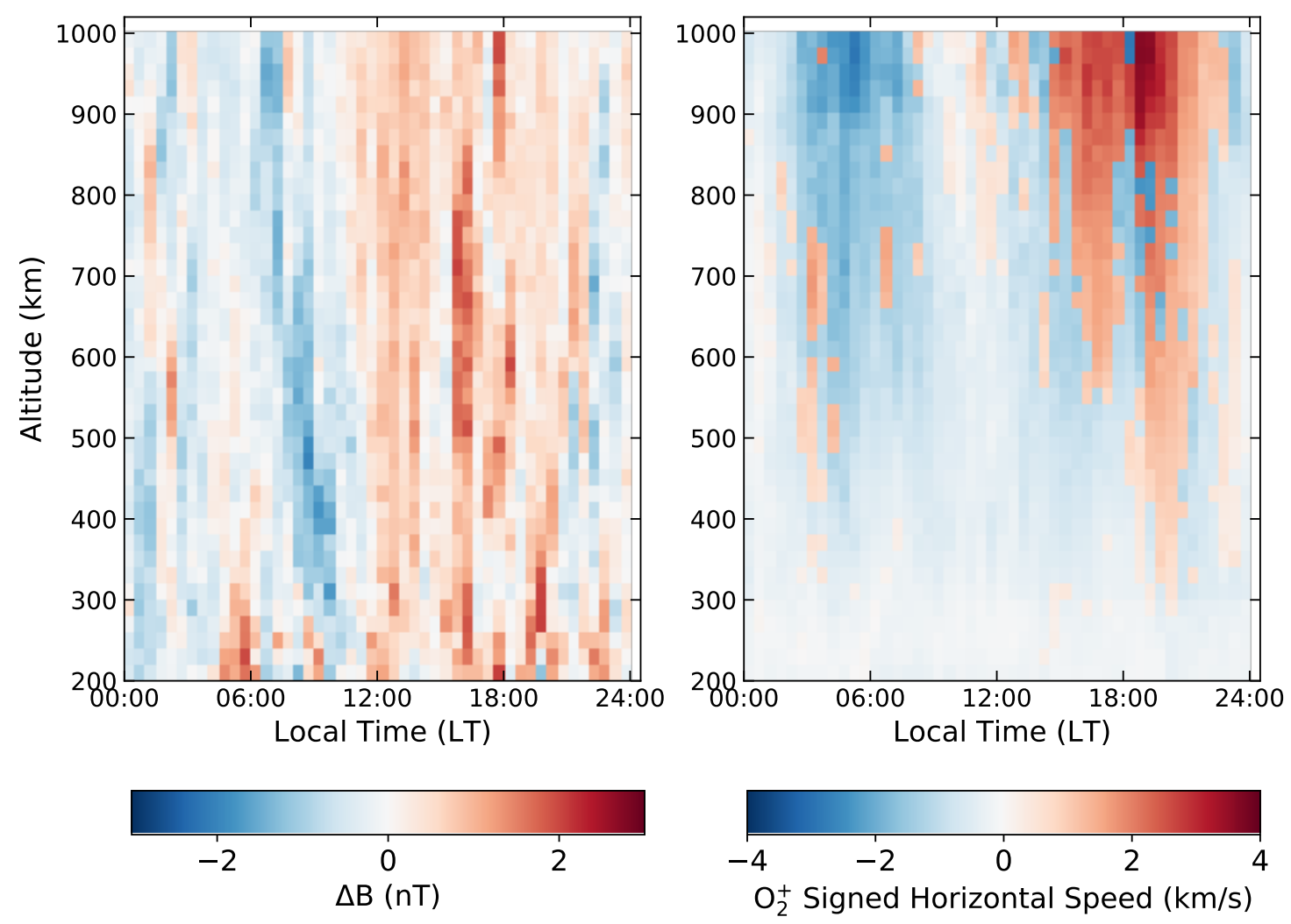

Difference between modeled and observed magnetic field (left) and $\mathrm{O}_{2}^{+}$signed horizontal speed (right).

SOURCE: Author's production.

From the $\mathrm{O}_{2}^{+}$horizontal speed plot, we see that the ionospheric speed increases with altitude. There are two periods of the day when the speed reaches its maximum values: between 02:00-09:00 LT, with high negative values (westward), and between 14:00-22:00 LT, with high positive values (eastward). This confirms the day-to-night flow of the ionospheric plasma.

In order to better understand the magnitude and direction of the flow over crustal magnetic field structures, we analyze the horizontal velocity of $\mathrm{O}_{2}^{+}$ions as a function of longitude and latitude. In order to do that, we select data at the altitude range of 200-400 km, for dawn and dusk sides. The calculated horizontal velocity vectors are averaged every $15^{\circ} \times 15^{\circ}$ and visually represented by arrows. The arrows are plotted over maps of the crustal magnetic field model, calculated at an altitude of $300 \mathrm{~km}$. 
The final plot is shown in Figure 3.8.

Figure 3.8 - Maps of modeled $B_{r}$, overplotted with arrows of $\mathrm{O}_{2}^{+}$horizontal velocity.

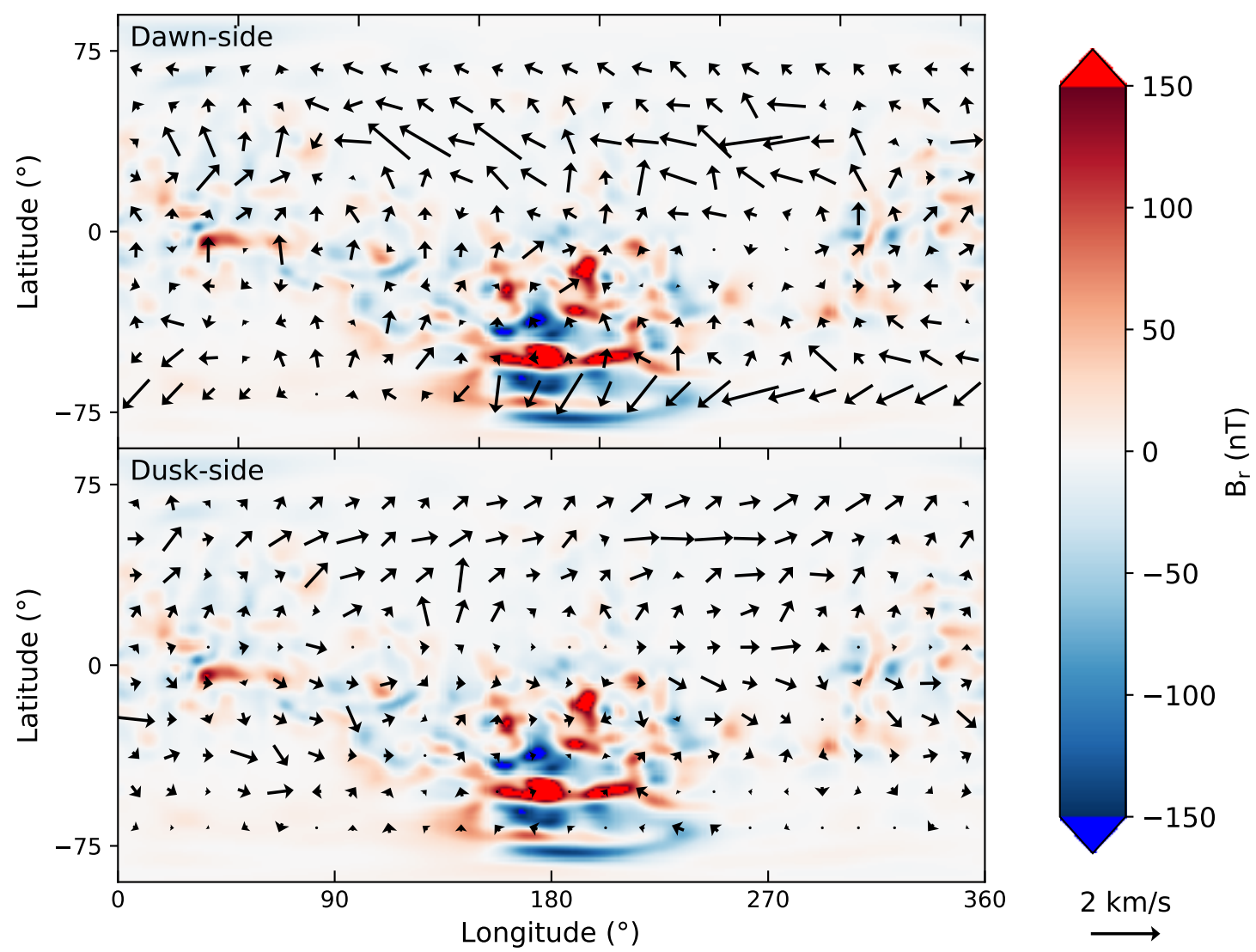

Radial component calculated from the crustal magnetic field model at $300 \mathrm{~km}$ altitude. The arrows show $\mathrm{O}_{2}^{+}$horizontal velocity data for altitudes between 200-400 km at dawnside (top) and at dusk-side (bottom). The bright blue and the bright red bins represent values which are below the minimum value and above the maximum value of the color scale, respectively. The longest arrows indicate a speed of $2 \mathrm{~km} / \mathrm{s}$.

SOURCE: Author's production.

Generally, the ionospheric plasma flow follows a day-to-night direction, in agreement to Figure 3.7. The flows are faster and ordenated above weak crustal magnetic fields, especially at the Northern hemisphere. Above regions of strong magnetic fields, the flows are slower and they seem to spin around the magnetic structures.

The flow directions are more disturbed at the dawn-side than at the dusk-side, which becomes very clear around the equatorial region. This means that there are 
asymmetries in the ionospheric behavior between dawn and dusk sides.

\subsection{Applied methods}

In this Section, the methods used for the study of the advection on Mars are described. As previously stated, the analyses concerning $\Delta \mathrm{B}$ are made using the Morschhauser model of the crustal magnetic field of Mars with the radial component.

To investigate whether the ionospheric plasma flux displaces the crustal magnetic fields of Mars, we look at the day-side of the planet, where the plasma density is higher. We select MAVEN data from 04:00 LT up to 20:00 LT, which roughly covers around $2 \mathrm{~h}$ before sun-rise ( 06:00 LT) and $2 \mathrm{~h}$ after sun-set $(\sim 18: 00 \mathrm{LT})$. We divide this data set into dawn-side (04:00-12:00 LT) and dusk-side (12:00-20:00 LT). This division is only a first approximation because we do not take into consideration the inclination of the rotation axis or the precession of the planet in order to define when MAVEN orbit crosses dawn and dusk over the four years of data.

As in Section 3.5, MAVEN data are selected for the altitude range between 200$1000 \mathrm{~km}$, as the latter is the altitude up to which the crustal magnetic fields have an influence on Mars. Therefore, this is the region where we expect to observe advection.

MGS data set is divided into a day-side set $(\sim 14: 00$ LT) and a night-side set $(\sim 02: 00$ LT), as these are the only two periods covered by the spacecraft during MPO. These data were gathered at altitudes of $\sim 400 \mathrm{~km}$.

\subsubsection{Shifting technique}

The first method used to investigate the problem is the "shifting technique". We develop this method as a direct and simple comparison between two magnetic field maps after a longitudinal shift is applied to one of them. The aim is to investigate whether the crustal magnetic fields show evident displacements along the direction of the ionospheric flow when analyzed over a long period of time. If these displacements can be observed, this would mean that the magnetic fields are being advected by the ionospheric flow, due to the reasonable conductivity of the ionospheric plasma.

First, we analyze MAVEN data, which are gridded in maps of latitude $\times$ longitude with bin sizes of $0.5^{\circ}$. We decide to decrease the bin size, in comparison to the analyses in Subsection 3.5, because we expect the advection to displace the crustal magnetic fields for very small distances from their sources. 
We plot $B_{r}$ for the dawn-side and the dusk-side magnetic field data. For a first estimate of the asymmetries among the dawn-side map and the dusk-side map, we subtract the bins of the dusk-side map from the bins of the dawn-side map, disregarding the bins that belong only to one of the data sets. Each data set is analyzed for four altitude ranges, every $200 \mathrm{~km}(200-400 \mathrm{~km}, 400-600 \mathrm{~km}, 600-800$ $\mathrm{km}$, and 800-1000 km).

Each bin in the dawn-side and in the dusk-side maps contains between 3-10 data points. The induced magnetic field has an arbitrary horizontal orientation, such that it cancels out when there is a sufficient number of data points per bin. Because the number of data points per bin is small for MAVEN data, the external field contributions are not completely averaged out. However, we consider that these contributions do not affect the movement of the magnetic fields, but only its magnitude. For this reason, we disregard further effects caused by the induced magnetic field for this analysis.

We now investigate whether there is a displacement between the observations (dawnside and dusk-side data sets) and the magnetic field model on a global scale. We produce maps of the radial component of the magnetic field model for the same altitude ranges of the dawn-side and dusk-side data sets. Then, we overlap the maps of the magnetic field model and the observed magnetic field and subtract the magnitude of the latter map from the former one, disregarding the bins that belong only to one of the maps.

We calculate an arbitrary parameter that consists of the sum of all the abolute residuals from the subtraction of the two maps. This new parameter is defined as

$$
\Delta \mathrm{B}_{\text {MAVEN }}^{\prime}=\frac{1}{j} \sum_{i=1}^{j}\left|B_{r_{i}}^{M}-B_{r_{i}}^{O}\right|
$$

where $j$ is the number of bins that belong to both maps and $B_{r}^{M}$ and $B_{r}^{O}$ are the radial components of the model and of the observed magnetic field, respectively.

Then, we shift the crustal magnetic field map in the longitudinal direction by $0.5^{\circ}$ and subtract the map of the observed magnetic field from it, calculating a new $\Delta \mathrm{B}_{\text {MAVEN }}$. The shift is made longitudinally because this is the direction we expect to see the movement of the magnetic fields.

This process is repeated for every $0.5^{\circ}$ between $-5.0^{\circ}$ (westward) and $+5.0^{\circ}$ (east- 
ward). The maps of the observed magnetic field are not shifted at any point, which means that we always compare a fixed map to a shifted map.

This shifting technique is applied for dawn-side and dusk-side maps, for the four altitude ranges. In total, there are eight shifted sets, each with 21 values of $\Delta \mathrm{B}^{\prime}{ }_{\text {MAVEN }}$.

We assume $\Delta \mathrm{B}^{\prime}$ MAVEN is composed of the sum of the induced day-side magnetic field and the possible displacement of the crustal magnetic fields. If advection occurs, a minimum value of $\Delta \mathrm{B}^{\prime}$ MAVEN is expected at some shift value different than zero. For example, if the minimum value of $\Delta \mathrm{B}^{\prime}$ MAVEN is observed at a shift of $+1.0^{\circ}$, this means that the observed magnetic field fits the crustal magnetic field model best if they are offset by $+1.0^{\circ}$. This implies that the observed magnetic field is $1.0^{\circ}$ farther to the east than where the magnetic field model predicts it would be.

In other words, if a minimum value of $\Delta \mathrm{B}^{\prime}$ MAVEN is observed at some shift value different than zero, this would indicate that the crustal magnetic fields are being advected. The offset corresponding to the minimum $\Delta \mathrm{B}^{\prime}$ MAVEN should be coherent with the expected direction of the dragging of the magnetic field, i.e., westward for the dawn-side analysis and eastward for the dusk-side analysis, according to Figure 2.2 .

It is important to clarify that the $\Delta \mathrm{B}^{\prime}$ MAVEN values are only qualitative results, even though they are represented by numbers. We are not interested in the values themselves, but only in their relative magnitudes. The $\Delta \mathrm{B}^{\prime}{ }_{\text {MAVEN }}$ parameter (Equation 3.2 ) is defined analogously to the first moment in mathematical statistics (HOEL, 1984). The first statistical moment, also known as the arithmetic mean of a set of numbers $(\bar{x})$, is the sum of all of the numbers $\left(x_{i}\right)$ divided by the amount of numbers (y). It is defined as

$$
\bar{x}=\frac{1}{y} \sum_{i=1}^{y} x_{i}
$$

In the case of $\Delta \mathrm{B}_{\text {MAVEN }}$, we take $x_{i}$ as the difference between the radial components of the model and of the observed magnetic field at the point $i$.

After a global scale analysis, we decide to use the shifting technique to investigate smaller regions of the planet, individually. Seven anomalous regions are selected, in different positions of the map and with different shapes and intensities of the magnetic field. The seven anomalies have in common a dipolar configuration, i.e., 
they present both inward $\left(B_{r}<0\right)$ and outward $\left(B_{r}>0\right)$ magnetic fields. These anomalies are named A1 to A7 and their locations are shown in Figure 3.9, in a global map of the modeled magnetic field at $300 \mathrm{~km}$ altitude.

Figure 3.9 - Map of the location of the seven selected anomalies.

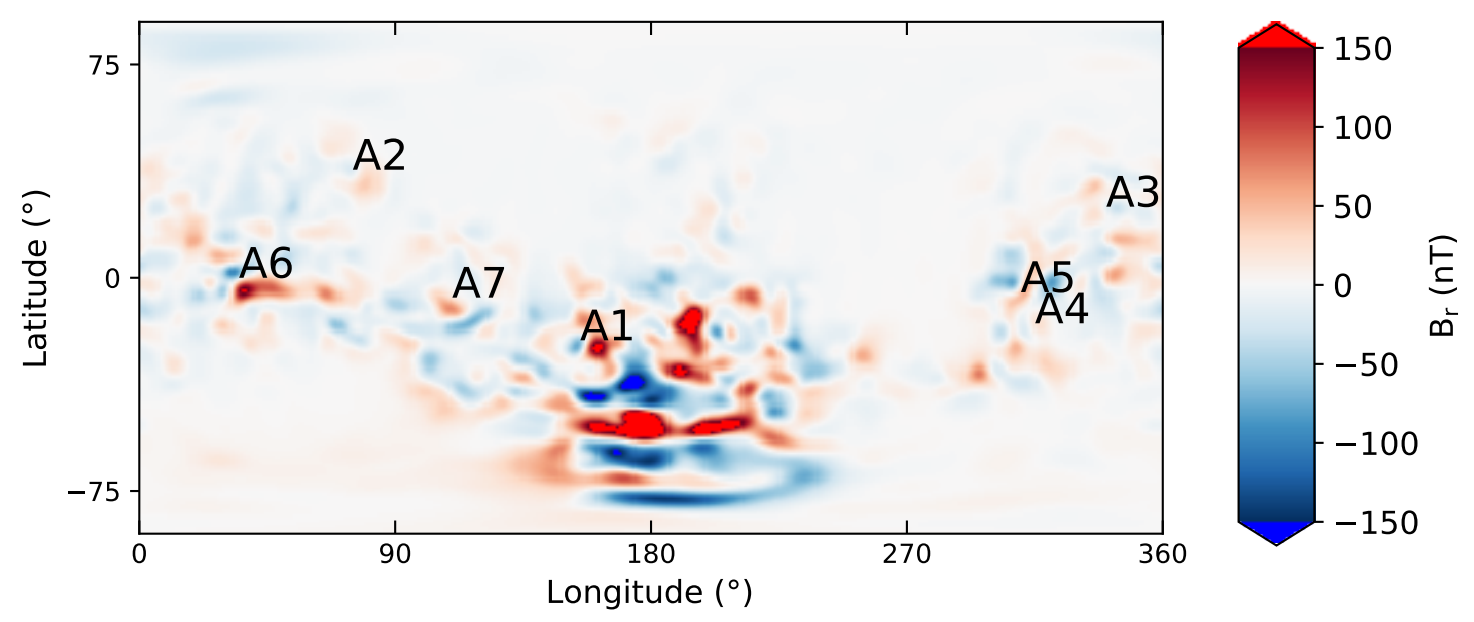

Map of modeled $B_{r}$ at $300 \mathrm{~km}$ altitude, with the location of A1, A2, A3, A4, A5, A6, and A7 anomalies.

SOURCE: Author's production.

The general characteristics of each magnetic anomaly are summarized as follows:

A1 - Low latitude region, medium size, strong magnetic field, and surrounded by the main magnetized portion of the crust.

A2 - Middle latitude region, medium size, moderate magnetic field, and isolated.

A3 - Middle latitude region, medium size, moderate magnetic field, and isolated.

A4 - Low latitude region, small size, moderate magnetic field, and near other magnetized regions.

A5 - Low latitude region, large size, moderate magnetic field, and near other magnetized regions.

A6 - Low latitude region, large size, strong magnetic field, and near other magnetized regions. 
A7 - Low latitude region, medium size, strong magnetic field, and next to the main magnetized portion of the crust.

Due to its yet sparse coverage, MAVEN data cannot reproduce the anomalous regions when they are plotted with bin sizes of $0.5^{\circ}$ or smaller, in local-scale maps. For this reason, we choose to use MGS magnetic field data for the analysis of these regions, because a higher spatial resolution can be achieved.

The crustal magnetic field model made by Morschhauser et al. (2014) was built based on MGS data, as explained in Subsection 3.2. The model does not take into consideration the advection of the magnetic fields on Mars. Therefore, it is likely that the model contains the effects of the advection on MGS data, which would affect its comparison with the day-side magnetic field data from MGS. To overcome possible bias by the crustal magnetic field model, we decide to apply the shifting technique comparing MGS day-side data to MGS night-side data.

We produce maps with a time resolution of $4 \mathrm{~s}$ and bin sizes of $0.1^{\circ}$ of longitude and $1.0^{\circ}$ of latitude. We choose a larger bin size in terms of latitude because the shift is made only longitudinally, which means we are not concerned with latitudinal changes. The data present a strong orbital bias, so a latitudinal smoothing was performed for every 10 bins. The grids contain between 20-80 data points, which means that the external field contributions are averaged out in this analysis.

The method of overlapping and subtracting the maps is applied for MGS data. Now, the shift is made in steps of $0.1^{\circ}$, between $-2.0^{\circ}$ and $+2.0^{\circ}$. For every shift, we calculate a new parameter $\Delta \mathrm{B}_{\text {MGS }}$, analogous to $\Delta \mathrm{B}_{\text {MAVEN }}$, as

$$
\Delta \mathrm{B}^{\prime}{ }_{\mathrm{MGS}}=\frac{1}{j} \sum_{i=1}^{j}\left|B_{r i}^{N}-B_{r_{i}}^{D}\right|
$$

where $B_{r}^{N}$ and $B_{r}^{D}$ are the radial components of the night-side and of the day-side magnetic field, respectively.

Besides the anomalous regions, we also apply the method for a global map of MGS magnetic field data. In the end, there are eight shifted sets, each with 41 values of $\Delta \mathrm{B}_{\text {MGS }}$.

For both MAVEN and MGS analyses, we fit a Gaussian function to each shifted set. Based on the best fit, we present the results of the shift value where $\Delta \mathrm{B}^{\prime}$ is minimum, 
for each set. The error in the results is calculated as the standard deviation of the best fit.

\subsubsection{Pressure analysis}

In general, the advection of magnetic fields in a moving plasma is a complicated problem, because it is influenced by the conductivity of the plasma (WILMOT-SMITH et al., 2005; LUI, 2018). In Mars' ionosphere, the conductivity of the plasma cannot be directly measured, and its derivation is not straightforward. Besides that, the conductivity changes significantly with altitude and there are still not enough studies that calculate this parameter for Mars' ionosphere. For these reasons, the continuity equation (Equation 2.13) cannot be solved, and the advection of the crustal magnetic fields cannot be directly quantified.

To get a general idea of the relative forces between the moving ionospheric plasma and the crustal magnetic fields, we decide to analyze the pressures involved in the advection process, using MAVEN data. The crustal magnetic fields generate a magnetic pressure. On the other side, the ionospheric flow opposes the magnetic field structures with a dynamic pressure. If the dynamic pressure exceeds the magnetic pressure in one spot, this means that at that spot, the ionospheric plasma flow is strong enough to cause displacement of the magnetic fields by advecting them.

The aim of the pressure analysis is to investigate whether there are regions on Mars where the dynamic pressure is generally larger than the magnetic pressure. In order to do that, we analyze data as a function of local time and altitude. MAVEN data are selected for local times between 04:00-20:30 LT and for altitudes between 200-1020 $\mathrm{km}$.

We estimate the dynamic pressure (Equation 2.17) based on data of low energy $\mathrm{O}_{2}^{+}$ ions since this is one of the dominant species at Mars' ionosphere. We use density and horizontal speed data, as well as an atomic weight of 32 Da. The magnetic pressure (Equation 2.19) is calculated with the total magnitude of the crustal magnetic field model, as our aim is to investigate the pressure due to the crustal magnetic fields solely.

We also investigate the magnitude of the local thermal pressure, in order to validate our analyses. If the thermal pressure is much larger than the dynamic pressure, it can disturb the ionospheric flow (e.g., turbulence) and, therefore, prevent the advection of the magnetic fields. For the thermal pressure (Equation 2.18), we consider density 
and temperature data of both electrons and low energy $\mathrm{O}_{2}^{+}$ions.

The data are sorted according to the local crustal magnetic field intensity, in order to analyze different scenarios. At $400 \mathrm{~km}$ altitude, we define "low intensity crustal magnetic field" when the magnitude of the $B_{r}$ is below $10 \mathrm{nT}$, and "high intensity crustal magnetic field" when this value is above $10 \mathrm{nT}$.

We create local time $\times$ altitude grids for the data, with bin sizes of $0.5 \mathrm{~h}$ and $20 \mathrm{~km}$, respectively. Figures 3.10, 3.11, and 3.12 show the data plots as a function of local time and altitude, for weak magnetic fields on the left panels and strong magnetic fields on the right panels.

Figure 3.10 shows the temperatures of $\mathrm{O}_{2}^{+}$ions on the top and of electrons on the bottom. $\mathrm{O}_{2}^{+}$ions have a more accentuated vertical gradient of temperature than electrons, in general. At low altitudes, the ions present lower temperatures than the electrons. At medium and high altitudes, the temperatures increase more for the ions. Between $640-940 \mathrm{~km}$, at $\sim 12: 00 \mathrm{LT}, \mathrm{O}_{2}^{+}$ions above low crustal magnetic fields present very low temperatures, which could be related to the magnetic field intensity. The temperatures decrease around dawn and dusk, creating a shape of "U" in all of the four plots. 
Figure 3.10 - Temperature as a function of local time and altitude.
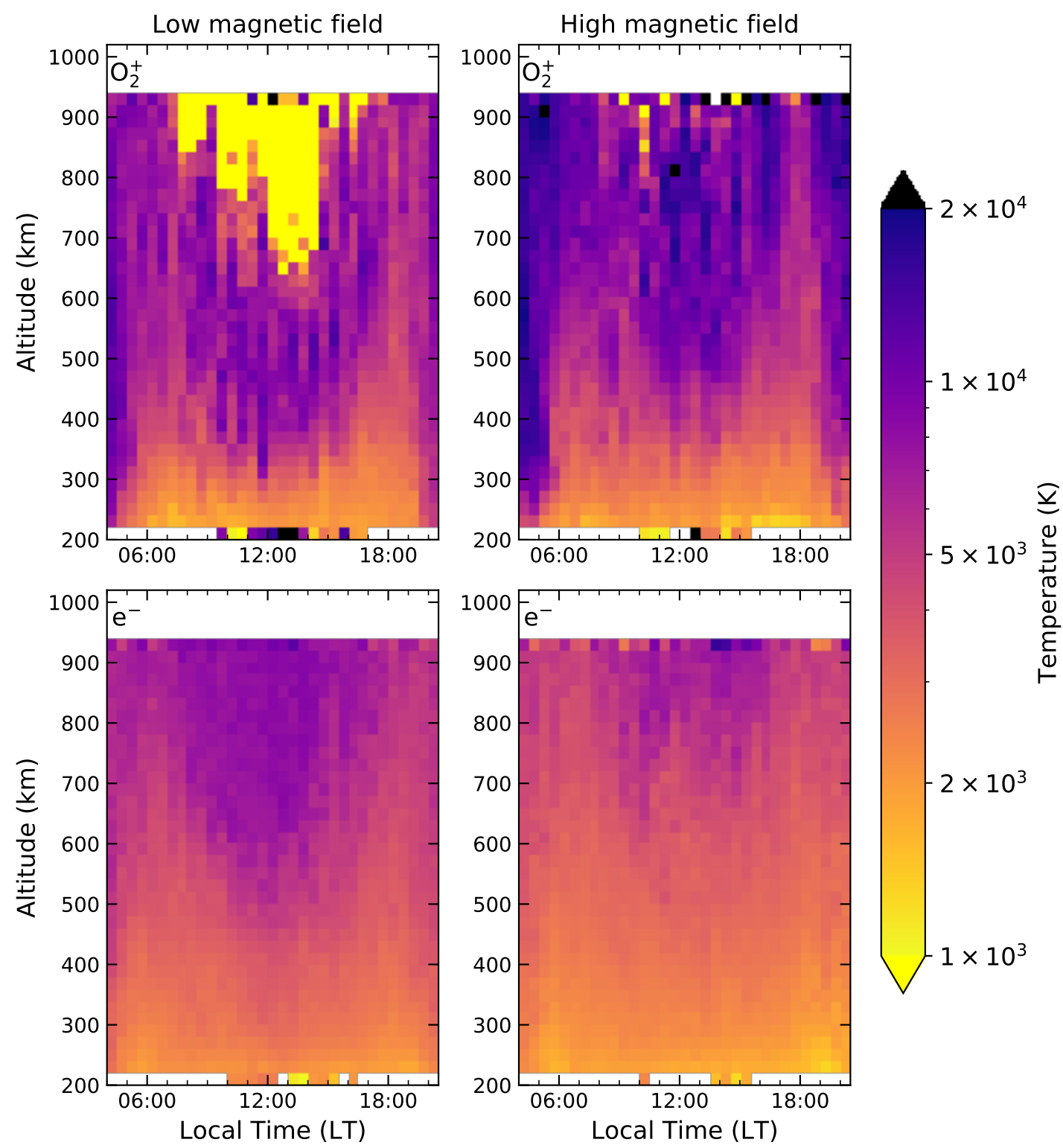

$\mathrm{O}_{2}^{+}$temperatures above low (top left) and high (top right) crustal magnetic field regions. Electron temperatures above low (bottom left) and high (bottom right) crustal magnetic field regions.

SOURCE: Author's production. 
Figure 3.11 shows the density plots, similarly to Figure 3.10. Again, the vertical gradient is more accentuated for $\mathrm{O}_{2}^{+}$than for electrons. However, unlike the temperature case, the density of the particles decreases with altitude. The densities above regions of intense magnetic fields are higher than above regions of weak magnetic fields. Around the terminator regions, the densities are higher than at around noon, and the plots also display the "U" shape.

Figure 3.12 presents the horizontal speed of $\mathrm{O}_{2}^{+}$ions on the top panels and the magnitude of the crustal magnetic fields on the bottom panels. The horizontal speed of $\mathrm{O}_{2}^{+}$ions increases with altitude and higher values are achieved above regions of weak magnetic fields. At dawn and dusk sides, the speed decreases, creating the "U" shape on the plot. The magnitudes of the magnetic fields are mostly uniform in local time, which is expected as only the crustal magnetic field model was considered. The small discrepancies are due to the different locations of the spacecraft since the model magnetic field was calculated in the spacecraft position.

Every parameter plot of $\mathrm{O}_{2}^{+}$ions and electrons presented in Figures 3.10, 3.11, and 3.12 show the characteristic " $U$ " shape. This means that the regions of dawn and dusk present very distinct features when compared to the noon region. 
Figure 3.11 - Density as a function of local time and altitude.
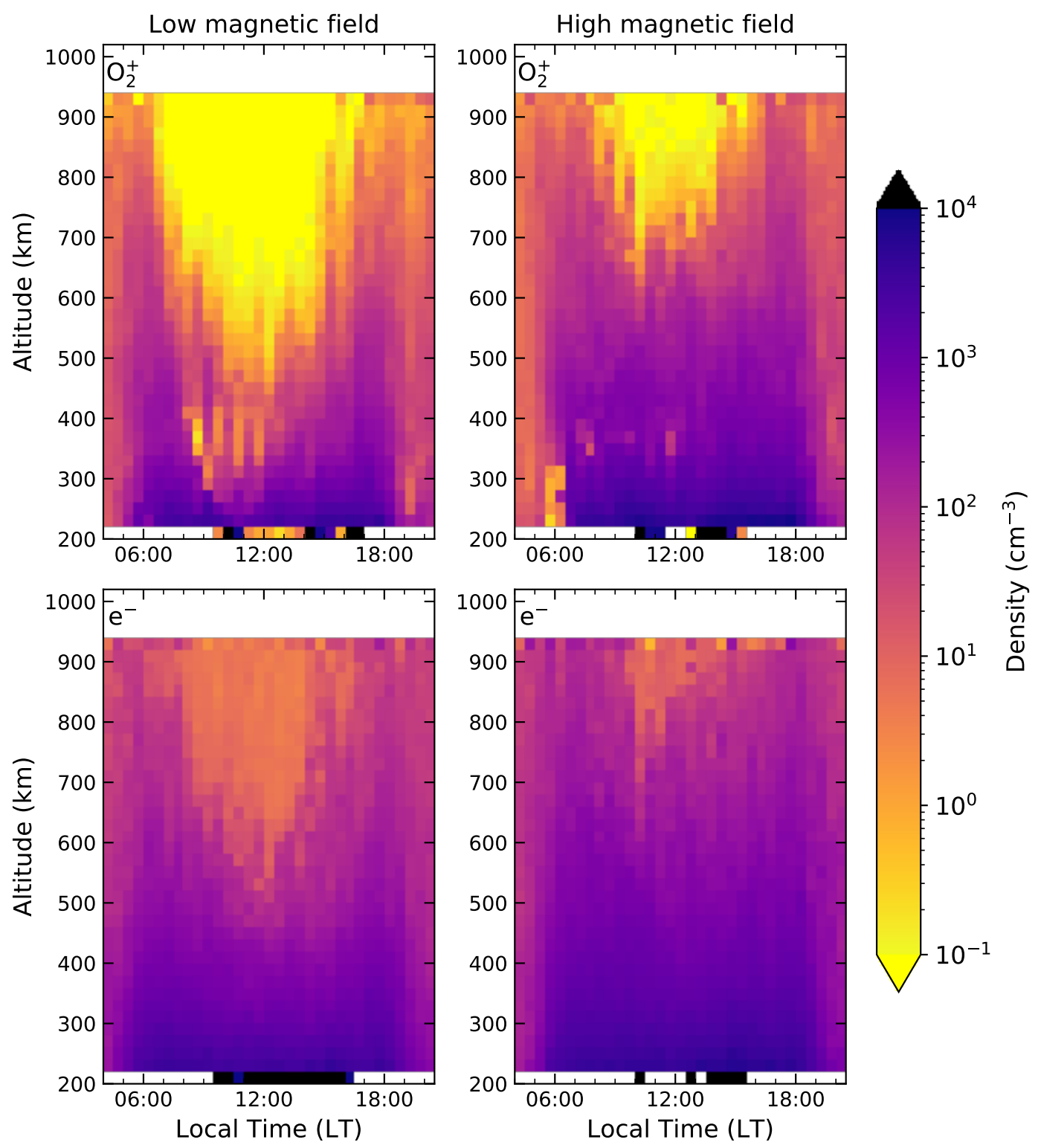

$\mathrm{O}_{2}^{+}$densities above low (top left) and high (top right) crustal magnetic field regions. Electron densities above low (bottom left) and high (bottom right) crustal magnetic field regions.

SOURCE: Author's production. 
Figure 3.12 - Horizontal speed and magnetic field intensity as a function of local time and altitude.
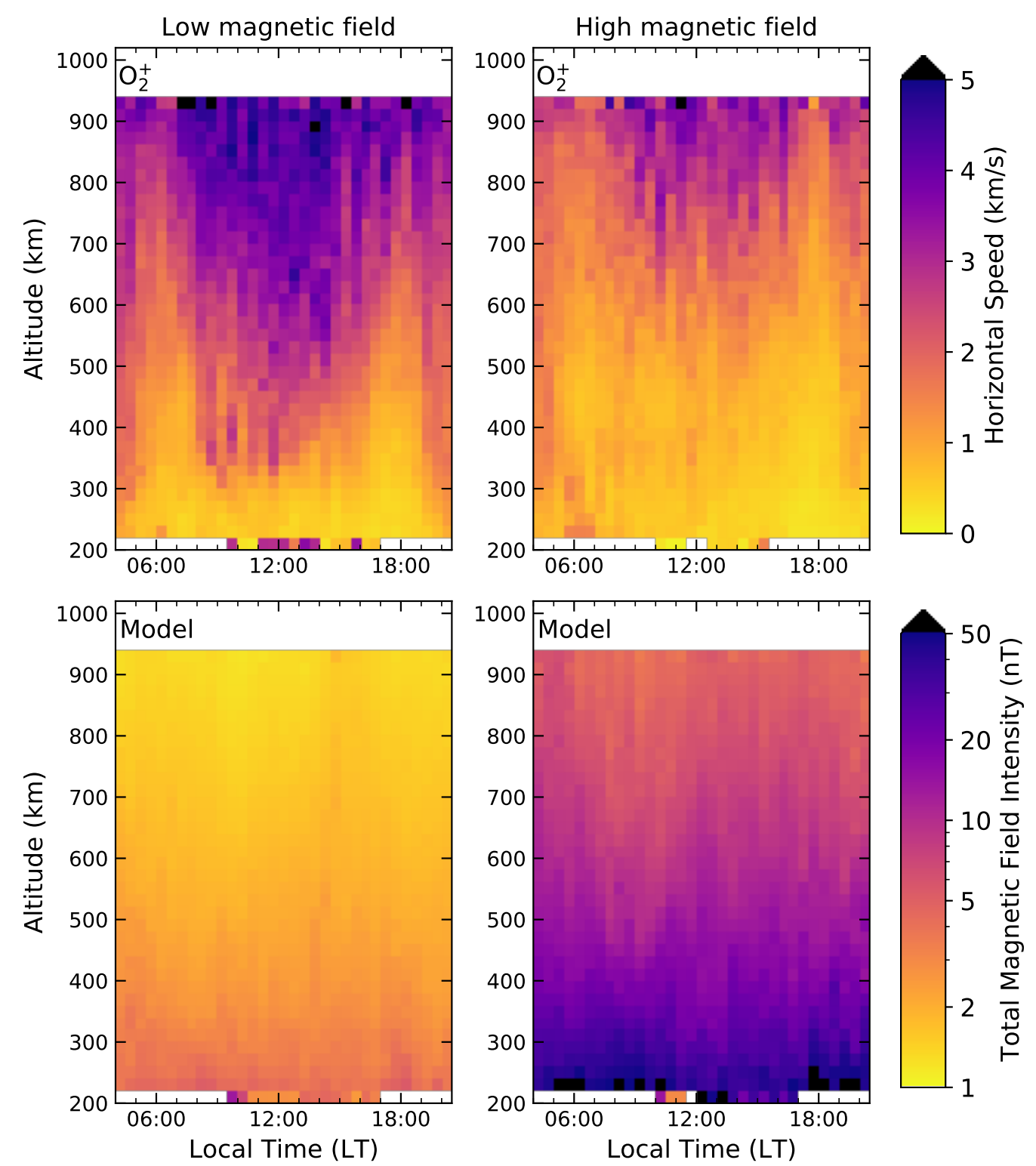

$\mathrm{O}_{2}^{+}$horizontal speed above low (top left) and high (top right) crustal magnetic field regions. Total intensity of the modeled crustal magnetic field above low (bottom left) and high (bottom right) crustal magnetic field regions.

SOURCE: Author's production. 
Figures 3.13 and 3.14 display the number of samples per bin for each parameter plot presented in this subsection. MAVEN data coverage as a function of local time and altitude is large and there are no significant discrepancies among the sampling of $\mathrm{O}_{2}^{+}$ions or electrons.

Figure 3.13 - Number of samples per bin as a function of local time and altitude for electron parameters.
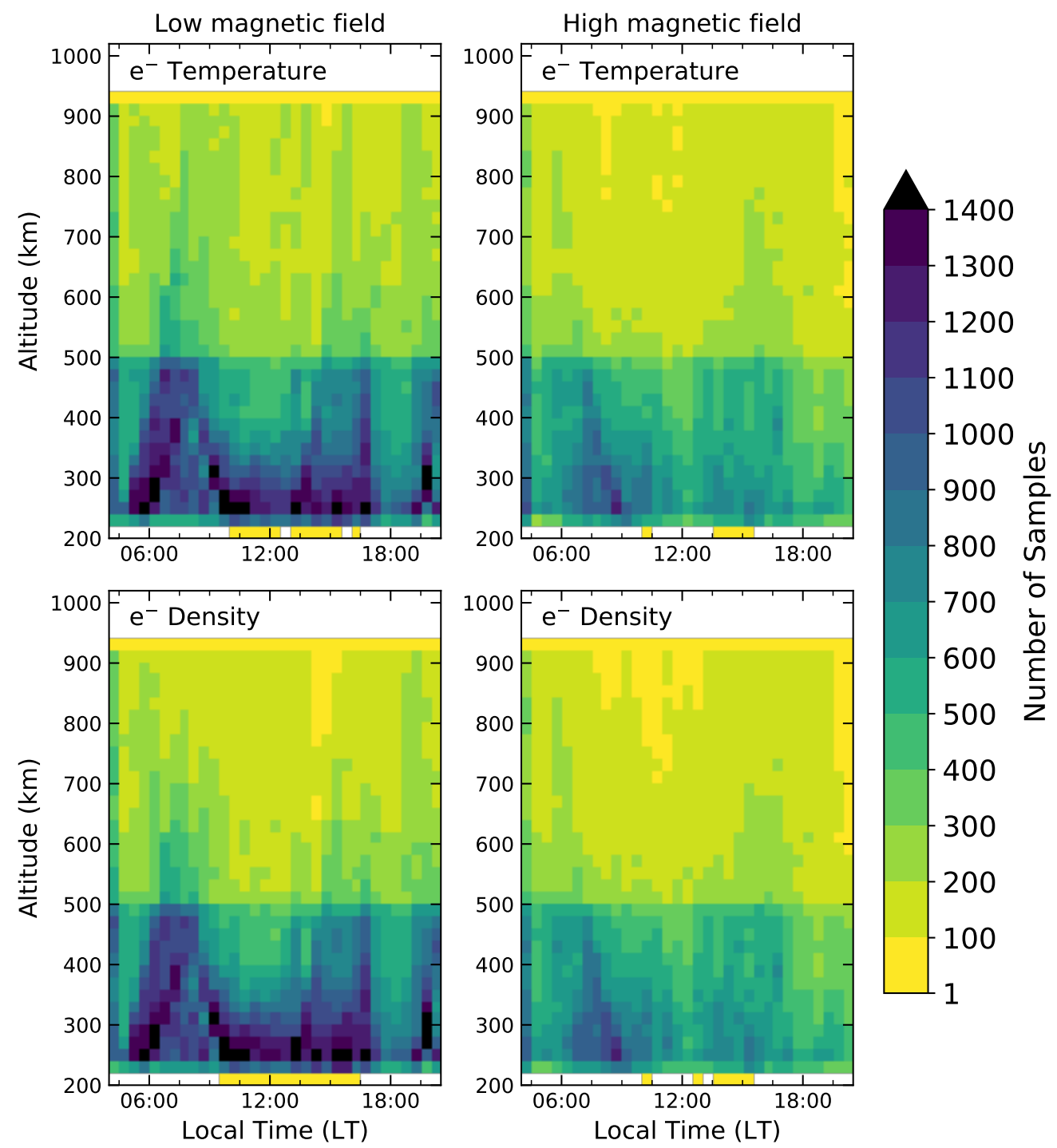

Left panel, from top to bottom: number of samples per bin of electron temperature and density, at low crustal magnetic field regions. Right panel, from top to bottom: number of samples per bin of electron temperature and density, at high crustal magnetic field regions.

SOURCE: Author's production. 
Figure 3.14 - Number of samples per bin as a function of local time and altitude for $\mathrm{O}_{2}^{+}$ parameters.
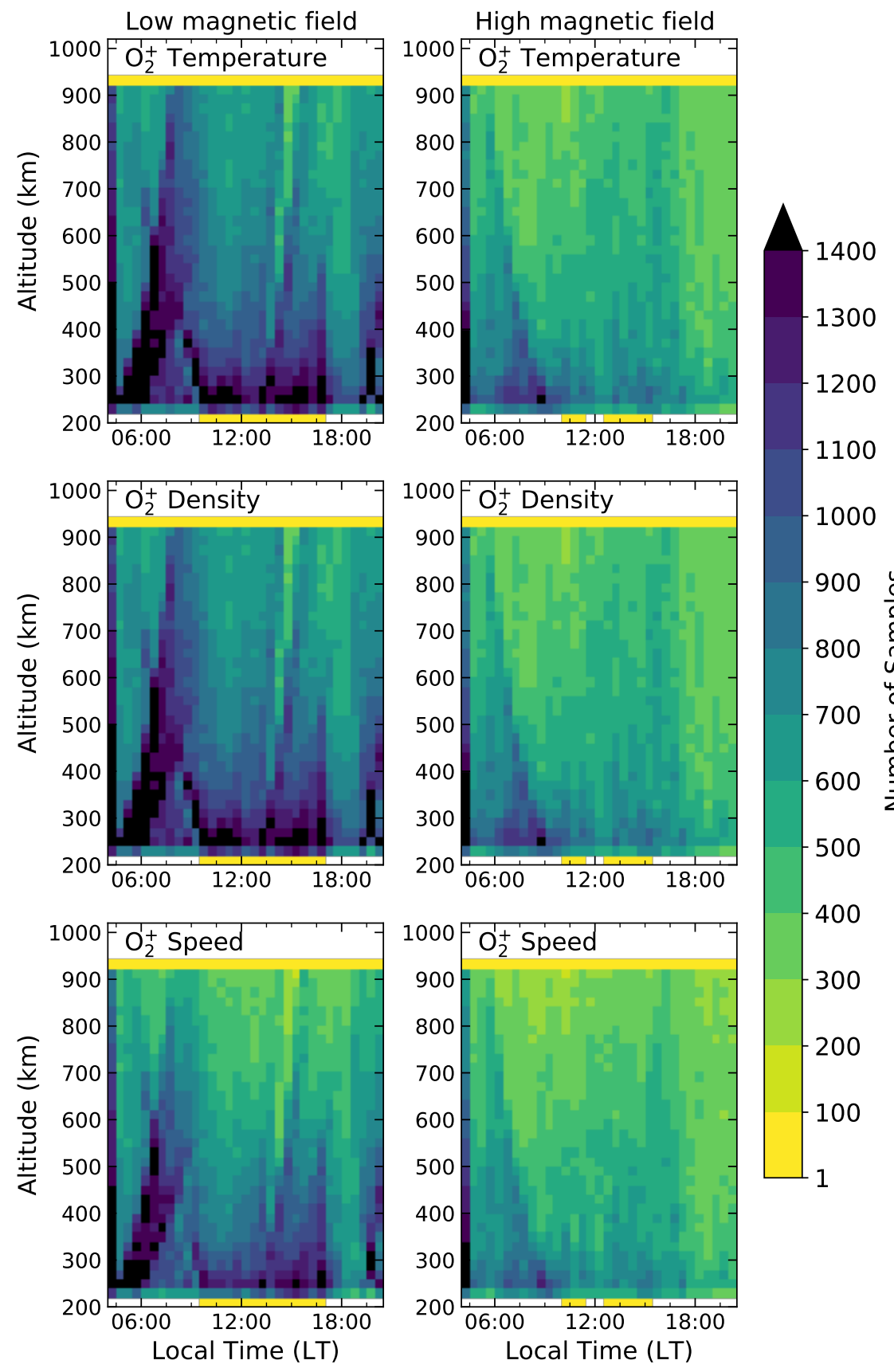

Left panel, from top to bottom: number of samples per bin of $\mathrm{O}_{2}^{+}$temperature, density and horizontal speed, at low crustal magnetic field regions. Right panel, from top to bottom: number of samples per bin of $\mathrm{O}_{2}^{+}$temperature, density and horizontal speed, at high crustal magnetic field regions.

SOURCE: Author's production. 
Regarding the comparison among $\mathrm{O}_{2}^{+}$and electron data, we infer that STATIC performance is more stable than LPW performance. STATIC is a shielded instrument, while LPW is not. Above $500 \mathrm{~km}$, LPW shows a clear reduction of sampling, which could be related to external factors, like solar incidence. Although the sampling is reduced, there are still enough samples per bin for the statistical analyses.

For both species, the number of samples per bin between 200-220 km and between 920-940 km is not sufficiently high and should not be taken into account for the analyses. Between 940-1000 km, the spacecraft does not gather data for the local time range of 04:00-20:00 LT.

At last, the data are used to calculate the pressures, which are also presented as a function of local time and altitude, for both ranges of crustal magnetic field intensity. In order to investigate the relative importance of the ionospheric flow on the crustal magnetic field structures, we calculate the ratio between the dynamic and the magnetic pressures. To investigate how large is the thermal pressure when compared to the dynamic pressure, we also calculate the ratio between these two. 


\section{RESULTS AND DISCUSSION}

In this Chapter, we present and explain the results of the shifting technique and of the pressure analysis, described in Section 3.6. We discuss how the results are related to the advection of the magnetic field.

With the shifting technique, we compare the magnetic fields from the data and from the crustal magnetic field model built by Morschhauser et al. (2014). In this analysis, we use the radial component of the magnetic field, because this component is the least affected by external sources.

Figures 4.1 to 4.5 and Table 4.1 show results from the shifting technique applied to MAVEN data, described in Subsection 3.6.1. Figures 4.1, 4.2, 4.3, and 4.4 show maps of $B_{r}$ at dawn and dusk sides, and the difference between the first two, at each corresponding bin.

Figure 4.1 shows the maps for the altitude range of 200-400 km. Because the MAVEN spacecraft has a dense spatial coverage at this altitude range, distinctions between the dawn-side and the dusk-side maps can be seen by the human eye. There are large differences between the two time periods of the day, especially above regions of high crustal magnetic fields. These differences can have intensities of around half the value of the local magnetic field.

Figure 4.2 shows the maps for the altitude range of 400-600 km. For this altitude range and upwards, we observe that MAVEN coverage is not uniform and there are regions where the coverage is clearly poor. At dawn-side, these gaps occur more often at around $-30^{\circ}$ of latitude. At dusk-side, the less covered regions are located at around $+15^{\circ}$ and $-50^{\circ}$ of latitude. Unfortunately, two of those areas are located above high crustal magnetic fields in the Southern hemisphere. This means that the analyses regarding these important regions between $400-1000 \mathrm{~km}$ are affected by the low data coverage of MAVEN.

In Figure 4.2, we also see higher differences in the magnetic field between dawn-side and dusk-side above regions of high crustal magnetic fields. However, in Figures 4.3 and 4.4, which show the maps for the altitude ranges of 600-800 km and 800-1000 $\mathrm{km}$, respectively, this visualization is not possible anymore. In these last Figures, the spatial coverage is so irregular that only a few bins share the same location in dawn-side and dusk-side regions. 
Figure 4.1 - Maps of $B_{r}$ at the altitude range of $200-400 \mathrm{~km}$.

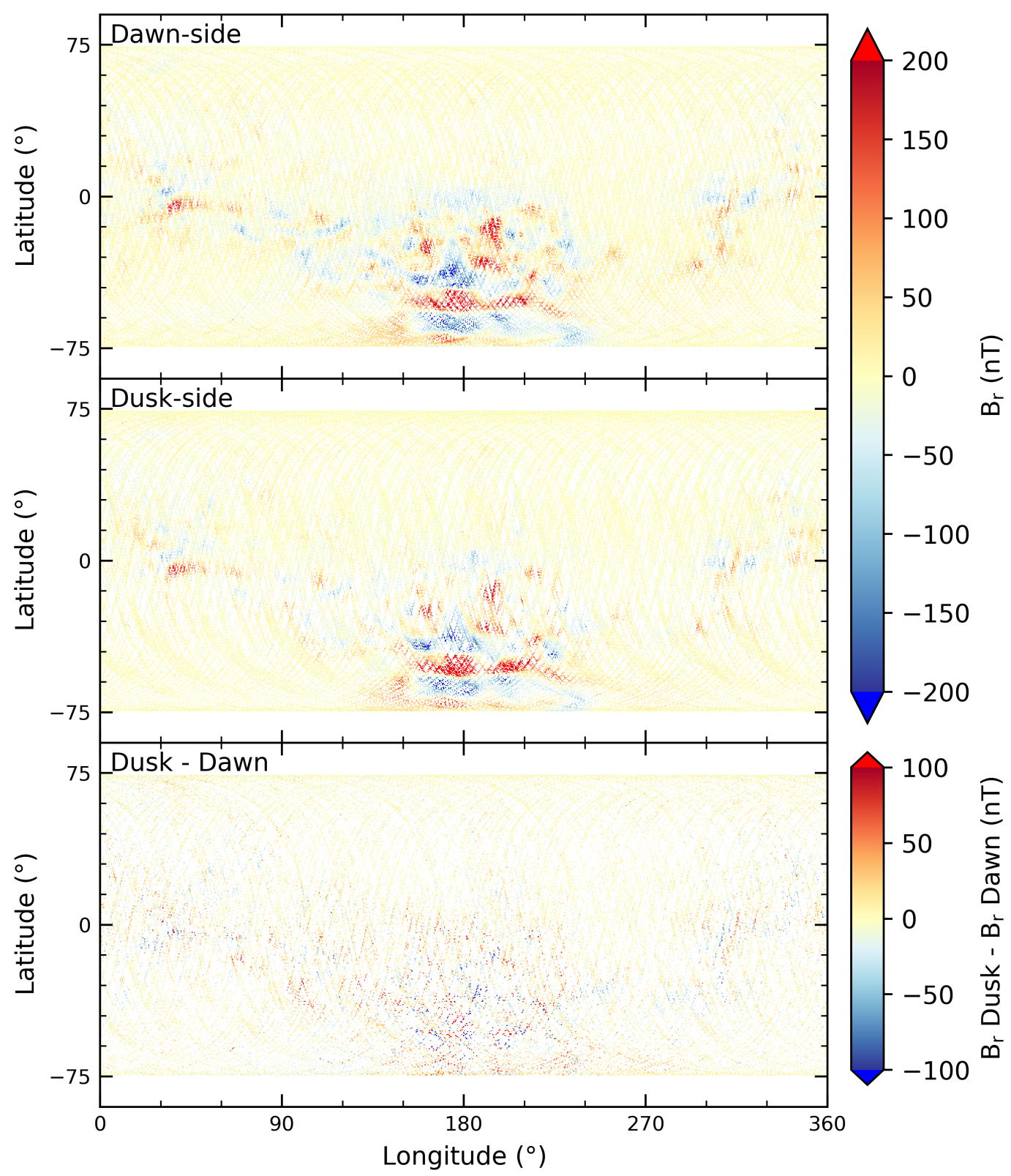

Radial component of MAVEN magnetic field data at 200-400 km altitude for the dawnside region (top) and the dusk-side region (middle), and the difference between dusk-side and dawn-side magnetic field data (bottom). We choose a color scale with yellow tones around zero, in order to point out the locations where there are no data sampling, i.e., the white gaps.

SOURCE: Author's production. 
Figure 4.2 - Maps of $B_{r}$ at the altitude range of 400-600 km.

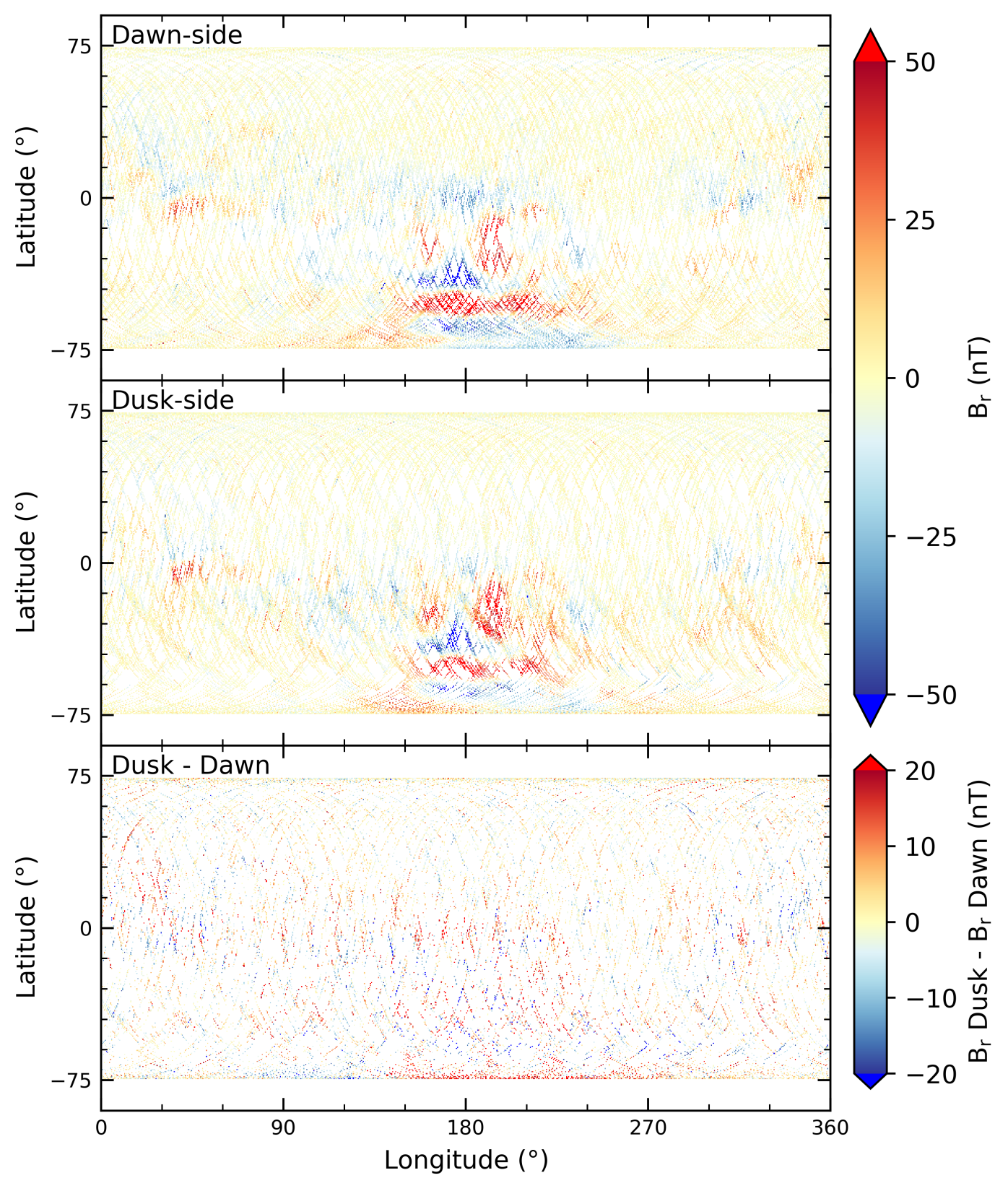

Radial component of MAVEN magnetic field data at 400-600 km altitude for the dawnside region (top) and the dusk-side region (middle), and the difference between dusk-side and dawn-side magnetic field data (bottom).

SOURCE: Author's production. 
Figure 4.3 - Maps of $B_{r}$ at the altitude range of $600-800 \mathrm{~km}$.

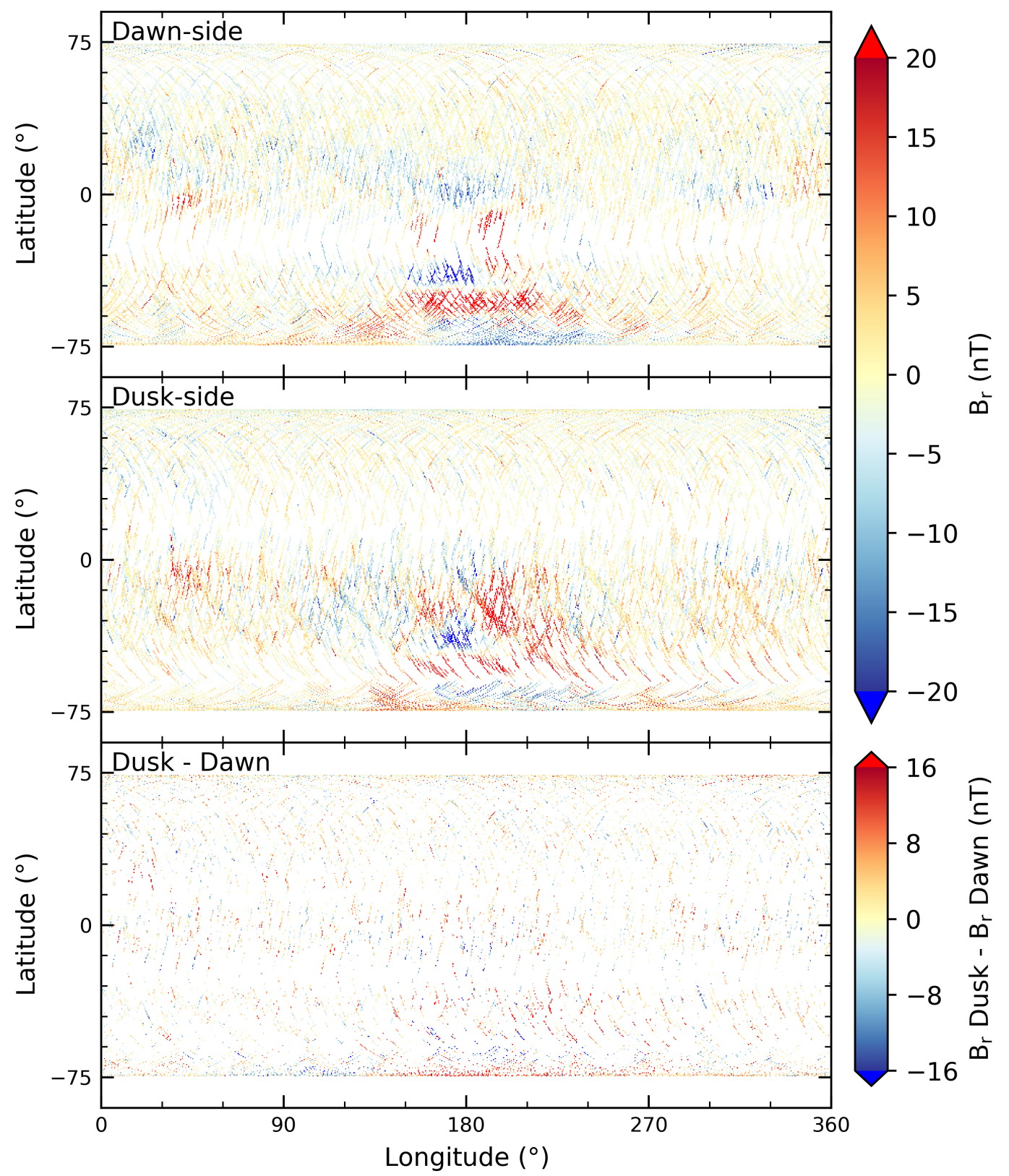

Radial component of MAVEN magnetic field data at $600-800 \mathrm{~km}$ altitude for the dawnside region (top) and the dusk-side region (middle), and the difference between dusk-side and dawn-side magnetic field data (bottom).

SOURCE: Author's production. 
Figure 4.4 - Maps of $B_{r}$ at the altitude range of $800-1000 \mathrm{~km}$.

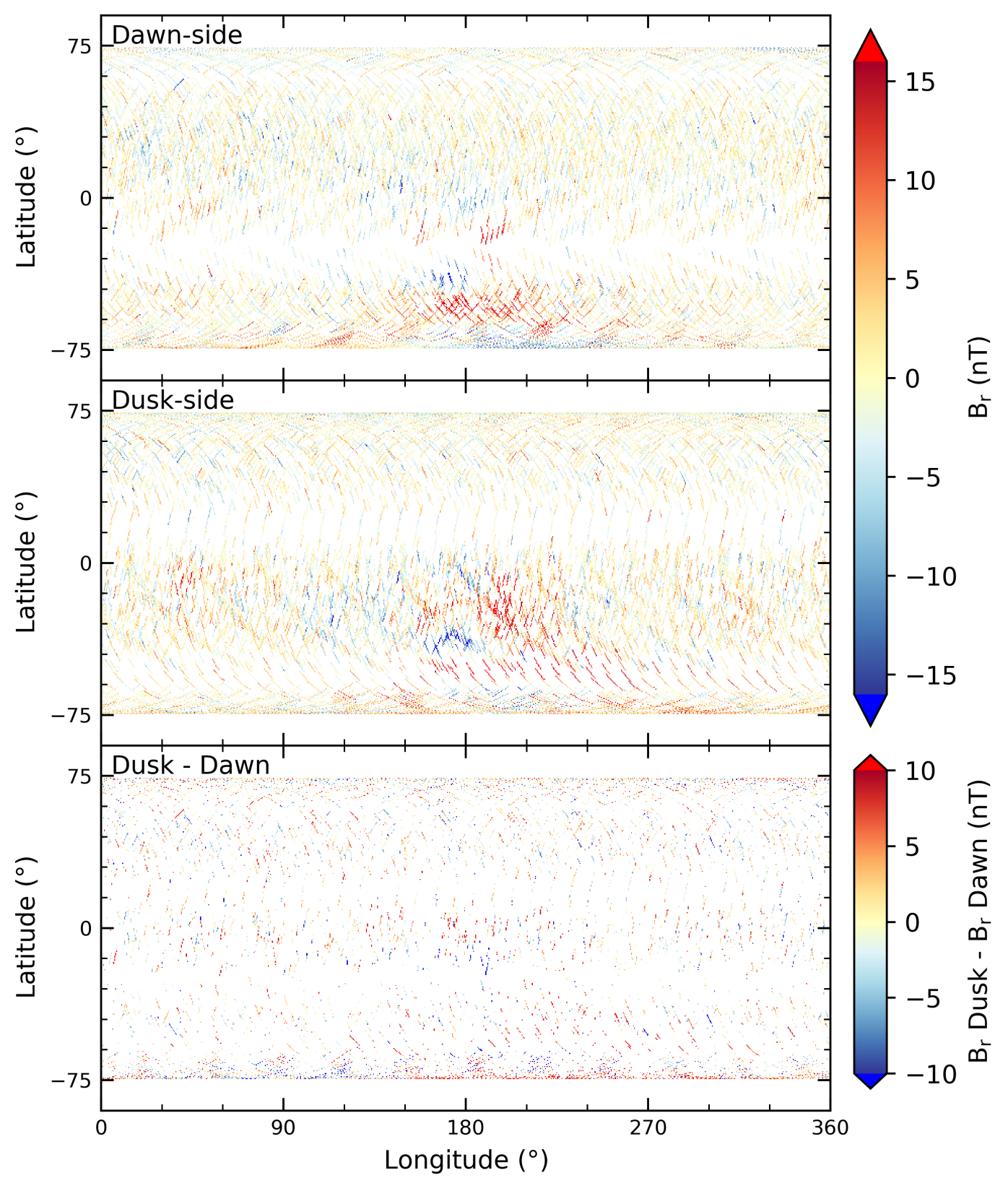

Radial component of MAVEN magnetic field data at 800-1000 km altitude for the dawnside region (top) and the dusk-side region (middle), and the difference between dusk-side and dawn-side magnetic field data (bottom).

SOURCE: Author's production. 
From the colorbar ranges seen in Figures 4.1, 4.2, 4.3, and 4.4, we evaluate that the magnitude of the differences of the magnetic field between the dawn-side and the dusk-side are at least $40 \%$ as large as the actual magnitudes of the magnetic field. As mentioned in Section 1.6, the radial component of the induced magnetic field at Mars is at most a few $\mathrm{nT}$ for all altitudes. This means that the differences we see in these maps are higher than the magnitudes of the induced field and are unlikely to be related to them.

Figure 4.5 presents the best-fit Gaussian curves, applied to the offset results of the shifting technique with MAVEN data. The results obtained for the analysis of 800-1000 km data are more irregular than for the other data sets and this can be explained by the smaller number of samples per bin at this altitude range.

Table 4.1 shows the offsets that correspond to the minimum $\Delta \mathrm{B}_{\text {MAVEN }}$, obtained by the Gaussian fits from Figure 4.5. The errors represent the standard deviation of the Gaussian fits.

Since negative values correspond to westward offsets and positive values correspond to eastward offsets, the directions of the offsets in Table 4.1 are in agreement with the expected direction of transport of the crustal magnetic field lines, i.e., westward at dawn-side and eastward at dusk-side (Figure 2.2). Additionally, for the same altitude range, the longitudinal offsets at dawn-side and at dusk-side have similar magnitudes.

Table 4.1 - Longitudinal offsets for minimum $\Delta \mathrm{B}^{\prime}$ MAVEN.

\begin{tabular}{|c|c|c|}
\hline Altitude range & Offset at dawn-side & Offset at dusk-side \\
\hline $200-400 \mathrm{~km}$ & $-0.33^{\circ} \pm 0.06^{\circ}$ & $0.37^{\circ} \pm 0.05^{\circ}$ \\
\hline $400-600 \mathrm{~km}$ & $-0.83^{\circ} \pm 0.07^{\circ}$ & $0.89^{\circ} \pm 0.05^{\circ}$ \\
\hline $600-800 \mathrm{~km}$ & $-1.41^{\circ} \pm 0.12^{\circ}$ & $1.48^{\circ} \pm 0.08^{\circ}$ \\
\hline $800-1000 \mathrm{~km}$ & $-2.40^{\circ} \pm 0.61^{\circ}$ & $2.62^{\circ} \pm 0.40^{\circ}$ \\
\hline
\end{tabular}

The angular displacements of the magnetic field relative to their source positions on the surface become larger at higher altitudes. This means that the crustal magnetic fields are being draped. This draping is not influenced by the induced magnetic field, because the latter is too weak to move the crustal fields. Therefore, these results indicate that the crustal magnetic fields are being draped by advection. 
Figure 4.5 - Plots of the best fit of $\Delta \mathrm{B}^{\prime}{ }_{\text {MAVEN }}$ to a Gaussian function.

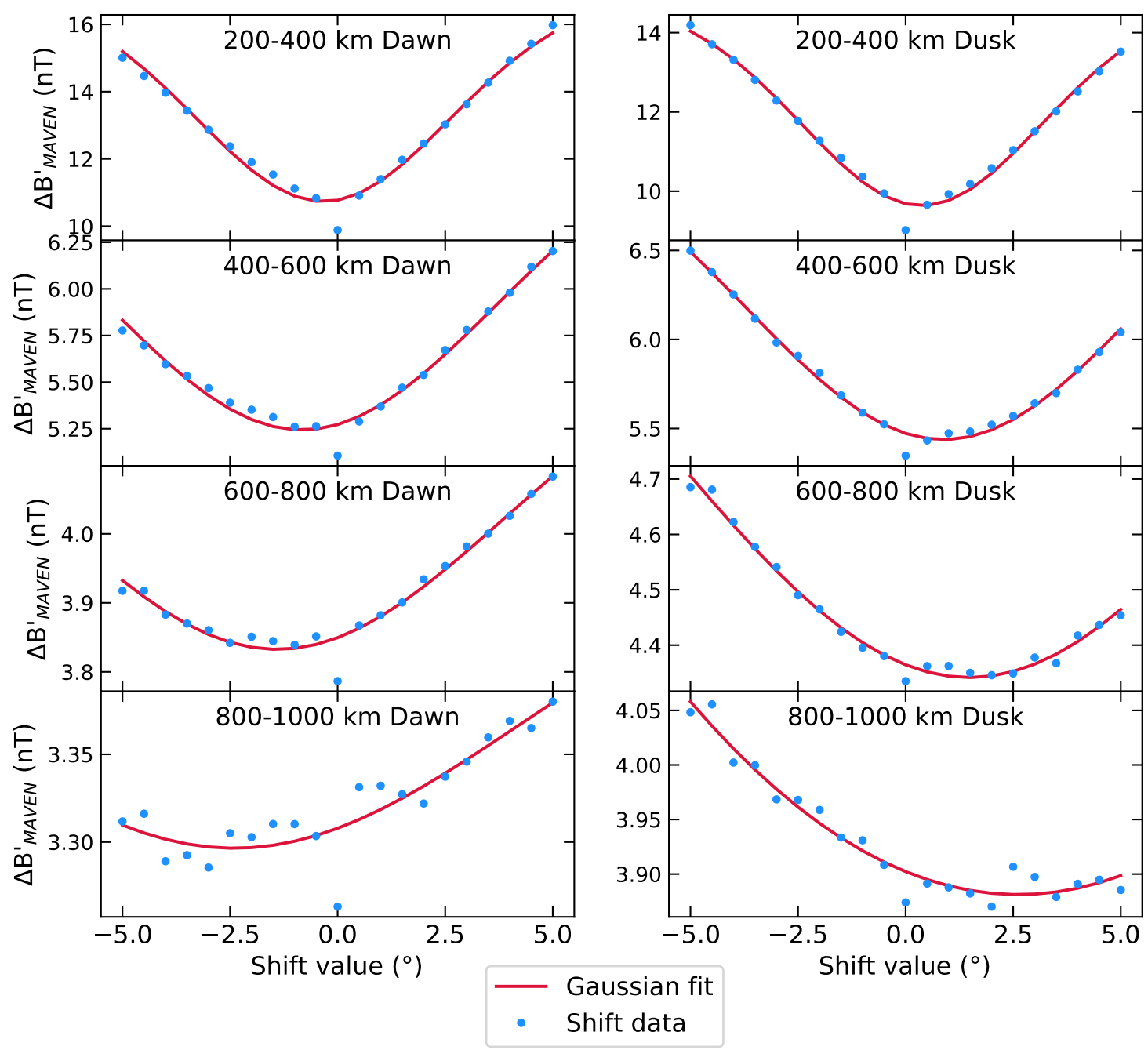

Each blue point is a value of $\Delta \mathrm{B}^{\prime}$ MAVEN for the given longitudinal shift. All of the Gaussian curves have negative amplitudes, meaning they are shaped as upside-down bells. Their widths increase with altitude.

SOURCE: Author's production.

There are gaps in the maps of Figures 4.2, 4.3, and 4.4, due to the low coverage of MAVEN spacecraft in those regions. These regions that contain gaps are not analyzed, which could affect the results of the shifting method. Although we consider the draping of the magnetic field to be likely caused by advection due to the ionospheric flow on Mars, an analysis with larger spatial coverage is necessary to confirm that our results are correct. 
Based on the results of Table 4.1, we calculate the rate at which the draping of the magnetic field structures increases with altitude. First, the absolute longitudinal offsets are converted to equivalent distances in $\mathrm{km}$, according to the corresponding altitude. We simplify the calculation by considering the offsets to be taking place at the equator, with a planetary radius of $3393.5 \mathrm{~km}$.

Figure 4.6 presents the absolute longitudinal distances for minimum $\Delta \mathrm{B}^{\prime}{ }_{\text {MAVEN }}$ and their error bars (standard deviation), at dawn-side and dusk-side, as a function of altitude. The data points are located at the average altitude for each altitude range, e.g., at $300 \mathrm{~km}$ for the altitude range of $200-400 \mathrm{~km}$.

Figure 4.6 - Plot of the linear regression of the absolute longitudinal offsets for minimum $\triangle \mathrm{B}$ 'MAVEN.

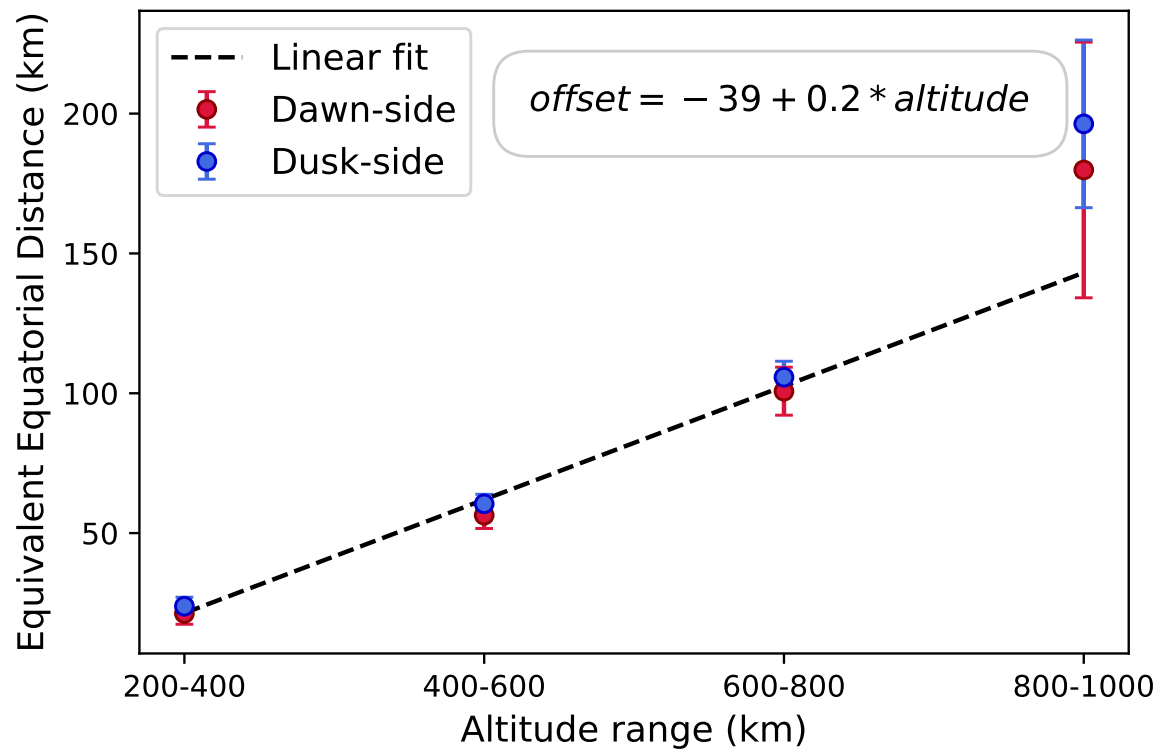

The linear equation derived from the linear regression is presented on the top of the curve. The offset and the altitude are in $\mathrm{km}$. The error bars are presented for each data point.

SOURCE: Author's production.

As a first estimate, we perform a linear fit of all of the absolute offsets, weighted by the inverse of the squared standard deviation related to each offset. The data points for the altitude range of $800-1000 \mathrm{~km}$ are much further from the linear regression than the other points in Figure 4.6. This could be attributed either to the lower MAVEN 
coverage on this altitude range or to the type of regression that is performed. It is possible that the rate at which the magnetic fields change with altitude is not a linear function, but a polynomial function of a higher degree or an exponential function. Nevertheless, it can be seen that the offsets or equivalent distances are very well fitted by a linear dependence on the altitude range of $200-800 \mathrm{~km}$.

The angular coefficient of the linear equation represents the rate that we are interested in. Then, for each $\mathrm{km}$ upwards in altitude, we calculate that the magnetic field lines are $0.2 \mathrm{~km}$ farther in longitude. Therefore, at higher altitudes, the magnetic field structures seem to be more disturbed due to the advection than at lower altitudes.

Figures 4.7 to 4.9 and Table 4.2 present the results of the shifting method applied to MGS data. Figures 4.7 and 4.8 show the maps of MGS day-side and nightside magnetic fields of the seven anomalies selected in Subsection 3.6.1. From the distribution of $B_{r}$ seen in the maps of the anomalies, we can make some observations:

A1 - It does not present clear changes in shape, but $B_{r}$ slightly increases during the day, in the south.

A2 - $B_{r}$ decreases during the day, but its shape does not change.

A3 - Its shape changes during the day, especially in the parts where $B_{r}$ is positive. Its magnitude decreases in the day-side.

A4 - It presents changes in shape and in magnetic field intensities. During the day, the intensities decrease where $B_{r}$ is positive and increase where $B_{r}$ is negative.

A5 - $B_{r}$ decreases in the north region and increases in the south region during the day.

A6 - It behaves similarly to A1.

A7 - It behaves similarly to A2.

As we can see, some magnetic fields of the anomaly regions become more intense during the day, while some others become weaker. Also, some of them show changes in shape, while some others do not. We infer that A1 and A6 anomalies present the same behavior because both of them have very strong magnetic fields. However, we still cannot take any conclusions on which processes control the behavior of the other regions solely from their magnetic field maps. 
Figure 4.7 - Maps of $B_{r}$ for A1, A2, A3, and A4 anomalies.
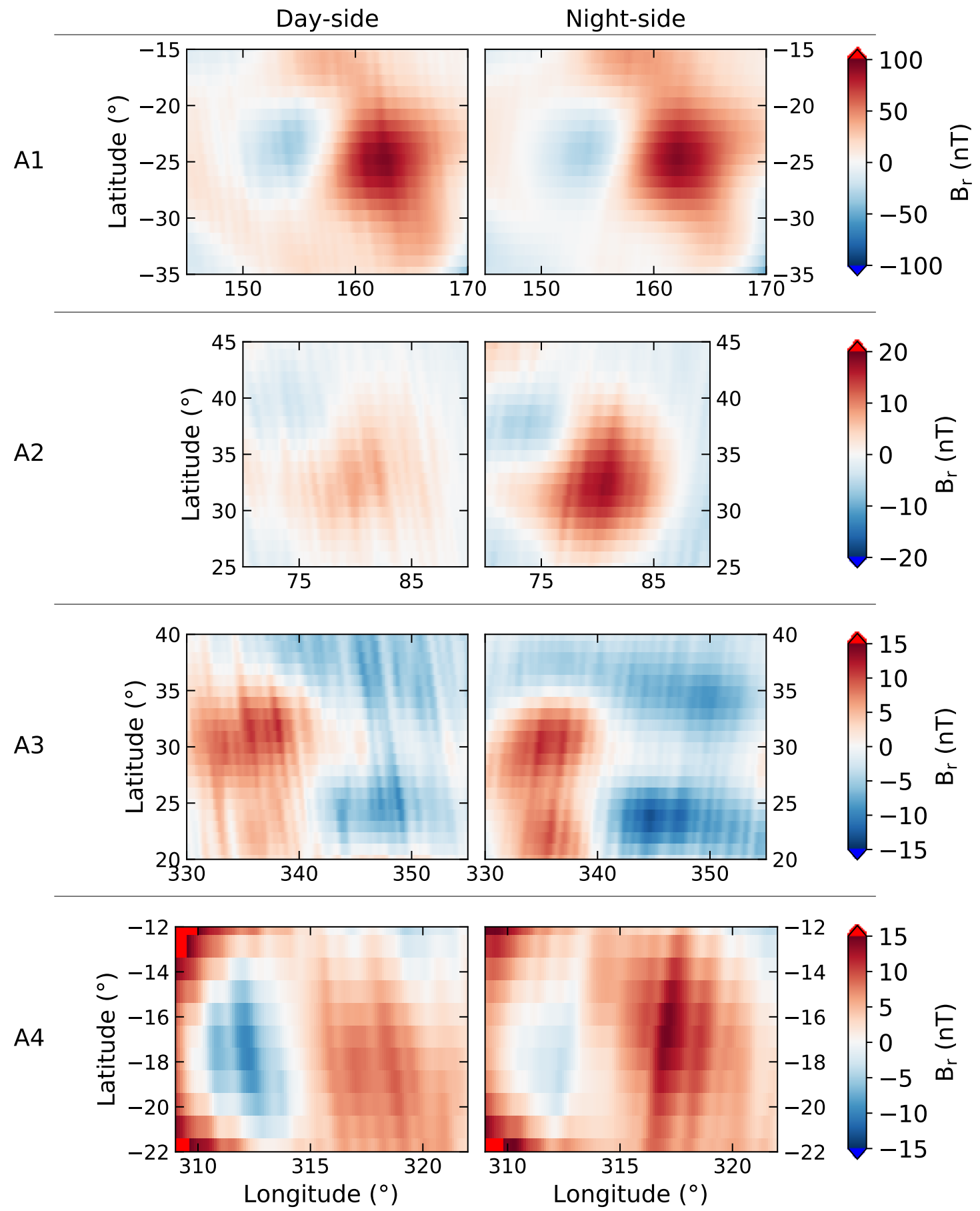

Left: $B_{r}$ at day-side. Right: $B_{r}$ at night-side. From top to bottom: A1, A2, A3, and A4. SOURCE: Author's production. 
Figure 4.8 - Maps of $B_{r}$ for A5, A6, and A7 anomalies.
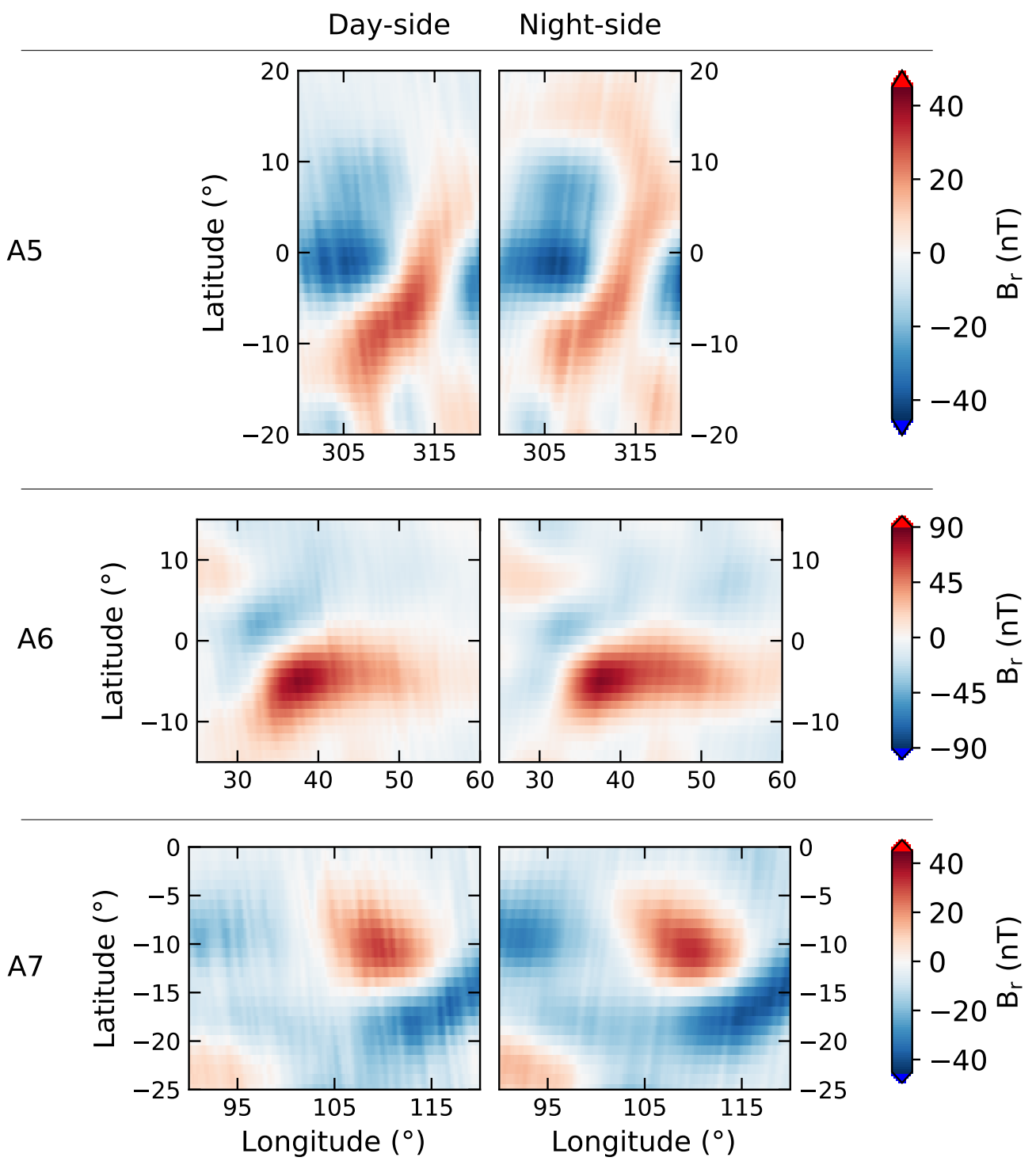

Left: $B_{r}$ at day-side. Right: $B_{r}$ at night-side. From top to bottom: A5, A6, and A7.

SOURCE: Author's production.

Figure 4.9 presents the best-fit Gaussian curves, applied to the offset results of the shifting technique with MGS global and local data. Table 4.2 shows the offsets that correspond to the minimum $\Delta \mathrm{B}^{\text {' }}$ MGS, obtained by the Gaussian fits from Figure 4.9, with the errors as the standard deviation of the Gaussian fits. 
Figure 4.9 - Plots of the best fit of $\Delta \mathrm{B}_{\text {MGS }}$ to a Gaussian function.

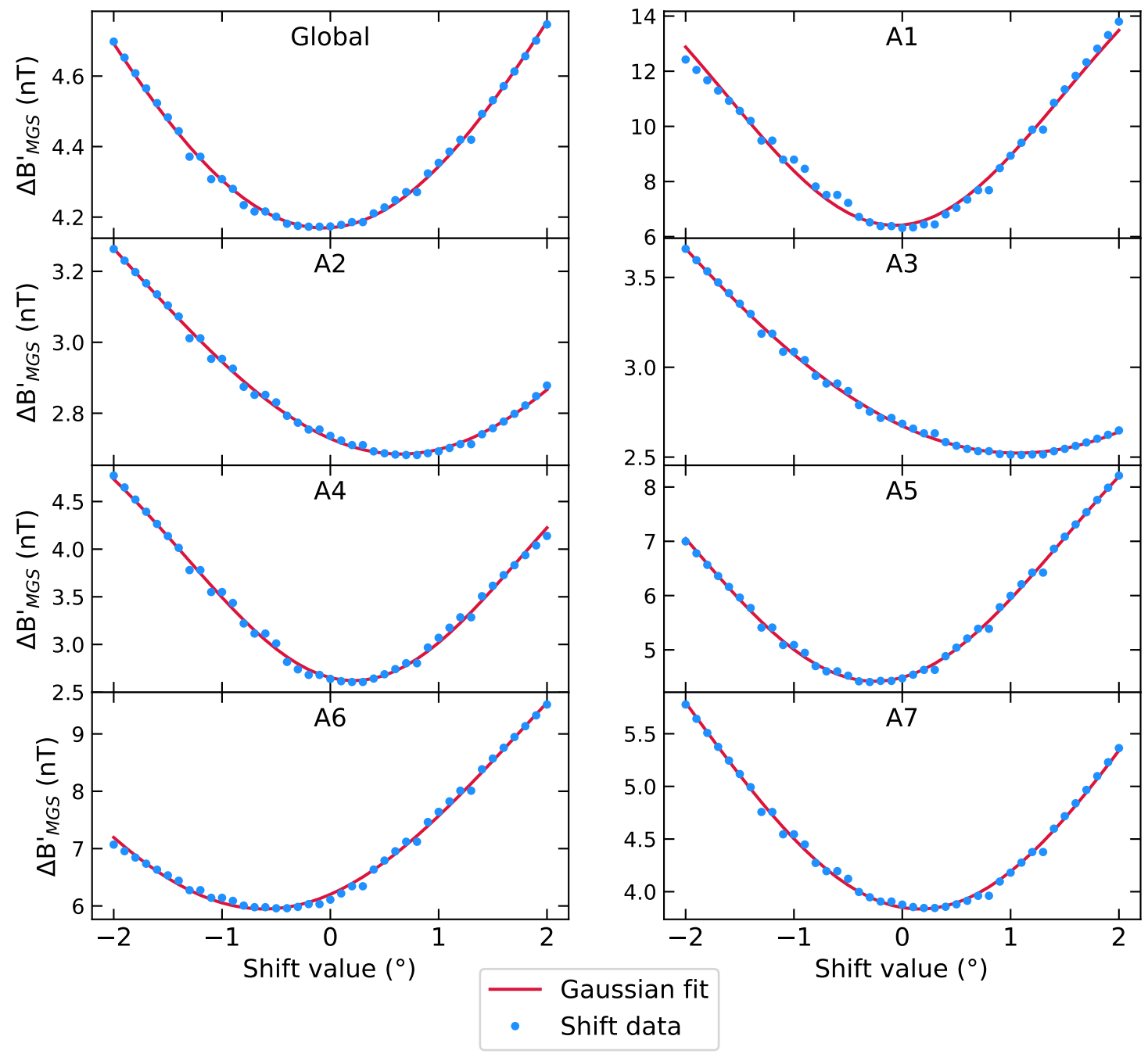

Each blue point is a value of $\Delta \mathrm{B}_{\text {MGS }}$ for the given longitudinal shift. All of the Gaussian curves have negative amplitudes.

SOURCE: Author's production. 
Table 4.2 - Longitudinal offsets for minimum $\Delta \mathrm{B}_{\text {MGS }}$.

\begin{tabular}{|c|c|}
\hline Region & Offset \\
\hline Global & $-0.07^{\circ} \pm 0.01^{\circ}$ \\
\hline A1 & $-0.07^{\circ} \pm 0.01^{\circ}$ \\
\hline A2 & $0.65^{\circ} \pm 0.01^{\circ}$ \\
\hline A3 & $1.06^{\circ} \pm 0.02^{\circ}$ \\
\hline A4 & $0.21^{\circ} \pm 0.01^{\circ}$ \\
\hline A5 & $-0.25^{\circ} \pm 0.01^{\circ}$ \\
\hline A6 & $-0.61^{\circ} \pm 0.01^{\circ}$ \\
\hline A7 & $0.16^{\circ} \pm 0.01^{\circ}$ \\
\hline
\end{tabular}

The directions of the offsets of the global map and of A1, A5, and A6 anomalies are westward, contrary to the expected direction of transport of the crustal magnetic field lines at dusk-side, according to what is shown in Figure 2.2. This could be possibly explained by the existence of local ionospheric currents opposite to the general day-to-night ionospheric flow.

Positive offsets can be observed for A2, A3, A4, and A7 anomalies, which are all eastward, as expected. These offsets range from $0.16^{\circ} \pm 0.01^{\circ}$ up to $1.06^{\circ} \pm 0.02^{\circ}$. This range includes the results of MAVEN dusk-side analysis between 200-600 km (Table 4.1 , which goes from $0.37^{\circ} \pm 0.05^{\circ}$ to $0.89^{\circ} \pm 0.05^{\circ}$. Then, these results indicate that the eastward offsets from MGS data are a consequence of advection.

Based on MGS results, we calculate the possible advection speed of the crustal magnetic field lines, considering an altitude of $400 \mathrm{~km}$ and a planetary radius of $3393.5 \mathrm{~km}$. A shift of the magnetic field by $1.0^{\circ}$ corresponds to a distance of $\sim 66$ $\mathrm{km}$ at this altitude. We take into account that the ionospheric flow has acted on the crustal field lines over a period of up to $2 \mathrm{~h}$ at the point of observation. The period of $2 \mathrm{~h}$ is defined as the period between 12:00 LT, when the ionospheric plasma begins to flow due to the pressure of the upstream solar wind, and 14:00 LT, when the MGS spacecraft has gathered the data.

We derive an advection speed of $\sim 10 \mathrm{~m} / \mathrm{s}$, at maximum. The ionospheric horizontal speed at $400 \mathrm{~km}$, above regions of strong magnetic field, is $\sim 1000-2000 \mathrm{~m} / \mathrm{s}$, shown by Figure 3.12. Therefore, the advection of the magnetic fields is a very slow process, 
about $1 \%$ of the ionospheric plasma flow speed.

Next, we present the results of the pressure analysis. As described in Subsection 3.6.2, we use MAVEN data to calculate the pressures related to the advection of the magnetic fields, as a function of local time and altitude. Dynamic, magnetic, and thermal pressures are analyzed in order to find the regions where the ionospheric plasma flow dominates over the magnetic field structures.

Figures 4.10 to 4.12 show the pressures and their ratio as a function of local time and altitude, for regions of weak magnetic fields $\left(B_{t} \leqslant 10 \mathrm{nT}\right)$ on the left panels and strong magnetic fields $\left(B_{t}>10 \mathrm{nT}\right)$ on the right panels.

Figure 4.10 presents the dynamic, the magnetic, and the thermal pressures. The magnetic pressure on regions of strong magnetic fields is comparable to the typical solar wind dynamic pressure of $1.0 \mathrm{nPa}$, at $400 \mathrm{~km}$ of altitude. Statistically, the dynamic and the thermal pressures by themselves do not exceed the typical solar wind dynamic pressure.

From Figure 4.10, we see that the magnetic pressure decreases with altitude, but it is constant for all local times since it does not depend on external factors. Both the dynamic and the thermal pressures increase above regions of strong magnetic fields, due to the higher density and temperature of $\mathrm{O}_{2}^{+}$ions at those regions.

Regarding the plots among the regions of different magnetic field intensities, it seems that the plots at regions of strong magnetic fields are displaced upwards compared to the plots at regions of weak magnetic fields. For the magnetic pressure, this is evident from Equation 2.19, because this pressure depends only on the magnetic field, which decays exponentially with altitude. As for the dynamic and the thermal pressures, this relation is not straightforward from Equations 2.17 and 2.18. However, as stated in Subsection 1.7, strong magnetic fields disturb ionospheric parameters, provoking changes in density, temperature, and speed of the ionospheric plasma. For this reason, we observe that the plots at regions of strong magnetic fields are displaced upwards. 
Figure 4.10 - Dynamic, magnetic, and thermal pressures as a function of local time and altitude.
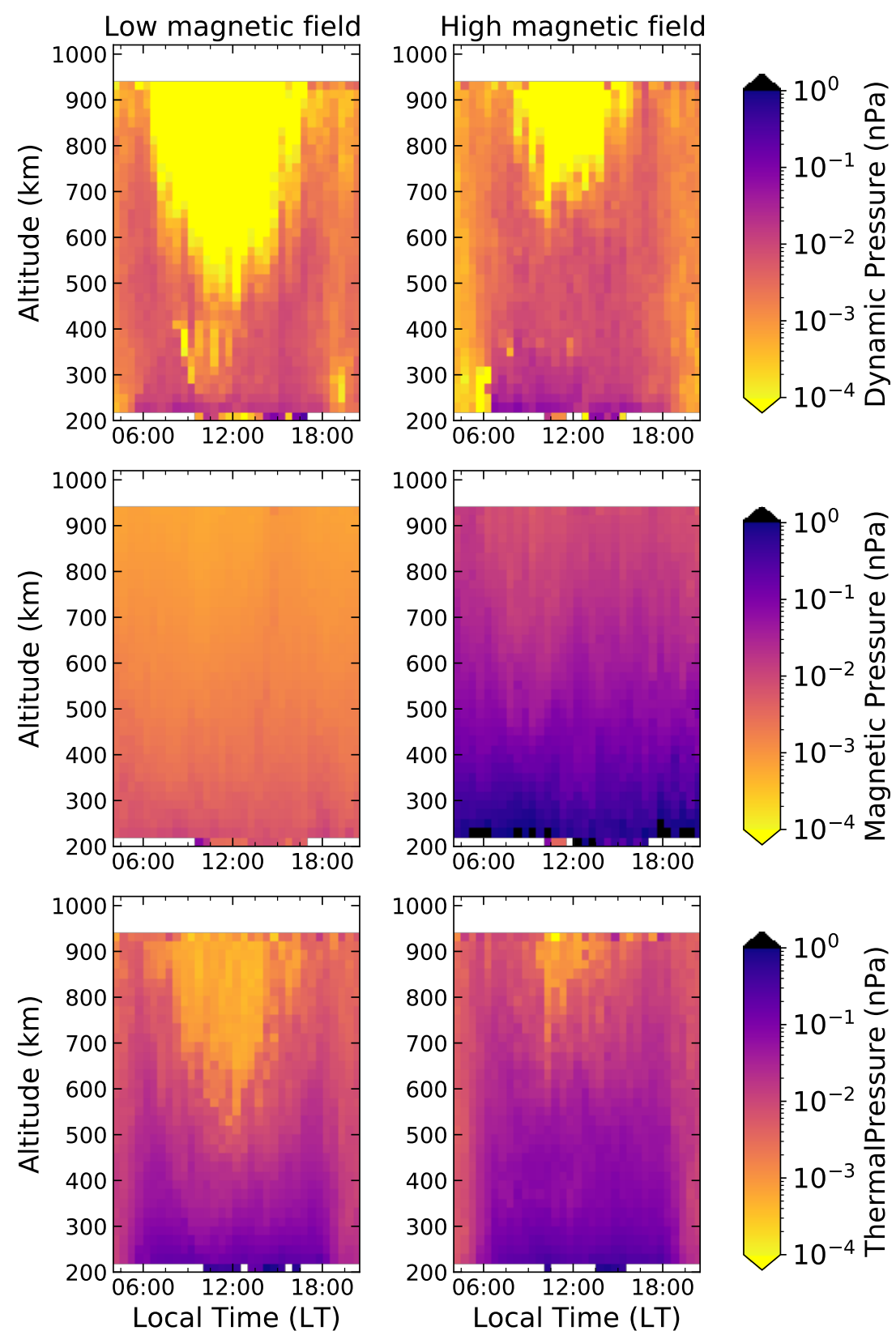

Top: dynamic pressure, at low (left) and at high (right) crustal magnetic field regions. Middle: magnetic pressure, at low (left) and at high (right) crustal magnetic field regions. Bottom: thermal pressure, at low (left) and at high (right) crustal magnetic field regions. The pressures are represented by the same color scale, which ranges between 0.0001-1.0 nPa.

SOURCE: Author's production. 
Figure 4.11 presents the ratio between the thermal and the dynamic pressures. For all altitudes and local times chosen for our analyses, the thermal pressure is at least twice the dynamic pressure. The ratio is mostly between $\sim 2-20$, but it can be larger than that at around 12:00 LT.

At regions where the thermal pressure is much greater than the dynamic pressure, the ionospheric flow can be highly disturbed due to turbulence. This means that the advection of magnetic field structures might be difficult to spot or might take place very slowly and subtly at those regions.

Figure 4.11 - Ratio between the thermal and the dynamic pressure as a function of local time and altitude.
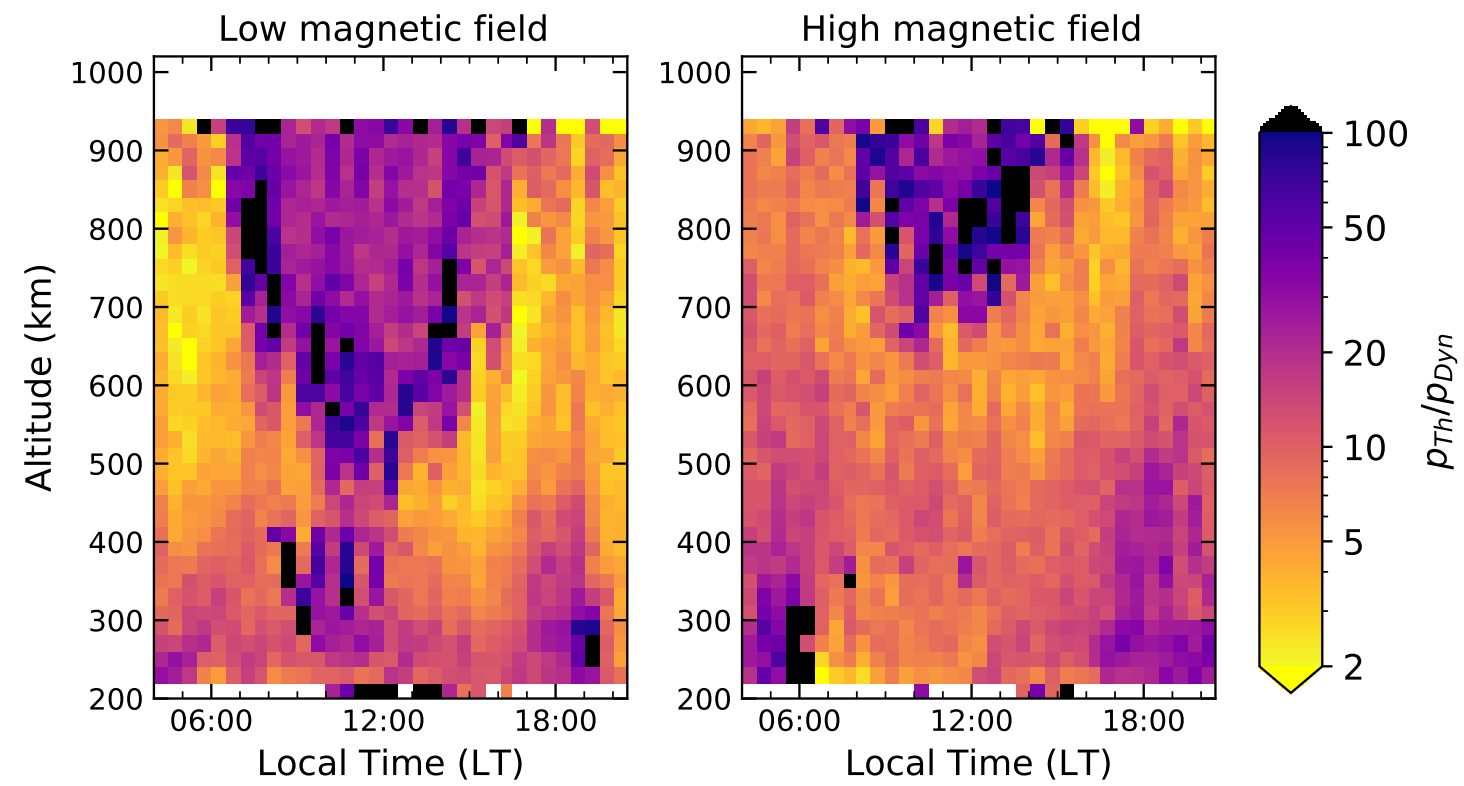

Left: pressure ratio, at low crustal magnetic field regions. Right: pressure ratio, at high crustal magnetic field regions. The color scale ranges between 2-100.

SOURCE: Author's production.

Figure 4.12 presents the plots of the ratio between the dynamic and the magnetic pressures. From this Figure, we observe that there are regions where the dynamic pressure is larger than the magnetic pressure and regions where the opposite happens. 
Figure 4.12 - Ratio between the dynamic and the magnetic pressure as a function of local time and altitude. The color scale ranges between 0.01-5.0.
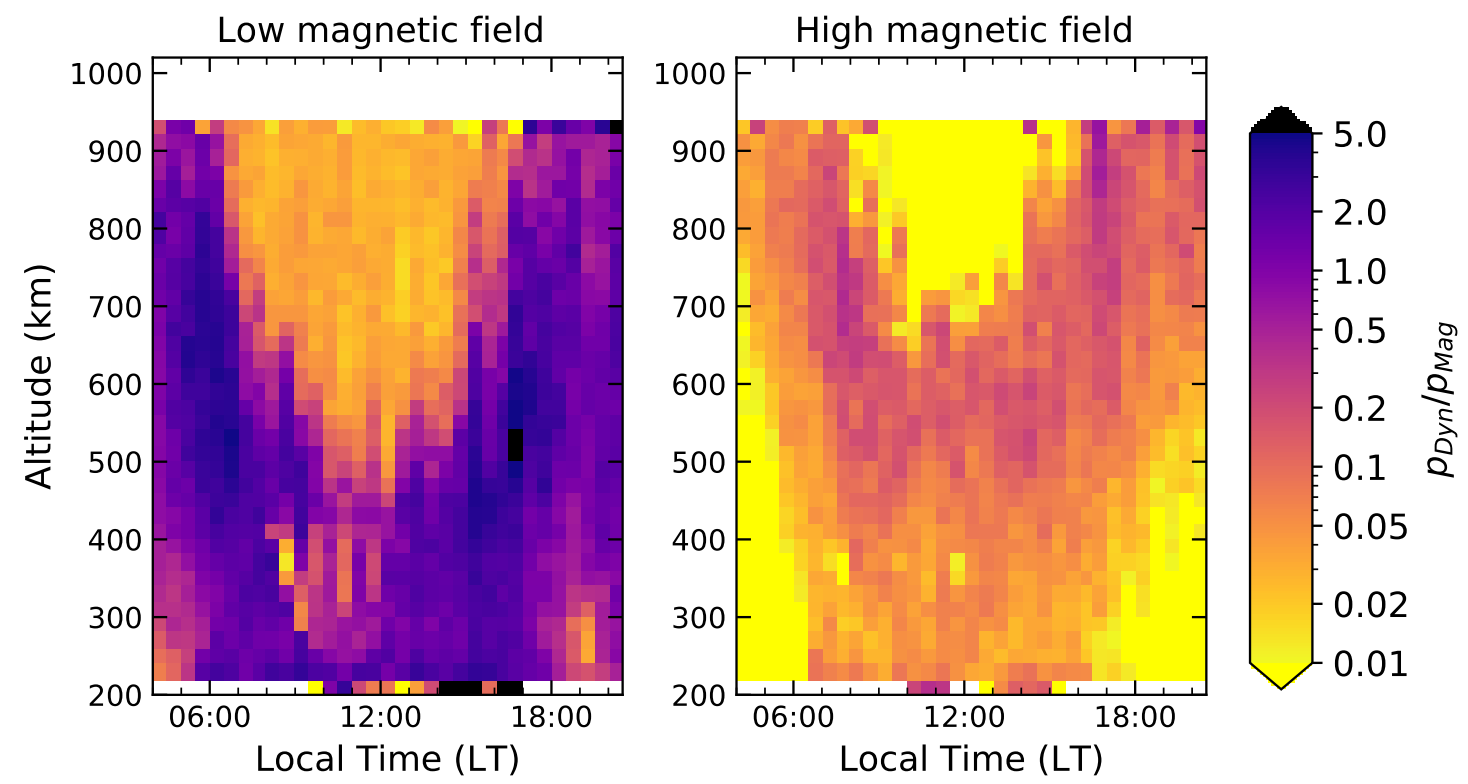

Left: pressure ratio, at low crustal magnetic field regions. Right: pressure ratio, at high crustal magnetic field regions.

SOURCE: Author's production.

Above weak magnetic fields at around 12:00 LT for all altitudes, the dynamic pressure is much lower than the magnetic pressure by at least one order of magnitude. The local time range in which this occurs becomes wider with altitude. Before 06:00 LT and after 18:00 LT, the ratio is smaller than 1.0, at low altitudes. At the other zones, the dynamic pressure is comparable or even greater than the magnetic pressure, reaching a ratio of 5.0 around 06:00 LT and 18:00 LT, at middle altitudes. This means that the advection of the magnetic fields is likely to be more expressive around 06:00 LT and 18:00 LT, because the magnetic field structures do not impose very strong barriers against the plasma flow at those regions.

On the other hand, above regions of strong magnetic fields, the dynamic pressure is generally smaller than the magnetic pressure. The magnetic pressure is at least two orders of magnitude greater than the dynamic pressure before 06:00 LT and after 18:00 LT, at low altitudes, and around 12:00 LT, at high altitudes. Surrounding the low ratio zone around 12:00 LT, there is a region where the ratio increases, forming an "U" shape. However, in this region, the magnetic pressure is still at least twice as 
large as the dynamic pressure. This means that the advection of the crustal magnetic fields might occur more slowly and less evidently above regions of strong magnetic fields.

The main point of Figure 4.12 is to show the relative importance that the dynamic pressure of the ionospheric flow has over the crustal magnetic field structures. In general, the ionospheric flow has more influence above regions of weak magnetic fields than above regions of strong magnetic fields. In other words, it is more likely that the advection of magnetic fields by the ionospheric flow happens in a more expressive way where the "magnetic background" is weak than where it is strong.

In a rough approximation, we can say that Mars' Northern hemisphere has a weak magnetic background, while the Southern hemisphere has a strong magnetic background (see Figure 1.3). In this scenario, we expect to observe the displacement of local strong magnetic field structures at the Northern hemisphere more clearly than at the Southern hemisphere.

Taking into consideration the results from the pressure analysis, Figure 3.9, and the description of the magnetic anomalies in Subsection 3.6.1, we can further discuss the shifting results of MGS data. In order to make the discussion easier to follow, we show once more the location of the anomalies selected for the shifting technique in Figure 4.13, which is the same as Figure 3.9. The yellow area in Figure 4.13 represents the main patch of magnetization of the Martian crust, i.e., the region with the strongest magnetic field background.

To present a different point of view about the shifting results of the individual anomalies, we sort Table 4.2 by ascending distance from the center of the yellow region and show the sorted results in Table 4.3. 
Figure 4.13 - Map of the location of the seven selected anomalies.

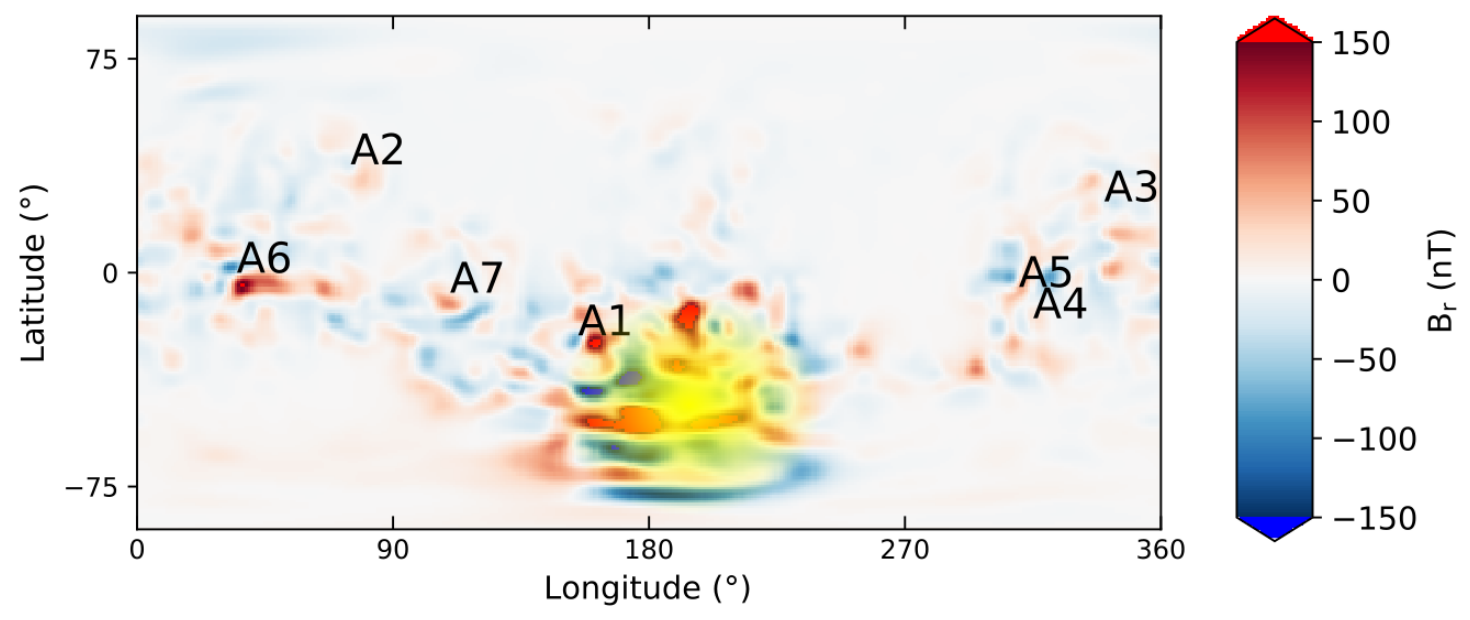

Map of modeled $B_{r}$ at $300 \mathrm{~km}$ altitude, with the location of A1, A2, A3, A4, A5, A6, and A7 anomalies. The yellow area defines the region with the strongest magnetic field background.

SOURCE: Author's production.

Table 4.3 - Longitudinal offsets for minimum $\Delta \mathrm{B}$ 'MGS (anomalies only). Sorted by ascending distance from the center of the region with the strongest magnetic background.

\begin{tabular}{|c|c|}
\hline Region & Offset \\
\hline $\mathrm{A} 1$ & $-0.07^{\circ} \pm 0.01^{\circ}$ \\
\hline $\mathrm{A} 7$ & $0.16^{\circ} \pm 0.01^{\circ}$ \\
\hline $\mathrm{A} 4$ & $0.21^{\circ} \pm 0.01^{\circ}$ \\
\hline $\mathrm{A} 5$ & $-0.25^{\circ} \pm 0.01^{\circ}$ \\
\hline $\mathrm{A} 2$ & $0.65^{\circ} \pm 0.01^{\circ}$ \\
\hline $\mathrm{A} 6$ & $-0.61^{\circ} \pm 0.01^{\circ}$ \\
\hline $\mathrm{A} 3$ & $1.06^{\circ} \pm 0.02^{\circ}$ \\
\hline
\end{tabular}

From Table 4.3 results, we notice that the absolute offsets generally increase with the distance of the anomalies from the region with the strongest magnetic field background in the crust (yellow region in Figure 4.13). This implies that there is a correlation between the displacement of the magnetic fields and the magnetic 
background in which these fields are located.

A2, A6, and A3 anomalies present the largest absolute offsets among the results from Table 4.3. From Figure 4.13, we see that A2 and A3 anomalies are located at middle latitude regions of the Northern hemisphere and isolated from other crustal magnetizations. This means that they are in a region with a very weak magnetic background on Mars

Another anomaly that presents a large absolute offset is A6. A6 anomaly has a very strong magnetic field intensity and, when compared to its surroundings, we can consider that this anomaly is also located at a region with a very weak magnetic background.

These results confirm that the advection of the magnetic fields is more expressive in regions with a very weak magnetic background, as inferred by the results of the pressure analysis.

The fact that some anomalies present offsets that are in the opposite direction to the expected might be a consequence of the effects of the magnetized regions on the ionosphere dynamics, especially on the creation/disturbance of local ionospheric flows. However, to confirm this hypothesis, further studies should be performed. 


\section{CONCLUSIONS}

In this Master Dissertation, we analyze MAVEN and MGS spacecraft data in order to investigate the possible occurrence of crustal magnetic field advection on Mars by the ionospheric plasma flow. The main conclusions obtained in this Dissertation are listed below:

1 - There are clear asymmetries between the magnetic field configuration on dawn-side and on dusk-side, especially above regions of strong crustal magnetic fields. These asymmetries are not caused by the induced day-side magnetic field. At the time of writing, MAVEN spacecraft does not have enough coverage to make this feature very clear at altitudes above $400 \mathrm{~km}$.

$\mathbf{2}$ - The results of the shifting technique with MAVEN data imply that the magnetic fields are being advected because:

$\mathbf{a}$ - the absolute offsets at dawn-side and at dusk-side are similar for the same altitude range;

b - the directions of the calculated offsets are in agreement to the expected directions of displacement of the magnetic fields, and

c - the absolute offsets increase with altitude, which means that the magnetic fields are being draped.

3 - We calculate that the rate at which the draping of the magnetic field increases with altitude is of 0.2 longitudinal $\mathrm{km}$ per each $\mathrm{km}$ in altitude. We also estimate a possible advection speed of $\sim 10 \mathrm{~m} / \mathrm{s}$ at $400 \mathrm{~km}$ of altitude, which is only $\sim 1 \%$ of the ionospheric plasma flow speed.

4 - The pressure analysis shows that the thermal pressure is too large in comparison to the dynamic pressure at around 12:00 LT, which means it is unlikely that we can observe any advection of magnetic field structures at this local time.

5 - The regions where the magnetic field background is weak (e.g., the Northern hemisphere of the planet) might present more expressive and clear observations of advection of the magnetic field structures. This might happen because the ionospheric plasma flow has more influence above those regions. 
6 - The results of the shifting technique with MGS data show that the absolute offsets increase with the distance of the anomalies from the region with the strongest magnetic field background in the Martian crust.

7 - Some of the results of the shifting technique with MGS data show longitudinal offsets in the direction that is opposite to the expected. This might happen due to the existence of local ionospheric currents opposite to the general day-to-night ionospheric flow.

In summary, we show evidence of the displacement of the crustal magnetic fields on Mars caused by the ionospheric plasma flow. Our results indicate that the advection of the magnetic fields is more likely to be observed at regions with a very weak magnetic field background.

As a suggestion, we propose that the advection of the crustal magnetic fields on Mars should be taken into consideration by the crustal magnetic field models that are to be built hereafter.

In a future work, it would be interesting to focus the analyses on regions with weak magnetic field background and restrict the selection of dawn-side and dusk-side to a smaller range of local times, centered at 06:00 LT and at 18:00 LT, respectively. With such refinements, we might be able to observe expressive displacements of the crustal magnetic fields and determine which other parameters dictate their occurrence. This study will be possible when MAVEN spacecraft has gathered more data. 


\section{REFERENCES}

ACUÑA, M. H.; CONNERNEY, J. E. P.; NESS, N. F.; LIN, R. P.; MITCHELL, D.; CARLSON, C. W.; MCFADDEN, J.; ANDERSON, K. A.; RÈME, H.; MAZELLE, C.; VIGNES, D.; WASILEWSKI, P.; CLOUTIER, P. Global distribution of crustal magnetization discovered by the Mars Global Surveyor MAG/ER Experiment. Science, v. 284, n. 5415, p. 790-793, 1999. 3, 6

ACUÑA, M. H.; CONNERNEY, J. E. P.; WASILEWSKI, P.; LIN, R. P.; ANDERSON, K. A.; CARLSON, C. W.; MCFADDEN, J.; CURTIS, D. W.; RÈME, H.; CROS, A.; MÈDALE, J. L.; SAUVAUD, J. A.; D’USTON, C.; BAUER, S. J.; CLOUTIER, P.; MAYHEW, M.; NESS, N. F. Mars Observer magnetic fields investigation. Journal of Geophysical Research: Planets, v. 97, n. E5, p. $7799-7814,1992.28$

ACUÑA, M. H.; CONNERNEY, J. E. P.; WASILEWSKI, P.; LIN, R. P.; ANDERSON, K. A.; CARLSON, C. W.; MCFADDEN, J.; CURTIS, D. W.; MITCHELL, D.; RÈME, H.; MAZELLE, C.; SAUVAUD, J. A.; USTON, C.; CROS, A.; MEDALE, J. L.; BAUER, S. J.; CLOUTIER, P.; MAYHEW, M.; WINTERHALTER, D.; NESS, N. F. Magnetic field and plasma observations at Mars: initial results of the Mars Global Surveyor mission. Science, v. 279, n. 5357, p. $1676-1680,1998.4$

ACUÑA, M. H.; CONNERNEY, J. E. P.; WASILEWSKI, P.; LIN, R. P.; MITCHELL, D.; ANDERSON, K. A.; CARLSON, C. W.; MCFADDEN, J.; RÈME, H.; MAZELLE, C.; VIGNES, D.; BAUER, S. J.; CLOUTIER, P.; NESS, N. F. Magnetic field of Mars: summary of results from the aerobraking and mapping orbits. Journal of Geophysical Research: Planets, v. 106, n. E10, p. 23403-23417, 2001. 4, 5, 6, 27, 28

ALBEE, A. L.; ARvidSOn, R. E.; PALluCONI, F.; THORPE, T. Overview of the Mars Global Surveyor mission. Journal of Geophysical Research:

Planets, v. 106, n. E10, p. 23291-23316, 2001. 27

ANDERSSON, L.; ERGUN, R. E.; DELORY, G. T.; ERIKSSON, A.; WESTFALL, J.; REED, H.; MCCAULY, J.; SUMMERS, D.; MEYERS, D. The Langmuir Probe and Waves (LPW) instrument for MAVEN. Space Science Reviews, v. 195, n. 1, p. 173-198, 2015. 30 
ARCHINAL, B. A.; ACTON, C. H.; A'HEARN, M. F.; CONRAD, A.; CONSOlmagno, G. J.; DUXBURY, T.; HeSTROFFER, D.; HILTON, J. L.; KIRK, R. L.; KLIONER, S. A.; MCCARTHY, D.; MEECH, K.; OBERST, J.; PING, J.; SEIDELMANN, P. K.; THOLEN, D. J.; THOMAS, P. C.; WILLIAMS, I. P. Report of the IAU working group on cartographic coordinates and rotational elements: 2015. Celestial Mechanics and Dynamical Astronomy, v. 130, n. 3 , p. $22,2018.17$

ARKANI-HAMED, J. A 50-degree spherical harmonic model of the magnetic field of Mars. Journal of Geophysical Research: Planets, v. 106, n. E10, p. 23197-23208, 2001. 6

ARKANI-HAMED, J. A coherent model of the crustal magnetic field of Mars. Journal of Geophysical Research: Planets, v. 109, n. E9, 2004. 7, 23, 31

ARKANI-HAMED, J. A.; DYMENT, J. Magnetic potential and magnetization contrasts of Earth's lithosphere. Journal of Geophysical Research: Solid Earth, v. 101, n. B5, p. 11401-11425, 1996. 6

BARLOW, N. Mars: an introduction to its interior, surface and atmosphere. Cambridge: Cambridge University Press, 2008. 286 p. (Cambridge Planetary Science). 1

BENNA, M.; MAHAFFY, P. R.; GREBOWSKY, J. M.; FOX, J. L.; YELLE, R. V.; JAKOSKY, B. M. First measurements of composition and dynamics of the Martian ionosphere by MAVEN's Neutral Gas and Ion Mass Spectrometer.

Geophysical Research Letters, v. 42, n. 21, p. 8958-8965, 2015. 8, 9, 10

BITTENCOURT, J. A. Fundamentals of plasma physics. 2. ed. São Paulo: Abaeté, 1995. 677 p. 8, 10, 21

BLAKELY, R. J. Potential theory in gravity and magnetic applications. Cambridge: Cambridge University Press, 1996. 464 p. 23

BRAIN, D. A. Mars Global Surveyor measurements of the Martian solar wind interaction. Space Science Reviews, v. 126, n. 1, p. 77-112, 2006. 11, 12, 13, 14

BRAIN, D. A.; BAGENAL, F.; ACUÑA, M. H.; CONNERNEY, J. E. P. Martian magnetic morphology: contributions from the solar wind and crust. Journal of Geophysical Research: Space Physics, v. 108, n. A12, 2003. 11 
BRAIN, D. A.; BAKER, A. H.; BRIGGS, J.; EASTWOOD, J. P.; HALEKAS, J. S.; PHAN, T.-D. Episodic detachment of Martian crustal magnetic fields leading to bulk atmospheric plasma escape. Geophysical Research Letters, v. 37, n. $14,2010.10,14,15$

BRAIN, D. A.; LILLIS, R. J.; MITCHELL, D. L.; HALEKAS, J. S.; LIN, R. P. Electron pitch angle distributions as indicators of magnetic field topology near Mars. Journal of Geophysical Research: Space Physics, v. 112, n. A9, 2007. 13

BRIGGS, J.; BRAIN, D.; CARTWRIGHT, M.; EASTWOOD, J.; HALEKAS, J. A statistical study of flux ropes in the Martian magnetosphere. Planetary and Space Science, v. 59, n. 13, p. 1498 - 1505, 2011. 14

BUTLER, R. Paleomagnetism: magnetic domains to geologic terranes. Boston: Blackwell Science Publications, 1992. 319 p. 5, 18

CAIN, J. C.; FERGUSON, B. B.; MOZZONI, D. An n $=90$ internal potential function of the Martian crustal magnetic field. Journal of Geophysical Research: Planets, v. 108, n. E2, 2003. 7, 14, 31

CAMPBELL, W. H. Introduction to geomagnetic fields. 2. ed. Cambridge: Cambridge University Press, 2003. 337 p. 18

CHAFFIN, M. S.; CHAUFRAY, J.-Y.; STEWART, I.; MONTMESSIN, F.; SCHNEIDER, N. M.; BERTAUX, J.-L. Unexpected variability of Martian hydrogen escape. Geophysical Research Letters, v. 41, n. 2, p. 314-320, 2014. 10

CHEN, F. F. Introduction to plasma physics and controlled fusion. 3. ed. Switzerland: Springer, 2016. 490 p. 21

CHIAO, L.-Y.; LIN, J.-R.; GUNG, Y.-C. Crustal magnetization equivalent source model of Mars constructed from a hierarchical multiresolution inversion of the Mars Global Surveyor data. Journal of Geophysical Research: Planets, v. 111, n. E12, 2006. 6

CHOUDHURI, A. R. An elementary introduction to solar dynamo theory. AIP Conference Proceedings, v. 919, n. 1, p. 49-73, 2007. 21

ClOUTIER, P. A.; LAW, C. C.; CRIDER, D. H.; WALKER, P. W.; CHEN, Y.; ACUÑA, M. H.; CONNERNEY, J. E. P.; LIN, R. P.; ANDERSON, K. A.; 
MITCHELL, D. L.; CARLSON, C. W.; MCFADDEN, J.; BRAIN, D. A.; RÃ “ME, H.; MAZElle, C.; SAUVAUd, J. A.; D’USTON, C.; VIGNES, D.; BAUER, S. J.; NESS, N. F. Venus-like interaction of the solar wind with Mars. Geophysical Research Letters, v. 26, n. 17, p. 2685-2688, 1999. 14

CONNERNEY, J. E. P.; ACUÑA, M.; NESS, N.; SPOHN, T.; SCHUBERT, G. Mars crustal magnetism. Space Science Reviews, v. 111, n. 1, p. 1-32, 2004. 5

CONNERNEY, J. E. P.; ACUÑA, M. H.; WASILEWSKI, P. J.; NESS, N. F.; RÈME, H.; MAZELLE, C.; VIGNES, D.; LIN, R. P.; MITCHELL, D. L.; CLOUTIER, P. A. Magnetic lineations in the ancient crust of Mars. Science, v. 284, n. 5415 , p. $794-798,1999.5$

CONNERNEY, J. E. P.; ESPLEY, J.; LAWTON, P.; MURPHY, S.; ODOM, J.; OLIVERSEN, R.; SHEPPARD, D. The MAVEN magnetic field investigation. Space Science Reviews, v. 195, n. 1, p. 257-291, 2015. 30

CUI, J.; GALAND, M.; YELLE, R. V.; WEI, Y.; ZHANG, S.-J. Day-to-night transport in the Martian ionosphere: implications from total electron content measurements. Journal of Geophysical Research: Space Physics, v. 120, n. 3, p. 2333-2346, 2015. 10

DAVIDSON, P. A. An introduction to magnetohydrodynamics. Cambridge: Cambridge University Press, 2001. 431 p. (Cambridge Texts in Applied Mathematics). 21, 25

DO, S.; OWENS, A.; HO, K.; SCHREINER, S.; WECK, O. de. An independent assessment of the technical feasibility of the Mars One mission plan - updated analysis. Acta Astronautica, v. 120, p. 192-228, 2016. 1

DUBININ, E.; FRAENZ, M.; PAETZOLD, M.; MCFADDEN, J.; MAHAFFY, P. R.; EPARVIER, F.; HALEKAS, J. S.; CONNERNEY, J. E. P.; BRAIN, D.; JAKOSKY, B. M.; VAISBERG, O.; ZELENYI, L. Effects of solar irradiance on the upper ionosphere and oxygen ion escape at Mars: MAVEN observations. Journal of Geophysical Research: Space Physics, v. 122, n. 7, p. 7142-7152, 2017. 30

DUXBURY, T.; KIRK, R.; ARCHINAL, B.; NEUMANN, G. Mars

Geodesy/Cartography Working Group recommendations on Mars cartographic constants and coordinate systems. The International Archives of the Photogrammetry, Remote Sensing and Spatial Information Sciences, v. 34, 2011. 17 
ELSASSER, W. M. On the origin of the Earth's magnetic field. Physical Review, v. 55, n. 5, p. 489-498, 1939. 4

FANG, X.; MA, Y.; MASUNAGA, K.; DONG, Y.; BRAIN, D.; HALEKAS, J.; LILLIS, R.; JAKOSKY, B.; CONNERNEY, J.; GREBOWSKY, J.; DONG, C. The Mars crustal magnetic field control of plasma boundary locations and atmospheric loss: MHD prediction and comparison with MAVEN. Journal of Geophysical Research: Space Physics, v. 122, n. 4, p. 4117-4137, 2017. 11 FANNING, D. W. Coyote's guide to traditional IDL graphics: using familiar tools creatively. Fort Collins: Coyote Book Publishing, 2011. 460 p. 32 FOX, J. L. Morphology of the dayside ionosphere of Mars: implications for ion outflows. Journal of Geophysical Research: Planets, v. 114, n. E12, 2009. 8 FOX, J. L.; BRANNON, J. F.; PORTER, H. S. Upper limits to the nightside ionosphere of Mars. Geophysical Research Letters, v. 20, n. 13, p. 1339-1342, 1993. 10

FOX, J. L.; DALGARNO, A. Ionization, luminosity, and heating of the upper atmosphere of Mars. Journal of Geophysical Research: Space Physics, v. 84, n. A12, p. $7315-7333,1979.8$

FRÄNZ, M.; DUBININ, E.; ANDREWS, D.; BARABASH, S.; NILSSON, H.; FEDOROV, A. Cold ion escape from the Martian ionosphere. Planetary and Space Science, v. 119, p. 92-102, 2015. 10

FRÄNZ, M.; DUBININ, E.; ROUSSOS, E.; WOCH, J.; WINNINGHAM, J. D.; FRAHM, R.; COATES, A. J.; FEDOROV, A.; BARABASH, S.; LUNDIN, R. Plasma moments in the environment of Mars. Mars Express ASPERA-3 observations. Space Science Reviews, v. 126, n. 1-4, p. 165-207, 2006. 22 GRANZOW, K. D. Spherical harmonic representation of the magnetic field in the presence of a current density. Geophysical Journal International, v. 74, n. 2, p. $489-505,1983.23$

GRIFFITHS, D. J. Introduction to electrodynamics. 3. ed. Upper Saddle River, NJ: Prentice Hall, 1999. 576 p. 18

GURNETT, D. A.; HUFF, R. L.; MORGAN, D. D.; PERSOON, A. M.; AVERKAMP, T. F.; KIRCHNER, D. L.; DURU, F.; AKALIN, F.; KOPF, A. J.; NIELSEN, E.; SAFAEINILI, A.; PLAUT, J. J.; PICARDI, G. An overview of 
radar soundings of the martian ionosphere from the Mars Express spacecraft. Advances in Space Research, v. 41, n. 9, p. 1335-1346, 2008. 11

HALL, A. Discovery of satellites of Mars. Monthly Notices of the Royal Astronomical Society, v. 38, p. 205-209, 1878. 2

HARA, T.; BRAIN, D. A.; MITCHELL, D. L.; LUHMANN, J. G.; SEKI, K.; HASEGAWA, H.; MCFADDEN, J. P.; HALEKAS, J. S.; ESPLEY, J. R.; HARADA, Y.; LIVI, R.; DIBRACCIO, G. A.; CONNERNEY, J. E. P.; MAZELLE, C.; ANDERSSON, L.; JAKOSKY, B. M. MAVEN observations of a giant ionospheric flux rope near Mars resulting from interaction between the crustal and interplanetary draped magnetic fields. Journal of Geophysical Research: Space Physics, v. 122, n. 1, p. 828-842, 2017. 15

HARA, T.; MITCHELL, D. L.; MCFADDEN, J. P.; SEKI, K.; BRAIN, D. A.; HALEKAS, J. S.; HARADA, Y.; ESPLEY, J. R.; DIBRACCIO, G. A.; CONNERNEY, J. E. P.; ANDERSSON, L.; MAZELLE, C.; JAKOSKY, B. M.

Estimation of the spatial structure of a detached magnetic flux rope at Mars based on simultaneous MAVEN plasma and magnetic field observations. Geophysical Research Letters, v. 42, n. 21, p. 8933-8941, 2015. 15

HARADA, Y.; HALEKAS, J. S.; MCFADDEN, J. P.; ESPLEY, J.; DIBRACCIO, G. A.; MITCHELL, D. L.; MAZELLE, C.; BRAIN, D. A.; ANDERSSON, L.; MA, Y. J.; LARSON, D. E.; XU, S.; HARA, T.; RUHUNUSIRI, S.; LIVI, R.; JAKOSKY, B. M. Survey of magnetic reconnection signatures in the Martian magnetotail with MAVEN. Journal of Geophysical Research: Space Physics, v. 122 , n. 5 , p. $5114-5131,2017.10$

HARGREAVES, J. K. The solar-terrestrial environment: an introduction to geospace - the science of the terrestrial upper atmosphere, ionosphere, and magnetosphere. Cambridge: Cambridge University Press, 1992. 208-248 p. (Cambridge Atmospheric and Space Science Series). 8

HEIRTZLER, J. R.; PICHON, X. L. Crustal structure of the mid-ocean ridges: 3. Magnetic anomalies over the mid-Atlantic ridge. Journal of Geophysical Research (1896-1977), v. 70, n. 16, p. 4013-4033, 1965. 5

HOEL, P. G. Introduction to mathematical statistics. 5. ed. Michigan: John Wiley \& Sons, 1984. 435 p. 45 
HUNDhAUSEN, A. J. The solar wind. In: KIVELSON, M. G.; RUSSELL, C. T. (Ed.). Introduction to space physics. Cambridge: Cambridge University Press, 1995. p. $91-128.8$

HUNTER, J. D. Matplotlib: A 2d graphics environment. Computing in Science \& Engineering, v. 9, n. 3, p. 90-95, 2007. 32

JAKOSKY, B. M.; LIN, R. P.; GREBOWSKY, J. M.; LUHMANN J.

G. MITCHELL, D. F.; BEUTELSCHIES, G.; PRISER, T.; ACUÑA, M.;

ANDERSSON, L.; BAIRD, D.; BAKER, D.; BARTLETT, R.; BENNA, M.;

BOUGHER, S.; BRAIN, D.; CARSON, D.; CAUFFMAN, S.; CHAMBERLIN, P.; CHAUFRAY, J.-Y.; CHEATOM, O.; CLARKE, J.; CONNERNEY, J.;

CRAVENS, T.; CURTIS, D.; DELORY, G.; DEMCAK, S.; DEWOLFE, A.; EPARVIER, F.; ERGUN, R.; ERIKSSON, A.; ESPLEY, J.; FANG, X.; FOLTA, D.; FOX, J.; GOMEZ-ROSA, C.; HABENICHT, S.; HALEKAS, J.; HOLSCLAW, G.; HOUGHTON, M.; HOWARD, R.; JAROSZ, M.; JEDRICH, N.; JOHNSON, M.; KASPRZAK, W.; KELLEY, M.; KING, T.; LANKTON, M.; LARSON, D.; LEBLANC, F.; LEFEVRE, F.; LILLIS, R.; MAHAFFY, P.; MAZELLE, C.; MCCLINTOCK, W.; MCFADDEN, J.; MITCHELL, D. L.; MONTMESSIN, F.; MORRISSEY, J.; PETERSON, W.; POSSEL, W.; SAUVAUD, J.-A.; SCHNEIDER, N.; SIDNEY, W.; SPARACINO, S.; STEWART, A. I. F.; TOLSON, R.; TOUBLANC, D.; WATERS, C.; WOODS, T.; YELLE, R.; ZUREK, R. The Mars Atmosphere and Volatile Evolution (MAVEN) Mission. Space Science Reviews, v. 195, n. 1, p. 3-48, 2015. 10, 29

JOHNSON, R. E. Plasma-induced sputtering of an atmosphere. Space Science Reviews, v. 69, n. 3-4, p. 215-253, 1994. 10

KIVELSON, M. G.; BAGENAL, F. Planetary magnetospheres. In: MCFADDEN, L.-A.; WEISSMAN, P. R.; JOHNSON, T. V. (Ed.). Encyclopedia of the solar system. 2. ed. San Diego: Academic Press, 2007. p. 519-540. 11, 13

KIVELSON, M. G.; RUSSELL, C. T. Introduction to space physics. New York: Cambridge Univerity Press, 1995. 588 p. 10, 11

KRASNOPOLSKY, V. A. Mars' upper atmosphere and ionosphere at low, medium, and high solar activities: implications for evolution of water. Journal of Geophysical Research: Planets, v. 107, n. E12, p. 5128, 2002. 9

LANGLAIS, B.; PURUCKER, M. E.; LILLIS, R. J. A new and improved description of the Martian magnetic crustal field using both MGS-MAG and 
MGS-ER measurements. In: AGU FALL MEETING, 2010, San Francisco, United States of America. Proceedings... San Francisco: American Geophysical Union, 2010. p. GP42A-02. 6

LANGLAIS, B.; PURUCKER, M. E.; MANDEA, M. Crustal magnetic field of Mars. Journal of Geophysical Research: Planets, v. 109, n. E2, 2004. 6

LANGLAIS, B.; THÈBAUlT, E.; HOUliEZ, A.; PURUCKER, M.; LILLIS, R. A new model of the crustal magnetic field of Mars using MGS and MAVEN.

Journal of Geophysical Research: Planets, v. 124, n. 6, p. 1542-1569, 2019. 7

LILLIS, R. J.; BRAIN, D. A.; BOUGHER, S. W.; LEBLANC, F.; LUHMANN, J. G.; JAKOSKY, B. M.; MODOLO, R.; FOX, J.; DEIGHAN, J.; FANG, X.; WANG, Y. C.; LEE, Y.; DONG, C.; MA, Y.; CRAVENS, T.; ANDERSSON, L.; CURRY, S. M.; SCHNEIDER, N.; COMBI, M.; STEWART, I.; CLARKE, J.; GREBOWSKY, J.; MITCHELL, D. L.; YELLE, R.; NAGY, A. F.; BAKER, D.; LIN, R. P. Characterizing atmospheric escape from Mars today and through time, with MAVEN. Space Science Reviews, v. 195, n. 1-4, p. 357-422, 2015. 10

LILLIS, R. J.; FILLINGIM, M. O.; MA, Y.; GONZALEZ-GALINDO, F.; FORGET, F.; JOHNSON, C. L.; MITTELHOLZ, A.; RUSSELL, C. T.; ANDERSSON, L.; FOWLER, C. M. Modeling wind-driven ionospheric dynamo currents at Mars: expectations for InSight magnetic field measurements.

Geophysical Research Letters, v. 46, n. 10, p. 5083-5091, 2019. 11

LILLIS, R. J.; ROBBINS, S.; MANGA, M.; HALEKAS, J. S.; FREY, H. V. Time history of the Martian dynamo from crater magnetic field analysis. Journal of Geophysical Research: Planets, v. 118, n. 7, p. 1488-1511, 2013. 5

LUHMANN, J.; ACUÑA, M.; PURUCKER, M.; RUSSELL, C.; LYON, J. The Martian magnetosheath: how Venus-like? Planetary and Space Science, v. 50, n. 5, p. 489-502, 2002. 14

LUHMANN, J. G.; CRAVENS, T. E. Magnetic fields in the ionosphere of Venus. Space Science Reviews, v. 55, n. 1-4, p. 201-274, 1991. 21

LUHMANN, J. G.; JOHNSON, R. E.; ZHANG, M. H. G. Evolutionary impact of sputtering of the Martian atmosphere by $\mathrm{O}^{+}$pickup ions. Geophysical Research Letters, v. 19, n. 21, p. 2151-2154, 1992. 10

LUHMANN, J. G.; LEDVINA, S. A.; RUSSELL, C. T. Induced magnetospheres. Advances in Space Research, v. 33, n. 11, p. 1905-1912, 2004. 11 
LUI, A. T. Y. Frozen-in condition for ions and electrons: implication on magnetic flux transport by dipolarizing flux bundles. Geoscience Letters, v. 5, n. 5, 2018. 48

LUNDIN, R.; ZAKHAROV, A.; PELLINEN, R.; BORG, H.; HULTQVIST, B.; PISSARENKO, N.; DUBININ, E. M.; BARABASH, S. W.; LIEDE, I.;

KOSKINEN, H. First measurements of the ionospheric plasma escape from Mars. Nature, v. 341, p. 609-612, 1989. 10

MA, Y.; NAGY, A. F.; SOKOLOV, I. V.; HANSEN, K. C. Three-dimensional, multispecies, high spatial resolution MHD studies of the solar wind interaction with Mars. Journal of Geophysical Research: Space Physics, v. 109, n. A7, 2004. 11

MARINOVA, M. M.; AHARONSON, O.; ASPHAUG, E. Mega-impact formation of the Mars hemispheric dichotomy. Nature, v. 453, n. 7199, p. 1216-1219, 2008. 3

MCFADDEN, J. P.; KORTMANN, O.; CURTIS, D.; DALTON, G.; JOHNSON, G.; ABIAD, R.; STERLING, R.; HATCH, K.; BERG, P.; TIU, C.; GORDON, D.; HEAVNER, S.; ROBINSON, M.; MARCKWORDT, M.; LIN, R.; JAKOSKY, B. MAVEN SupraThermal and Thermal Ion Compostion (STATIC) instrument. Space Science Reviews, v. 195, n. 1, p. 199-256, 2015. 30

MILBURY, C.; SCHUBERT, G.; RAYMOND, C. A.; SMREKAR, S. E.; LANGLAIS, B. The history of Mars' dynamo as revealed by modeling magnetic anomalies near Tyrrhenus Mons and Syrtis Major. Journal of Geophysical Research: Planets, v. 117, n. E10, 2012. 5

MITCHELL, D. L.; LIN, R. P.; MAZELle, C.; RÈME, H.; CLOUTIER, P. A.; CONNERNEY, J. E. P.; ACUÑA, M. H.; NESS, N. F. Probing Mars' crustal magnetic field and ionosphere with the MGS Electron Reflectometer. Journal of Geophysical Research: Planets, v. 106, n. E10, p. 23419-23427, 2001. 11 MORSCHHAUSER, A.; LESUR, V.; GROTT, M. A spherical harmonic model of the lithospheric magnetic field of Mars. Journal of Geophysical Research: Planets, v. 119, n. 6, p. 1162-1188, 2014. 6, 7, 31, 47, 57

NAGY, A. F.; WINTERHALTER, D.; SAUER, K.; CRAVENS, T. E.; BRECHT, S.; MAZELlE, C.; CRIDER, D.; KALliO, E.; ZAKHAROV, A.; DUBININ, E.; VERIGIN, M.; KOTOVA, G.; AXFORD, W. I.; BERTUCCI, C.; TROTIGNON, J. G. The plasma environment of Mars. Space Science Reviews, v. 111, n. 1, p. 33-114, 2004. 11 
NATIONAL AERONAUTICS AND SPACE ADMINISTRATION. Artist's concept of Mars Global Surveyor in orbit above Mars. Jet Propulsion Laboratory - California Institute of Technology, 2002. Available from: $<$ https://mars.nasa.gov/mgs/gallery/images_mgs-mons.html>. Access in: July 2020. 28

NATIONAL AERONAUTICS AND SPACE ADMINISTRATION. Mars and its moons, Phobos and Deimos. Jet Propulsion Laboratory - California Institute of Technology, 2008. Available from:

<https://solarsystem.nasa.gov/moons/mars-moons/in-depth/>. Access in: July 2020. 2

NATIONAL AERONAUTICS AND SPACE ADMINISTRATION. Artist's concept of Mars Atmsphere and Volatile Evolution at Mars. Goddard Space Flight Center, 2014. Available from:

$<$ https://lasp.colorado.edu/home/maven/multimedia/spacecraft/>. Access in: July 2020. 29

NESS, N.; BEHANNON, K.; LEPPING, R.; WHANG, Y. Observations of Mercury's magnetic field. Icarus, v. 28, n. 4, p. 479-488, 1976. 5

NIER, A. O.; MCELROY, M. B. Composition and structure of Mars' upper atmosphere: results from the neutral mass spectrometers on Viking 1 and 2 . Journal of Geophysical Research, v. 82, n. 28, p. 4341-4349, 1977. 8

NIMMO, F.; STEVENSON, D. J. Influence of early plate tectonics on the thermal evolution and magnetic field of Mars. Journal of Geophysical Research:

Planets, v. 105, n. E5, p. 11969-11979, 2000. 5

OLIPHANT, T. E. A guide to NumPy. 2. ed. North Charleston: CreateSpace Independent Publishing Platform, 2015. 32

PANNING, M. P.; LOGNONNÉ, P.; BANERDT, W. B.; GARCIA, R.; GOLOMBEK, M.; KEDAR, S.; KNAPMEYER-ENDRUN, B.; MOCQUET, A.; TEANBY, N. A.; TROMP, J.; WEBER, R.; BEUCLER, E.;

BLANCHETTE-GUERTIN, J.-F.; BOZDAĞ, E.; DRILLEAU, M.; GUDKOVA, T.; HEMPEL, S.; KHAN, A.; LEKIĆ, V.; MURDOCH, N.; PLESA, A.-C.; RIVOLDINI, A.; SCHMERR, N.; RUAN, Y.; VERHOEVEN, O.; GAO, C.; CHRISTENSEN, U.; CLINTON, J.; DEHANT, V.; GIARDINI, D.; MIMOUN, D.; PIKE, W. T.; SMREKAR, S.; WIECZOREK, M.; KNAPMEYER, M.; 
WOOKEY, J. Planned products of the Mars structure service for the InSight mission to Mars. Space Science Reviews, v. 211, n. 1-4, p. 611-650, 2017.1

PATER, I. de; LISSAUER, J. J. Planetary sciences. 2. ed. Cambridge: Cambridge University Press, 2010. 647 p. 1, 2

PETRANEK, S. L. How we'll live on Mars. New York: Simon \& Schuster/TED, 2015. 96 p. 1

PURUCKER, M.; RAVAT, D.; FREY, H.; VOORHIES, C.; SABAKA, T.; ACUÑA, M. An altitude-normalized magnetic map of Mars and its interpretation. Geophysical Research Letters, v. 27, n. 16, p. 2449-2452, 2000. 6, 7 ROBERTS, J. H.; LILLIS, R. J.; MANGA, M. Giant impacts on early Mars and the cessation of the Martian dynamo. Journal of Geophysical Research: Planets, v. 114, n. E4, 2009. 5

ROBERTS, J. H.; ZHONG, S. Degree-1 convection in the Martian mantle and the origin of the hemispheric dichotomy. Journal of Geophysical Research: Planets, v. 111, n. E6, 2006. 3

RUSSELL, C. The dynamics of planetary magnetospheres. Planetary and Space Science, v. 49, n. 10, p. 1005-1030, 2001. 11

RUSSELL, C. T.; ELPHIC, R. C. Observation of magnetic flux ropes in the Venus ionosphere. Nature, v. 279, n. 5714, p. 616-618, 1979. 14

SHINAGAWA, H.; CRAVENS, T. E. The ionospheric effects of a weak intrinsic magnetic field at Mars. Journal of Geophysical Research: Planets, v. 97, n. E1, p. 1027-1035, 1992. 11

SMITH, D. E.; ZUBER, M. T.; FREY, H. V.; GARVIN, J. B.; HEAD, J. W.; MUHLEMAN, D. O.; PETTENGILL, G. H.; PHILlIPS, R. J.; SOLOMON, S. C.; ZWALlY, H. J.; BANERDT, W. B.; DUXBURY, T. C.; GOLOMBEK, M. P.; LEMOINE, F. G.; NEUMANN, G. A.; ROWLANDS, D. D.; AHARONSON, O.; FORD, P. G.; IVANOV, A. B.; JOHNSON, C. L.; MCGOVERN, P. J.; ABSHIRE, J. B.; AFZAL, R. S.; SUN, X. Mars Orbiter Laser Altimeter: experiment summary after the first year of global mapping of Mars. Journal of Geophysical Research: Planets, v. 106, n. E10, p. 23689-23722, 2001. 3

SMITH, D. E.; ZUBER, M. T.; SOLOMON, S. C.; PHILLIPS, R. J.; HEAD, J. W.; GARVIN, J. B.; BANERDT, W. B.; MUHLEMAN, D. O.; PETTENGILL, 
G. H.; NEUMANN, G. A.; LEMOINE, F. G.; ABSHIRE, J. B.; AHARONSON, O.; BROWN, D.; HAUCK, S. A.; IVANOV, A. B.; MCGOVERN, P. J.; ZWALLY, H. J.; DUXBURY, T. C. The global topography of Mars and implications for surface evolution. Science, v. 284, n. 5419, p. 1495-1503, 1999. 2, 3

STEVENSON, D. J. Mars' core and magnetism. Nature, v. 412, n. 6843, p. 214-219, 2001. 5

VAUCOUlEURS, G. de; DAVIES, M. E.; JR., F. M. S. Mariner 9 areographic coordinate system. Journal of Geophysical Research, v. 78, n. 20, p. 4395-4404, 1973. 17

VERVELIDOU, F.; LESUR, V.; GROTT, M.; MORSCHHAUSER, A.; LILLIS, R. J. Constraining the date of the Martian dynamo shutdown by means of crater magnetization signatures. Journal of Geophysical Research: Planets, v. 122, n. 11 , p. 2294-2311, 2017. 5

VIGNES, D.; ACUÑA, M. H.; CONNERNEY, J. E. P.; CRIDER, D. H.; RÈME, H.; MAZELLE, C. Magnetic flux ropes in the Martian atmosphere: global characteristics. Space Science Reviews, v. 111, n. 1, p. 223-231, 2004. 14

VIGNES, D.; MAZELLE, C.; RÈME, H.; ACUÑA, M. H.; CONNERNEY, J. E. P.; LIN, R. P.; MITCHELL, D. L.; CLOUTIER, P.; CRIDER, D. H.; NESS, N. F. The solar wind interaction with Mars: locations and shapes of the bow shock and the magnetic pile-up boundary from the observations of the MAG/ER Experiment onboard Mars Global Surveyor. Geophysical Research Letters, v. 27, n. 1, p. $49-52,2000.17$

VIRTANEN, P.; GOMMERS, R.; OLIPHANT, T. E.; HABERLAND, M.; REDDY, T.; COURNAPEAU, D.; BUROVSKI, E.; PETERSON, P.; WECKESSER, W.; BRIGHT, J.; WALT, S. J. van der; BRETT, M.; WILSON, J.; MILLMAN, K. J.; MAYOROV, N.; NELSON, A. R. J.; JONES, E.; KERN, R.; LARSON, E.; CAREY, C.; POLAT, İ.; FENG, Y.; MOORE, E. W.; ERPLAS, J. V.; LAXALDE, D.; PERKTOLD, J.; CIMRMAN, R.; HENRIKSEN, I.; QUINTERO, E. A.; HARRIS, C. R.; ARCHIBALD, A. M.; RIBEIRO, A. H.; PEDREGOSA, F.; MULBREGT, P. van. SciPy 1.0: fundamental algorithms for scientific computing in Python. Nature Methods, v. 17, p. 261-272, 2020. 32 WEBER, T.; BRAIN, D.; MITCHELL, D.; XU, S.; CONNERNEY, J.; HALEKAS, J. Characterization of low-altitude nightside Martian magnetic 
topology using electron pitch angle distributions. Journal of Geophysical Research: Space Physics, v. 122, n. 10, p. 9777-9789, 2017. 13

WEBER, T.; BRAIN, D.; MITCHELL, D.; XU, S.; ESPLEY, J.; HALEKAS, J.;

LILLIS, R.; JAKOSKY, B. The influence of solar wind pressure on Martian crustal magnetic field topology. Geophysical Research Letters, v. 46, n. 5, p. 2347-2354, 2019. 14

WHALER, K. A.; PURUCKER, M. E. A spatially continuous magnetization model for Mars. Journal of Geophysical Research: Planets, v. 110, n. E9, 2005. 6

WILHELMS, D. E.; SQUYRES, S. W. The martian hemispheric dichotomy may be due to a giant impact. Nature, v. 309, p. 138-140, 1984. 3

WILMOT-SMITH, A.; PRIEST, E.; HORNIG, G. Magnetic diffusion and the motion of field lines. Geophysical \& Astrophysical Fluid Dynamics, v. 99, n. 2, p. 177-197, 2005. 48

WITHERS, P. A review of observed variability in the dayside ionosphere of Mars.

Advances in Space Research, v. 44, n. 3, p. 277-307, 2009. 11

WITHERS, P.; MENDILLO, M.; RISHBETH, H.; HINSON, D. P.;

ARKANI-HAMED, J. Ionospheric characteristics above Martian crustal magnetic anomalies. Geophysical Research Letters, v. 32, n. 16, 2005. 11

WITHERS, P.; VOGT, M.; MAYYASI, M.; MAHAFFY, P.; BENNA, M.; ELROD, M.; BOUGHER, S.; DONG, C.; CHAUFRAY, J.-Y.; MA, Y.; JAKOSKY, B. Comparison of model predictions for the composition of the ionosphere of Mars to MAVEN NGIMS data. Geophysical Research Letters, v. 42 , n. 21 , p. 8966-8976, 2015. 8, 11

ZHONG, S.; ZUBER, M. T. Degree-1 mantle convection and the crustal dichotomy on Mars. Earth and Planetary Science Letters, v. 189, n. 1-2, p. $75-84,2001.3$ 



\section{PUBLICAÇÕES TÉCNICO-CIENTÍFICAS EDITADAS PELO INPE}

\section{Teses e Dissertações (TDI)}

Teses e Dissertações apresentadas nos Cursos de Pós-Graduação do INPE.

\section{Manuais Técnicos (MAN)}

São publicações de caráter técnico que incluem normas, procedimentos, instruções e orientações.

\section{Relatórios de Pesquisa (RPQ)}

Reportam resultados ou progressos de pesquisas tanto de natureza técnica quanto científica, cujo nível seja compatível com o de uma publicação em periódico nacional ou internacional.

\section{Publicações Didáticas (PUD)} (PRP)

São propostas de projetos técnicocientíficos e relatórios de acompanhamento de projetos, atividades e convênios.

\section{Publicações Seriadas}

São os seriados técnico-científicos: boletins, periódicos, anuários e anais de eventos (simpósios e congressos). Constam destas publicações o Internacional Standard Serial Number (ISSN), que é um código único e definitivo para identificação de títulos de seriados.

\section{Pré-publicações (PRE)}

Todos os artigos publicados em periódicos, anais e como capítulos de livros.
Incluem apostilas, notas de aula e manuais didáticos.

\section{Programas de Computador (PDC)}

São a sequência de instruções ou códigos, expressos em uma linguagem de programação compilada ou interpretada, a ser executada por um computador para alcançar um determinado objetivo. Aceitam-se tanto programas fonte quanto os executáveis. 